\title{
REDES NEURAIS: UMA NOVA PERSPECTIVA NA INTERPRETAÇÃO DE INFORMAÇÕES AMBIENTAIS
}

ANTONIO DE CASTRO BRUNI

São Paulo

2000 


\section{REDES NEURAIS: UMA NOVA PERSPECTIVA NA INTERPRETAÇÃO DE INFORMAÇÕES AMBIENTAIS}

\section{ANTONIO DE CASTRO BRUNI}

Dissertação de Mestrado apresentada ao Departamento de Saúde Ambiental da Faculdade de Saúde Pública da Universidade de São Paulo para obtenção do Grau de Mestre em Saúde Pública.

Área de concentração:

Saúde Ambiental

Orientador:

Prof. Dr. JOÃO VICENTE DE ASSUNÇÃO

São Paulo

2000 
Autorizo, exclusivamente para fins acadêmicos e científicos, a reprodução total
ou parcial desta dissertação, por processos foto copiadores. A fonte deverá ser
necessariamente citada.
Assinatura:
São Paulo, 30 de maio de 2.000 


\section{DEDICATÓRIA}

Dedico este trabalho aos meus filhos Michelangelo e Leonardo, aos amigos e a toda geração do Novo Milênio. 


\section{RESUMO}

As informações ambientais são o resultado de uma complexa interação entre as condições dos ambientes natural e antropogênico.

Sobre os processos envolvidos, na maioria das vezes há pouca ou nenhuma informação e, freqüentemente há carência de dados.

Face a esta problemática o emprego de uma técnica que minimize a necessidade de tais dados, que não tenha restrições operacionais para a execução dos cálculos ou ainda que possa ser aplicada quando não há muito conhecimento sobre o equacionamento do problema, presponta como uma alternativa estratégica para a interpretação das informações ambientais.

As técnicas de Inteligência Artificial lidam com estas restrições e, face aos recursos de software [aplicativos] e hardware [máquinas] hoje disponíveis, tiveram suas aplicações viabilizadas em diversas áreas.

Neste trabalho conceituamos além das Redes Neurais, os Sistemas Fuzzy [Nebulosos] e sua lógica específica, os Algoritmos Genéticos - seu fundamento e aplicações - e finalizando, os Sistemas Neuro-Fuzzy.

As principais Técnicas Estatísticas utilizadas em recentes trabalhos para a interpretação de dados são listadas e, sempre que necessário, são conceituadas.

Apresentamos as Redes Neurais Artificiais não só como uma alternativa às Técnicas Estatísticas e outras abordagens, mas sim na complementação destas no trabalho de análise de dados. O emprego de ambas as técnicas no equacionamento dos problemas na área ambiental, como mostramos, garante os melhores resultados. 
Nas Ciências Atmosféricas apresentamos aplicações de Redes Neurais contemplando: o processo de reconhecimento de partículas, a identificação de partículas e de fontes de poluição atmosférica, no Balanço Químico de Massas, na interpretação de dados, na previsão de concentrações de poluentes e na análise de riscos à saúde.

Os resultados das aplicações evidenciam o grande potencial que a técnica de Redes Neurais oferece para esta ciência.

Face as características de distribuição espacial e temporal da poluição do ar pesquisamos e encontramos uma topologia de Rede Neural que se ajusta ao objetivo de previsão das concentrações horárias do monóxido de carbono na a cidade de São Paulo.

Uma proposta de Sistema Inteligente baseado na teoria dos sistemas Fuzzy-Neurais também é apresentada para o mesmo problema.

Uma relação dos aplicativos comerciais disponíveis no mercado para trabalhar com esta tecnologia é apresentada ao final. 


\section{Descritores}

Inteligência Artificial, Rede Neural, Fuzzy, Ciências Atmosféricas, Modelagem, Poluição do ar, Monóxido de carbono. 


\section{SUMMARY}

Neural Networks techniques are presented in an Artificial Intelligence context including: Fuzzy Systems, Genetic Algorithms and Neuro-Fuzzy Systems. The Neural Networks topologies and the learning procedures are presented too.

The approach we used to introduce the concepts was to show the similarities with the Natural Neuron.

We selected and presented some usual Statistical Techniques currently used in air pollution data analysis and, always if it is available, a comparison with the Artificial Neural Networks.

We observed that almost always the Neural Network offers better results than other approaches, but when both techniques are used, one complement another.

We selected Neural Networks applications in air pollution including: particle identification process, particle and atmospheric pollution source identification, Chemical Mass Balance techniques, data analysis and interpretation, forecasting of atmospheric pollutant concentrations and health risk analysis.

The Multilayer perceptron is the most common topology applied.

The air pollution problem is spatio-temporal and a Neural Network topology, that take it into account, is suggested to forecast carbon monoxide concentrations at São Paulo City, Brazil. A Fuzzy-Neuro system to predict carbon monoxide critical episodes is proposed too.

A list of commercial software available to work with this technology is presented to encourage future applications. 


\section{Descriptors}

Artificial Intelligence, Neural Network, Fuzzy, Atmospheric Science, Modelling, Air pollution, Carbon monoxide.

\section{AGRADECIMENTOS}

Agradeço ao Prof. Dr. JOÃO VICENTE DE ASSUNÇÃO, pela ajuda prestada e incentivo para realização deste trabalho.

À Cia. de Tecnologia de Saneamento Ambiental - CETESB que, através de seu Programa de Capacitação, possibilitou minha participação neste Curso de Mestrado da Faculdade de Saúde Pública. 
Ao Prof. Dr. NESTOR FELIPE CATICHA do Departamento de Mecânica Estatística do Instituto de Física da Universidade de São Paulo, pelas sugestões.

A Maria de Lourdes do Nascimento, pelo trabalho de adequação do texto à forma da publicação. 
1. INTRODUÇÃO .................................................................................. 3

1.1 INFORMAÇÕES AMBIENTAIS: A DIFICULDADE DE INTERPRETÁ-LAS ................ 3

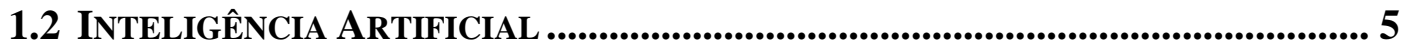

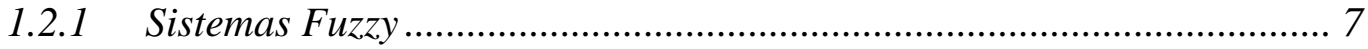

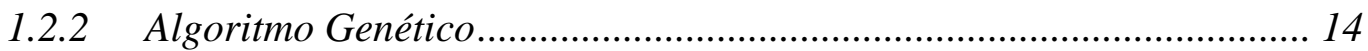

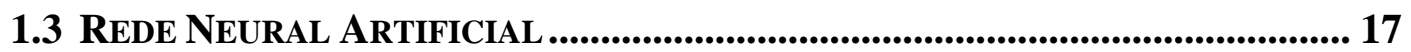

1.3.1 Um pouco sobre a fisiologia de um neurônio humano .......................... 18

1.3.2 O aprendizado do cérebro humano ....................................................... 20

1.3.3 O aprendizado da máquina........................................................... 21

1.3.4 Componentes de um modelo de Neurônio Artificial .............................. 22

1.3.5 Rede Neural x Computação convencional........................................... 23

1.3.6 Alguns Conceitos de Programação Paralela ...................................... 25

1.3.7 Redes Neurais e as Técnicas Estatísticas............................................ 26

1.3.8 Taxonomia das Redes Neurais Artificiais ........................................... 28

1.3.9 Processo de Aprendizado de uma Rede Neural Artificial ..................... 38

1.3.10 Áreas com aplicação de Redes Neurais................................................ 41

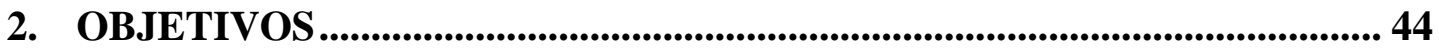

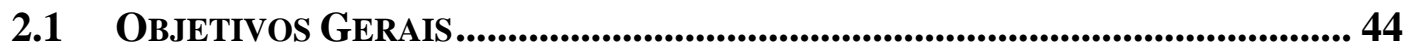

2.2 OBJETIVOS ESPECÍFICOS ..................................................................... 44

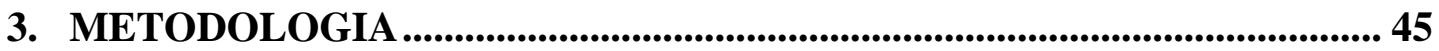

4. REVISÃO BIBLIOGRÁFICA ................................................................................ 49

4.1 REDES NEURAIS APLICADAS AO CONTROLE DE PROCESSOS ............................. 49

4.2 Redes NeURAis NAS CiênCIAS ATMOSFÉriCAS................................................ 50

4.2.1 Reconhecimento, classificação e caracterização de aerosóis..............................................51

4.2.2 Classificação de partículas e fontes de poluição do ar.......................................................51

4.2.3 Balanço Químico de Massas e Redes Neurais ....................................................................52

4.2.4 Interpretação de dados de poluentes atmosféricos ..............................................................53

4.2.5 Previsão de concentrações de poluentes atmosféricos ........................................................55

4.3 TÉCNICAS ESTATísticas EM USO NA INTERPRETAÇÃO DE DADOS AMBIENTAIS

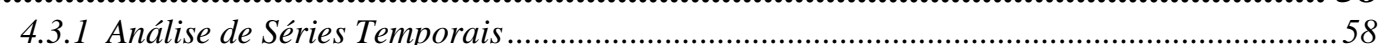

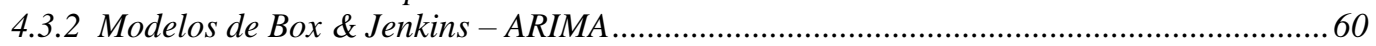

4.3.3 Método de simulação de Monte Carlo ............................................................................66

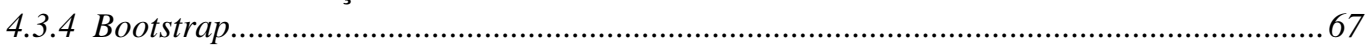

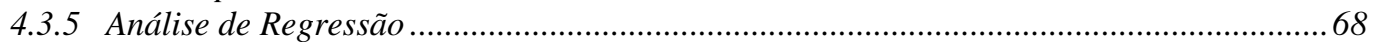

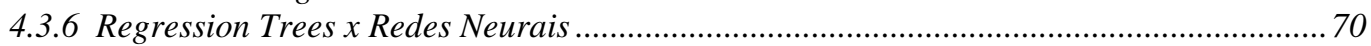

4.3.7 Análise Fatorial [Factor Analysis] ......................................................................... 71 


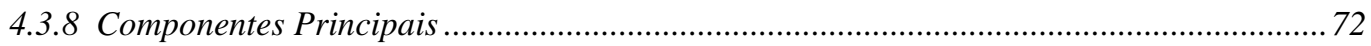

4.3.9 Análise de Agrupamentos [Cluster Analysis] ................................................................ 73

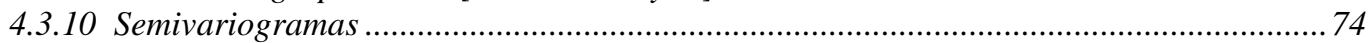

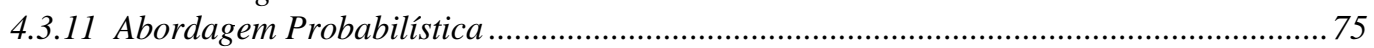

4.4 SISTEMAS ESPECIALISTAS: A TENDÊNCIA FUTURA.....................................76

5. APLICATIVOS COMERCIAIS PARA REDES NEURAIS ........................ 78

6. TOPOLOGIA DE UM SISTEMA INTELIGENTE PARA PREVISÃO DAS CONCENTRAÇÕES DE CO NA CIDADE DE SÃO PAULO...................... 83

6.1 INFORMAÇÕES PRELIMINARES E DADOS EXISTENTES................................83

6.2 A qualidade do AR na Cidade de SÃo PaUlo........................................ 85

6.2.1 O monóxido de carbono na Cidade de São Paulo ....................................................8 87

6.2.2 O monóxido de carbono em São Paulo e a Saúde Pública ………………………........90

6.2.3 Situação atual e perspectivas.................................................................................. 92

6.3 PROPOSTA DE MODELOS INTELIGENTES COM ENFOQUE ESPAÇO-TEMPORAL 93 6.3.1 Proposta de Modelo Espaço-temporal.......................................................................93

6.3.2 Proposta de Sistema Fuzzy-Neural ............................................................................ 96

7. CONCLUSÕES E RECOMENDAÇÕES ...................................................... 100

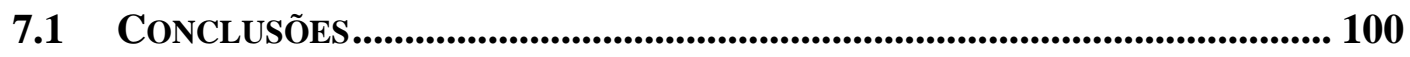

7.2 RECOMENDAÇÕES.............................................................................. 101

8. REFERÊNCIAS BIBLIOGRÁFICAS........................................................ 105

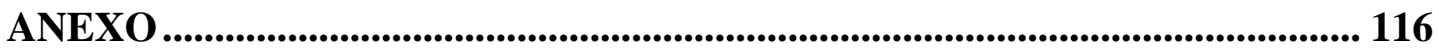




\section{INTRODUÇÃO}

\subsection{Informações ambientais: a dificuldade de interpretá-las}

A poluição do ar nas grandes cidades é o resultado de uma complexa iteração entre as condições dos ambientes natural e antropogênico conforme apontado por MAYER em 1999.

Nas áreas urbanas os veículos automotores representam uma importante fonte de poluição do ar, os autores apontam que o quadro tende a se agravar à medida em que a população, os veículos, a industrialização e o uso de energia aumentam.

Podemos observar que este é exatamente o quadro descrito em GUARDANI et al. (1999) para a cidade de São Paulo e, neste contexto, o conhecimento dos processos envolvidos, da avaliação das tendências e do comportamento sazonal e da influência dos fatores meteorológicos é estratégico para se tomar medidas preventivas ou até mesmo medidas de contingência em episódios críticos.

A poluição do ar apresenta variações espaciais e temporais. Vários são os trabalhos que tratam destes aspectos, dentre eles: HAAS 1998; CHOW et al. 1998; CHEN et al. 1998; SCHLINK et al. 1997; ANH et al. 1997a, 1997b; MILIONIS \& DAVIES 1997; HOGREFE et al. 1998; McNAIR et al. 1996; SEN 1995; CASADO et al. 1994; MILFORD et al. 1994; ANEJA et al. 1994.

Outros trabalhos analisam a relação entre os poluentes. SILLMAN em 1999 e TREVIÑO \& MÉNDEZ (1999) empregam em seus trabalhos o enfoque químiocinético para avaliar a relação entre o ozônio, os óxidos de nitrogênio e hidrocarbonetos na área urbana. WAKAMATSU et al. (1999) já se valeram de um modelo consolidado, o UAM - Urban Airshed Model [Modelo para Bacia Aérea Urbana], para a mesma finalidade.

Quando a influência predominante é meteorológica no comportamento do poluente e a estrutura deste relacionamento não é conhecida ou é difícil de ser explicitada, 
técnicas estatísticas são amplamente utilizadas. MILIONIS \& DAVIS (1994) usaram modelos de regressão linear e modelos do tipo ARIMA $^{1}$ empregando a metodologia de Box \& Jenkins para estudar a relação entre as concentrações de fumaça e inversões térmicas ${ }^{2}$.

Séries Temporais também podem ser usadas em poluição do ar para ajustar um modelo apenas com base na própria série de dados, sem a necessidade de nenhuma outra variável para compor o modelo, os trabalhos de SALCEDO et al. (1999), HOGREFE et al. (1998) e ANH (1997b) ilustram esta afirmação.

Os efeitos das variáveis meteorológicas nos poluentes atmosféricos são abordados em diversos trabalhos principalmente visando avaliar tendências, alguns exemplos encontramos em: BLOOMFIELD et al. 1996; SOJA \& SOJA 1999; MILANCHUS et al. 1998; STATHEROPOULOS et al. 1998; COX \& CHU 1993; DAVIS et al. 1998; HUBBARD \& COBOURN 1998.

Técnicas estatísticas como: Análise de Séries Temporais, Análises Multivariadas, Análise de Regressão, Bootstrap e Variogramas estão entre as mais empregadas na interpretação dos dados de poluição do ar. Alguns poucos trabalhos usando Redes Neurais começaram a aparecer na década de 90, mas ainda em pequeno número nas ciências atmosféricas, dentre estas citamos: BOZNAR et al. 1993; XIE et al. 1994; REGE \& TOCK 1996; YI \& PRYBUTOK 1996; SONG \& HOPKE 1996; COMRIE 1997; REIFMAN \& FELDMAN 1998; GARDNER \& DORLING 1998, 1999; SOJA \& SOJA 1999; REICH et al. 1999; ZHANG \& STANLEY 1999; SONG et al. 1999; GUARDANI et al. 1999.

Pela abrangência das áreas onde a tecnologia de Redes Neurais foram aplicadas nas ciências atmosféricas (identificação de fontes, controle de processos, identificação de

\footnotetext{
${ }^{1}$ Auto Regressivo, Integrados e de Médias Móveis [Auto Regressive Integrated and Moving Averages]

${ }^{2}$ Inversão no comportamento de decréscimo da temperatura com a altitude, aproximadamente $-1^{\circ}$ por $100 \mathrm{~m}$.
} 
partículas, previsão de concentrações de poluentes), temos um indicativo do potencial desta técnica a ser explorado.

Apresentamos neste trabalho as referências das aplicações de Redes Neurais nas ciências atmosféricas, apresentamos os conceitos, as definições e apontamos as técnicas e os aplicativos [software] disponíveis no mercado para sua implementação.

Conceituamos ainda as técnicas estatísticas mais utilizadas na interpretação de dados de poluição do ar e apresentamos os trabalhos que comparam essas técnicas com as Redes Neurais. Os resultados dos estudos comparativos são discutidos.

Esperamos assim estar contribuindo para a melhoria na interpretação dos dados de qualidade do ar.

\subsection{Inteligência Artificial}

O objetivo da Inteligência Artificial (IA) é o desenvolvimento de paradigmas ou algoritmos que requisitam as máquinas a executarem tarefas cognitivas (HAYKIN 1999, p.34).

As tarefas cognitivas, conforme encontramos no site da Universidade Federal do Rio Grande do Sul [UFRGS 2000], compreendem:

1. conhecimento (capacidade de reproduzir com exatidão uma informação que tenha sido dada);

2. compreensão (capacidade de usar uma informação original, de ampliá-la ou reduzi-la ou ainda de prever consequiências resultantes da informação original);

3. aplicação (capacidade de transportar uma informação genérica para uma situação nova e específica),

4. análise (capacidade de separar uma informação em elementos componentes e estabelecer relações entre eles); 
5. síntese (capacidade de reunir elementos de informação para compor algo novo e com traços individuais distintos); e

6. avaliação (capacidade de confrontar um dado, uma informação, uma teoria, um produto etc. com um critério ou conjunto de critérios, podendo estes critérios serem internos ou externos ao processo de avaliação).

Um sistema inteligente deve ser capaz de executar três tarefas:

1. armazenar conhecimento;

2. aplicar o conhecimento armazenado na resolução de problemas; e

3. adquirir novos conhecimentos através da experiência.

Esses sistemas tem três componentes chaves: representação, raciocínio e aprendizado.

Através da representação se pode efetuar a comunicação do homem com a máquina. Raciocínio é a habilidade de resolver problemas e o aprendizado se dá pela oferta do ambiente de elementos de aprendizado, os quais ampliam a base de conhecimento gerando melhora no desempenho para executar as tarefas.

O sistema nervoso humano pode ser visto como um sistema de três estágios conforme apresentado na Figura 1.

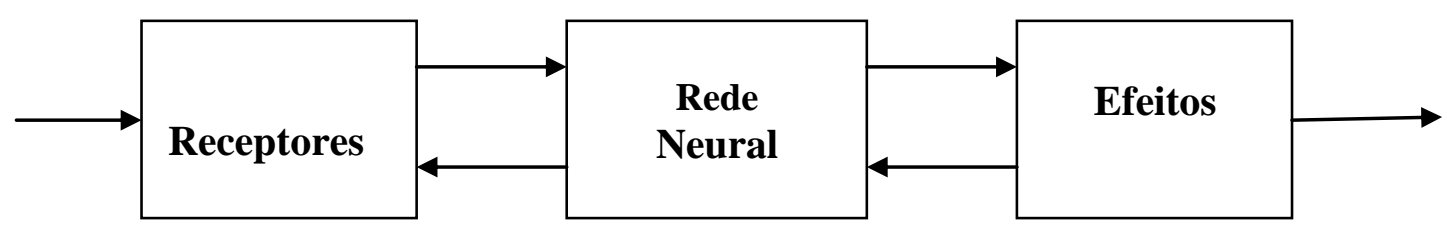

Figura 1 - Representação do sistema nervoso em diagrama de blocos Fonte: (HAYKIN 1999)

A parte central do sistema é o cérebro, representado pela Rede Neural natural (nervos), a qual continuamente recebe informações, percebem-nas, e toma as decisões apropriadas. 
Os receptores convertem os estímulos do corpo humano ou do ambiente externo em impulsos elétricos que transmitem informação à Rede Neural para que esta gere respostas discerníveis como saída do sistema.

As Redes Neurais Artificiais foram concebidas com o propósito de reproduzir o que se conhece do comportamento do neurônio natural. No item 1.3 - Rede Neural Artificial apresentamos estas redes.

Apresentamos outras duas importantes técnicas de Inteligência Artificial nos itens 1.2.1 e 1.2.2, Sistemas $\boldsymbol{F u z z y}^{3}$ [Nebulosos] e Algoritmos Genéticos, respectivamente.

\subsubsection{Sistemas Fuzzy}

Conforme TAY \& ZHANG (1999), Modelagem Fuzzy ou Sistemas Fuzzy "são todas as aplicações que envolvam a Teoria de Conjuntos desenvolvida por Lotfi Zadeh em 1965".

Os princípios básicos da teoria desses sistemas são:

$>\quad \mathrm{O}$ uso de variáveis lingüísticas em conjunto ou em substituição a variáveis numéricas;

$>$ A caracterização de relações simples entre as variáveis através das declarações condicionais Fuzzy;

> A caracterização das relações complexas entre as variáveis através de algoritmos Fuzzy.

HAYKIN (1999, p. 793) aponta que "os sistemas híbridos - aqueles formados por Sistemas Fuzzy e Redes Neurais - se constituem numa poderosa ferramenta para controles inteligentes e outras aplicações".

\footnotetext{
${ }^{3}$ Impreciso no sentido de que a lógica não se resume ao Verdadeiro/Falso podendo assumir valores intermediários. Na literatura é utilizado o termo Nebuloso.
} 
Encontramos em PAL \& MITRA (1999) uma vasta abordagem deste tipo de sistemas além de vários estudos comparativos evidenciando a superioridade dos sistemas híbridos.

KOSKO (1997, p. 90) aponta inclusive algumas equivalências entre Sistemas Fuzzy e dois tipos de Redes Neurais:

$>$ Redes Neurais Progressivas; e

$>$ Funções de Bases Radiais.

KOSKO (1997, p.140) descreve o procedimento de treinamento de um sistema Neuro-Fuzzy para regras elípticas [ellipsoid rules] e podemos observar que este é similar ao treinamento de uma Rede Neural do tipo ART ${ }^{4}$.

Uma variável lingüística é toda aquela cujos valores são palavras ou sentenças em linguagem natural ou artificial, elas tomam as variáveis $\boldsymbol{F}$ uzzy como seus valores. Um exemplo deste tipo de variável encontramos em TAY \& ZHANG (1999) - se velocidade é considerada como uma variável lingüística, ela pode então assumir as variáveis $\boldsymbol{F u z z y , ~ c o m ~ s e u s ~ p o s s i ́ v e i s ~ v a l o r e s : ~ l e n t a , ~ m o d e r a d a ~ o u ~ r a ́ p i d a . ~}$

Observar que o tratamento desta variável num sistema $\boldsymbol{F} \boldsymbol{u z z y}$ estabelecerá uma relação com a respectiva variável numérica através do processo denominado fuzzilização. No enfoque estatístico ela seria tratada como variável ordinal e as propriedades da escala de uma variável numérica seriam perdidas.

$\mathrm{Na}$ lógica usual só há duas possibilidades pois ela é dicotômica: sim/não, verdadeiro/falso etc.

SCHALKOFF (1997, p.361) aponta que "a lógica Fuzzy é uma tecnologia com larga aplicabilidade na resolução de problemas, principalmente onde métodos convencionais não foram aplicados ou foram mal sucedidos na aplicação”.

\footnotetext{
${ }^{4}$ Detalhes apresentados no item 1.3.8.
} 
Sistemas Fuzzy são desenvolvidos para lidar com problemas que envolvem fundamentalmente três tipos de incertezas:

$>$ imprecisão ou indefinição;

$>$ ambigüidade; ou

generalidade.

Eles empregam a lógica Fuzzy, sendo que esta difere da lógica convencional devido ao fato desta poder assumir outros valores distintos de VERDADEIRO e FALSO ou generalizando, valores dicotômicos, como citado anteriormente.

Em lógica Fuzzy, raciocínio exato e visto com um caso limite, tudo é relativo, a inferência é vista como um processo de propagação de uma restrição elástica.

A lógica Fuzzy é um super conjunto ${ }^{5}$ da lógica convencional booleana ${ }^{6}$ (falso/verdadeiro), ela introduziu o conceito de verdade parcial, assim os valores verdadeiros variam nos extremos de totalmente verdadeiro/nada falso até totalmente falso/nada verdadeiro.

KOSKO (1997, p.5) utiliza a nomenclatura de Lógica Vaga [Vague Logic] como sinônimo da Lógica $\boldsymbol{F u z z y}$. Optamos neste trabalho por manter a nomenclatura original e quando necessário empregamos a palavra imprecisa ao invés de vaga ou nebulosa, inclusive pela sua própria definição.

Temos ainda como resultado que todo sistema lógico dicotômico pode ser transportado para a lógica $\boldsymbol{F u z z y}$.

Os conceitos fundamentais envolvidos nos Sistemas $\boldsymbol{F u z z y}$, de acordo com SCHALKOFF (1997, p.363) são:

variáveis lingüísticas;

\footnotetext{
${ }^{5}$ Conjunto formado por conjuntos
} 
$>$ conjuntos Fuzzy;

$>$ tipos de fuzzilidade

$>$ funções de participação ou indicativas de grupos [membership functions];

variáveis lingüísticas e seus rótulos;

procedimento de fuzzilização;

$>$ regras Fuzzy (se aplicáveis);

$>$ regras de inferência composicional; e

$>$ procedimentos de defuzzilização.

O processo de inferência em geral é produto das etapas ${ }^{7}$ :

> Fuzzilização ou Fuzzificação na qual a função de grupo é definida para as variáveis de entrada e são então aplicadas aos valores numéricos para obtermos os graus de verdade para cada regra premissa aplicada.

Na etapa de Inferência, o valor da verdade para a premissa de cada regra é calculado, e é aplicado à parte de conclusiva de cada regra. Isto resulta, num subconjunto $\boldsymbol{F u z z y}$ e devem ser atribuídos a cada variável de saída, para cada uma das regras. Usualmente MíNIMO ou PRODUTO são usados como regras de inferência.

Na etapa de Composição, todos os subconjuntos $\boldsymbol{F} u z z y$ atribuídos a cada variável de saída são combinados formando um único conjunto para cada uma destas variáveis. Usualmente o MÁXIMO ou a SOMA são utilizados.

A etapa de Defuzzilização ou Desfuzzilização a qual é utilizada quando é necessário converter os resultados das saídas $\boldsymbol{F}$ uzzy em valores numéricos. Há diversos métodos conhecidos para conduzir este procedimento, os dois mais conhecidos são as técnicas de $\mathrm{CENTROIDE}^{8}$ e MÁXIMO.

\footnotetext{
${ }^{6}$ Devida a Boolean.

7 (STERGIOU \& SIGANOS 1999).

${ }^{8} \mathrm{O}$ valor numérico atribuído à variável de saída será determinado como sendo o centro de gravidade da função de agrupamento para os valores no conjunto fuzzy de resultados.
} 
Na Figura 2 apresentamos a arquitetura dos Sistemas $\boldsymbol{F u z z y}$ do tipo aditivo, nela o vetor $\underline{\mathbf{x}}$ de entrada tem dimensão $\mathbf{n}$ e a função de saída é um escalar, ou seja, um número.

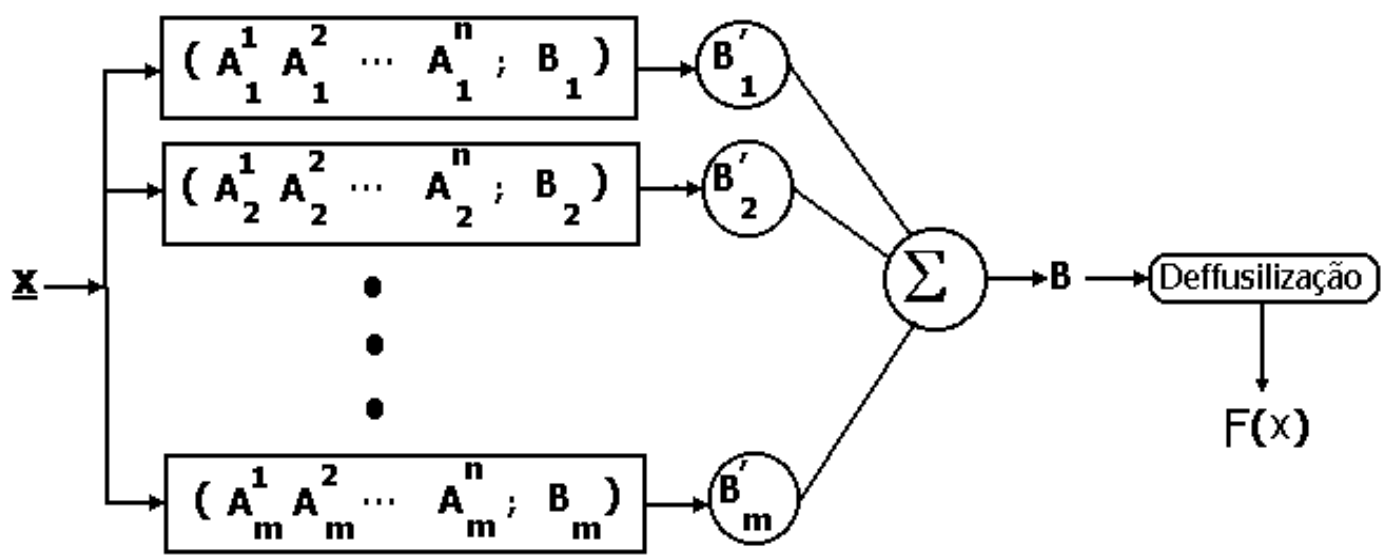

\section{Figura 2 - Arquitetura de um Sistema Fuzzy Aditivo} Fonte: (KOSKO 1997, p. 215)

As regras do procedimento de fuzzilização são aplicadas aos dados de entrada gerando os valores $\mathrm{B}^{\prime}{ }_{\mathrm{i}}$. A este conjunto é aplicado um procedimento de composição gerando uma saída única B. Este valor pode, dependendo da necessidade, passar por um processo de defuzzilização e daí obteremos o valor $\mathrm{F}(\mathrm{x})$.

KOSKO (1997, p.215) aponta um importante resultado: "Simulações mostraram que a forma do conjunto de funções não é de maior importância”. Esta constatação é útil nos casos onde o pesquisador não está seguro sobre como construir o conjunto de funções.

O tipo de função mais empregada nos Sistemas $\boldsymbol{F} u z z y$ é o triangular. No exemplo a seguir definimos as funções com base no conhecimento do tema poluição do ar. 


\subsubsection{Exemplo de aplicação de lógica $F u z z y$ em poluição do ar}

Seja X a medida de concentração média horária de monóxido de carbono, em ppm(partes por milhão), numa dada estação de monitoramento. Vamos supor que $0<\mathrm{X}<100 \mathrm{ppm}$, sem perda de generalidade.

Seja Y a previsão meteorológica para a dispersão dos poluentes atmosféricos, esta previsão iremos considerar no exemplo como assumindo os valores: Favorável (0), Desfavorável (1).

Seja $\mathrm{Z}$ a variável indicativa de episódio crítico de poluição, assim $\mathrm{Z}=1$ indica presença de episódio e Z=0 indica ausência de episódio.

Definimos então a função de agrupamento[membership function] para as variáveis:

$\operatorname{Low}(\mathrm{x})=1-\mathrm{x} / 50$ para $0<\mathrm{x}<50$ e zero caso contrário;

$\operatorname{Medium}(\mathrm{x})=(\mathrm{x} / 25)-1$ para $25<\mathrm{x}<50$;

$=3-(\mathrm{x} / 25)$ para $50<\mathrm{x}<75$;

= 0 caso contrário;

$>\operatorname{High}(\mathrm{x})=\mathrm{x} / 50 ;$ se $\mathrm{x}>50$ e $0 ;$ caso contrário.

$>\operatorname{Low}(\mathrm{y})=1-\mathrm{y}$;

$>\operatorname{High}(\mathrm{y})=\mathrm{y}$.

$>\operatorname{Low}(\mathrm{z})=1-\mathrm{z}$

$>\operatorname{High}(\mathrm{z})=\mathrm{z}$.

Podemos então definir as regras, são elas:

Regra 1 : Se X é Low e Y é Low, então Z é Low.

Regra 2 : Se X é Low e Y é High, então Z é Low.

Regra 3 : Se X é Medium e Y é Low, então Z é Low.

Regra 4 : Se X é Medium e Y é High, então Z é Low.

Regra 5 : Se X é High e Y é Low, então Z é Low.

Regra 6 : Se X é High e Y é High, então Z é High. 
Considerando então o conjunto de dados hipotéticos para X e Y apresentados na

Tabela 1, procedemos ao cálculo dos valores das regras acima. Usualmente o resultado da aplicação das regras é denominado alfa.

Tabela 1 - Processo de Fuzzilização

\begin{tabular}{c|c|c|c|c|c|c|c|c|c|c|c|c}
\hline $\mathbf{X}$ & $\mathbf{Y}$ & low(x) & $\mathbf{m e d}(\mathbf{x})$ & high(x) & low(y) & high(y) & Alfa 1 & Alfa 2 & Alfa 3 & Alfa 4 & Alfa 5 & Alfa 6 \\
\hline 4,5 & 0 & 0,9 & 0 & 0 & 1 & 0 & 0,9 & 0 & 0 & 0 & 0 & 0 \\
\hline 9 & 0 & 0,8 & 0 & 0 & 1 & 0 & 0,8 & 0 & 0 & 0 & 0 & 0 \\
\hline 35 & 1 & 0,222 & 0,4 & 0 & 0 & 1 & 0 & 0,222 & 0 & 0,4 & 0 & 1 \\
\hline 70 & 1 & 0 & 0,2 & 0,4 & 0 & 1 & 0 & 0 & 0 & 0,2 & 0 & 1 \\
\hline 90 & 1 & 0 & 0 & 0,8 & 0 & 1 & 0 & 0 & 0 & 0 & 0 & 1 \\
\hline 10 & 1 & 0,778 & 0 & 0 & 0 & 1 & 0 & 0,778 & 0 & 0 & 0 & 1 \\
\hline
\end{tabular}

Obs. Dados hipotéticos.

Os valores de Alfa 1 são relativos à Regra 1, Alfa 2 à Regra 2 e assim sucessivamente.

Devemos observar que as regras foram elaboradas com base no fenômeno que estamos interessados em modelar e com base nas funções de agrupamento anteriormente definidas.

Através deste exemplo ilustramos o processo de fuzzilização de variáveis.

Os valores obtidos através do processo de fuzzilização, (alfa 1, alfa 2 etc.) podem então servirem de entrada para uma Rede Neural criando assim um sistema híbrido. Podemos encontrar em PAL \& MITRA (1999 p. 111) um esquema apontando este procedimento aplicado ao problema de identificação de padrões.

Em KOSKO (1997, p.264) encontramos uma comparação feita entre: um Sistema Fuzzy Elipsoidal, um Sistema Fuzzy de Covariâncias e duas Redes Neurais do tipo Função de Bases Radiais - FBR, uma usando distância Euclidiana e outra usando distância de Mahalanobis ${ }^{9}$. 
O resultado apresentamos na Tabela 2.

Tabela 2 - Erro quadrático médio de previsões em função do parâmetro $\alpha$ da distribuição Alfa-estável de probabilidades ${ }^{10}$.

\begin{tabular}{c|c|c|c|c|c}
\hline $\boldsymbol{\alpha}$ & $\begin{array}{c}\text { Variância } \\
\text { estimada }\end{array}$ & $\begin{array}{c}\text { Sistema } \\
\text { Elipsoidal }\end{array}$ & $\begin{array}{c}\text { Sistema de } \\
\text { Covariâncias }\end{array}$ & $\begin{array}{c}\text { FBR } \\
\text { (Euclidiana) }\end{array}$ & $\begin{array}{c}\text { FBR } \\
\text { (Mahalanobis) }\end{array}$ \\
\hline 2,0 & 0,0197 & 0,0731 & 0,0305 & 0,0499 & 0,0308 \\
1,9 & 0,0282 & 0,0606 & 0,0395 & 0,0504 & 0,0313 \\
1,5 & 0,1932 & 0,2248 & 0,1503 & 0,1518 & 0,1357 \\
1,0 & 2,7585 & 0,3967 & 0,3088 & 0,3069 & 0,3191 \\
\hline
\end{tabular}

Fonte: (KOSKO 1997, p.264)

Diversas comparações envolvendo Sistemas Neuro-Fuzzy podemos encontrar em PAL \& MITRA (1999) e a superioridade destes em relação aos demais modelos é uma constante.

\subsubsection{Algoritmo Genético}

Uma das principais ferramentas da Computação Amigável [Soft Computing] ${ }^{11}$ são os Algoritmos Genéticos (PAL \& MITRA 1999, p. 359).

FREEMAN (1994, p. 260) aponta os Algoritmos Genéticos como sendo “um procedimento geral de pesquisa baseado nas idéias de genética e seleção natural”.

SCHALKOFF (1999, p.211) define Algoritmos Genéticos Artificiais como sendo “algoritmos que transformam populações de objetos matemáticos, os quais podem ser strings [cadeia de caracteres], ou estruturas como as redes neurais".

\footnotetext{
${ }^{9}$ Distância de Mahalanobis é uma medida de distância que leva em consideração a estrutura de correlações entre as variáveis que compõem os eixos.

${ }^{10}$ Nos casos onde $\alpha=1$ é a densidade de Cauchy e no caso $\alpha=2$ é a distribuição normal ou gaussiana.
} 
MICHALSKI et al. (1998, p.59) também definem Algoritmos Genéticos com base nos conceitos de Genética humana e acrescenta que "a evolução na natureza é controlada por três princípios fundamentais":

1. sobrevivência dos melhores adaptados indicando que as espécies mais fortes tem mais chance de sobreviver e de reproduzir, os mais fracos dificilmente chegam ao estágio reprodutivo, morrendo antes;

2. na reprodução sexual os indivíduos procuram parceiros que consideram os melhores, contribuindo assim para o princípio anterior onde os mais fortes e melhor adaptados sobrevivem;

3. mutações causam aleatoriamente e de maneira rara, mudanças nas informações genéticas.

Apresentamos a seguir o algoritmo:

1. Definir a população inicial como um conjunto de caracteres binários ${ }^{12}$ gerados aleatoriamente ou por algum mecanismo predefinido;

2. Replicar as espécies na população em um conjunto de sobreviventes através de um mecanismo que garanta que as espécies com alto grau de adaptação tenham mais chances de sobreviver, podendo inclusive se reproduzir mais de uma vez;

3. Para cada sobrevivente, encontrar um parceiro com o qual trocará parte da informação codificada na sua seqüência binária. Com uma freqüência muito baixa, um único bit é alterado induzindo assim uma mutação;

4. Se a função de aptidão não aumentar seu valor após vários ciclos, parar o processo, caso contrário retornar a etapa 2.

O exemplo que apresentamos na Tabela 3 teve como fonte (MICHALSKI et al. 1998, p.61), e ilustra este procedimento.

${ }^{11}$ Tipo de técnica computacional que utiliza inteligência artificial. 
Tabela 3 - Exemplo de aplicação dos conceitos de Algoritmos Genéticos

\begin{tabular}{|c|c|c|c|c|c|c|}
\hline Antiga geração & $\mathbf{x}$ & $1 /(x+1)$ & Sobreviventes & Nova geração & $\mathbf{x}$ & $1 /(x+1)$ \\
\hline (1) 100101 & 37 & 0,026 & (4) $0000 \mid \mathbf{1} 11$ & 000011 & 3 & 0,250 \\
\hline (2) 0001011 & 11 & 0,083 & (2) $0001 \mid \begin{array}{lll}\mathbf{0} & 1 & 1\end{array}$ & 001111 & 15 & 0,063 \\
\hline (3) 010100 & 20 & 0,048 & (4) $000 \mid \mathbf{1 1 1}$ & 0000100 & 4 & 0,200 \\
\hline (4) 0000111 & 7 & 0,125 & (1) $010 \mid \begin{array}{llll}1 & 0 & 0\end{array}$ & 0101011 & 23 & 0,042 \\
\hline
\end{tabular}

Fonte: (MICHALSKI et al. 1998, p.61)

No exemplo da Tabela 3 a função de ajuste [fitness function] foi considerada como sendo $\mathbf{f}(\mathbf{x})=\mathbf{1} /(\mathbf{x + 1})$. Esta função visa indicar a chance de sobrevivência da espécie. O valor de $\mathbf{x}$ é obtido pela transformação do valor do cromossomo na forma binária para o respectivo número na base decimal, por exemplo, o indivíduo (4) “000111” equivale ao número 7 pois $1 \times 2^{2}+1 \times 2^{1}+1 \times 2^{0}=7$.

O maior valor observado da função de ajuste para os cromossomos da geração antiga foi $\mathrm{f}(7)=0,125$ e o menor foi $\mathrm{f}(37)=0,027$, este último com poucas chances de sobreviver na etapa de reprodução do Algoritmo Genético pois a escolha é dos mais fortes (maiores valores de $\mathrm{f}(\mathrm{x})$ ).

Através deste processo conseguimos gerar espécies melhor adaptadas e com maior capacidade de sobrevivência (refletida nos valores da função de ajuste $f(x)$ ).

Uma importante aplicação de Algoritmo Genético nas Redes Neurais podemos encontrar em SCHALKOFF (1997, p. 211), na qual o procedimento de treinamento de uma Rede Neural é conduzido com base neste tipo de técnica de Inteligência Artificial.

${ }^{12}$ Binário é indicativo de apresentação do número na base 2. 
Aplicação de Algoritmos Genéticos para otimizar a topologia e/ou otimizar as ponderações de uma Rede Neural ou ainda no próprio desenho da rede podemos encontrar em SCHALKOFF (1997).

Existe uma aplicação especial na qual as técnicas de Redes Neurais, variáveis Fuzzy e Algoritmos Genéticos são aplicados em conjunto, é na Rede Neural tipo Celular, este tipo de topologia de rede visa a extração de padrões (PAL \& MITRA 1999, p.199).

\subsection{Rede Neural Artificial}

Rede Neural Artificial, usualmente chamada de Rede Neural, tem seus fundamentos baseados no que conhecemos sobre o funcionamento do cérebro humano, ela representa um modelo simplificado da Rede Natural (formada por neurônios) e resolve problemas de maneira totalmente diferente que um algoritmo convencional e utilizando os mesmos recursos computacionais.

Conforme descrito em HAYKIN (1999, p.1) “O cérebro é altamente complexo, não linear e com capacidade de processamento paralelo". No site da Neural Networks ${ }^{13}$ encontramos que ... "assim como as pessoas, uma Rede Neural também aprende através de exemplos e tem capacidade de descobrir, por ela mesma, uma solução para um problema”.

No histórico apresentado por HAYKIN (1999, p.39), e conforme apontado por STERGIOU \& SIGANOS (1999) o primeiro neurônio artificial foi produzido em 1943 pelo neurofisiologista Warren McCulloch e pelo matemático Walter Pitts, um especialista em lógica matemática.

No trabalho eles mostraram que "uma Rede Neural constituída da maneira indicada poderia calcular qualquer valor de uma função dada e de maneira não usual"(sic). 


\subsubsection{Um pouco sobre a fisiologia de um neurônio humano}

Um neurônio humano é um tipo de célula que apresenta as seguintes características:

$>$ Fibras nervosas chamadas de dendritos são dispostas como galhos de árvore e conectadas ao corpo da célula onde se localiza o núcleo da célula ou soma;

A partir do corpo da célula se estende uma longa fibra denominada axônio, ao final deste há uma ramificação formando o terminal do axônio. Este terminal se conecta (não fisicamente) a outro neurônio através da sinapse.

Na Figura 3 apresentamos os elementos citados.

A transmissão de sinais de um neurônio para outro é um complexo processo químico no qual substâncias transmissoras específicas são liberadas no terminal do axônio, na junção ou zona da sinapse. Essas substâncias são denominadas neurotransmissoras e é através delas que os diversos neurônios se comunicam.

Vale observar que não há contato físico entre os neurônios na zona de sinapse. Ilustramos este fato na Figura 3.

O efeito causado é o aumento do potencial elétrico no corpo da célula excitada. Se este potencial atinge um determinado limite, um pulso é enviado pelo axônio na direção do terminal, neste caso dizemos que o neurônio foi disparado [fired] ou ativado ou ainda excitado.

${ }^{13}$ (STERGIOU \& SIGANOS 1999) 


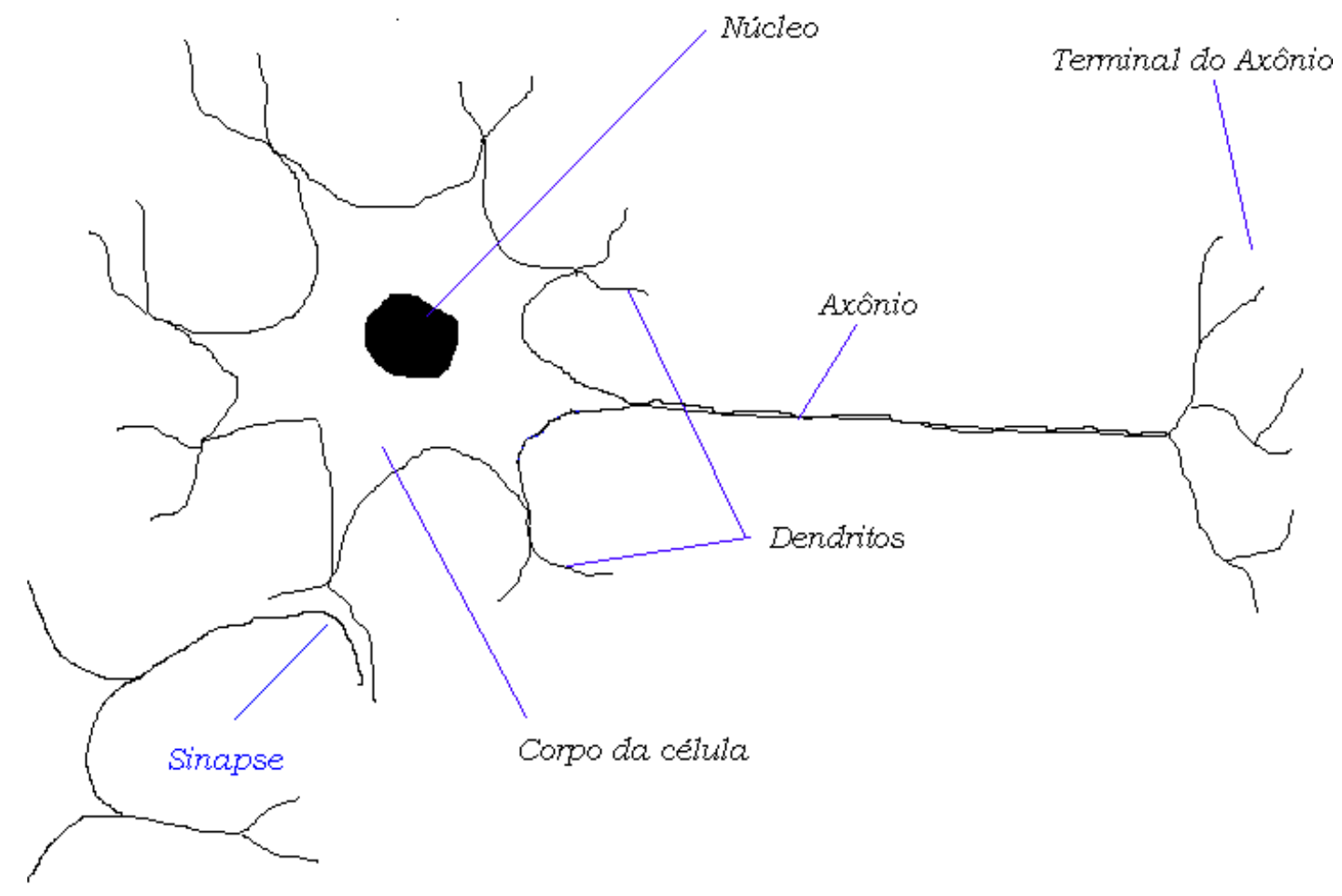

Figura 3 - Esquema representativo de um neurônio natural Fontes: (SNIPES 1998; HAYKIN 1999)

Na Tabela 4 apresentamos algumas características elétricas do Neurônio Natural.

Na Tabela 5 apresentamos um quadro comparativo entre o Neurônio Natural e o Artificial.

Tabela 4 - Caracterização dos potenciais elétricos dos pulsos nos neurônios.

\begin{tabular}{c|c|c|c}
\hline Característica & Potencial no & Potencial sináptico & Potencial de ação \\
& Receptor & & \\
\hline Amplitude & $0,1-10 \mathrm{mV}$ & $0,1-10 \mathrm{mV}$ & $70-110 \mathrm{Mv}$ \\
Duração & $5-100 \mathrm{~ms}$ & $5 \mathrm{~ms} \mathrm{a} 20 \mathrm{~min}$. & $1-10 \mathrm{~ms}$ \\
Resolução & Gradual (cont.) & Gradual & Dicotômica \\
\hline
\end{tabular}

Fonte: (SCHALKOFF 1997, p. 67)

Há grupos de pesquisa que estudam a possibilidade de que as informações também sejam passadas através da distribuição dos próprios intervalos entre os pulsos. 
Tabela 5 - Equivalências entre o neurônio natural e o artificial

\begin{tabular}{l|l}
\hline \multicolumn{1}{c|}{ Neurônio natural } & \multicolumn{1}{c}{ Neurônio artificial } \\
\hline Célula(neurônio) & Unidade de processamento \\
Sinapse & Ponderação da interligação \\
Impulso de excitação & Ponderação (grande) e positiva \\
Impulso de inibição & Ponderação (grande) e negativa \\
Ativação por frequiência & Nível DC [Direct Current] \\
Amplitude de ativação limitada pela & Amplitude de ativação limitada por \\
física da célula & função \\
\hline
\end{tabular}

Fonte: (SCHALKOFF 1997, p. 68)

\subsubsection{O aprendizado do cérebro humano ${ }^{14}$}

Muito ainda é desconhecido sobre como o cérebro humano treina ele próprio para processar informação.

No cérebro, um típico neurônio coleta sinais de outros através de um hospedeiro de finas estruturas chamadas dendritos. O neurônio envia pulsos elétricos através do axônio, o qual se divide em milhares de ramos, ao final destes há uma forma de comunicação chamada sinapse.

O sinal elétrico será então convertido em atividade pelos neurotransmissores.

Quando um neurônio recebe excitação suficientemente elevada quando comparada com o impulso inibidor, ele envia um pulso elétrico através do axônio. $\mathrm{O}$ aprendizado do neurônio ocorre através da mudança da eficácia com que o processo de sinapse influencia um outro neurônio.

Uma Rede Neural visa processar informações de maneira similar ao cérebro humano. A rede é composta por um grande número de unidades (neurônios)

${ }^{14}$ (STERGIOU \& SIGANOS 1999) 
altamente interligados e trabalhando em paralelo para atender à demanda que levou à construção da rede.

Uma definição formal de uma Rede Neural, vista como uma máquina adaptativa, podemos encontrar em HAYKIN (1999, p.2): "Uma Rede Neural é um processador massivo, paralelo e distribuído formado de unidades simples de processamento, as quais tem propensão para armazenamento de conhecimento experimental $e$ disponibilização para uso"(sic).

Vale comentarmos que não há uma necessidade proeminente de que a rede seja constituída por um número elevado de neurônios.

Uma Rede Neural em dois aspectos é similar ao cérebro humano:

1) o conhecimento é adquirido pela Rede Neural a partir do ambiente através do processo de aprendizado;

2) a intensidade das ligações entre os neurônios, conhecida como ponderação sináptica é a forma usada para armazenar conhecimento.

\subsubsection{O aprendizado da máquina}

É citado em (MICHALSKI 1998, p.57) que ... “em 1958 Frank Rosenblatt publicou um artigo sugerindo, para reconhecimento de padrões, um dispositivo simples, inspirado nos modelos matemáticos de neurônios biológicos apresentados à época. Mais tarde, em 1962, ele publicou um livro específico sobre este dispositivo, o perceptron ${ }^{, 15}$.

No livro é mostrado como ele poderia ser treinado para o trabalho de reconhecimento, baseando-se simplesmente no ajuste automático de seus parâmetros e num conjunto de exemplos já pré selecionados e classificados.

\footnotetext{
${ }^{15}$ É apresentada somente parte da referência: Principles of Neurodynamics: Perceptrons and the theory of brain mechanisms. Spartan Books.
} 
O princípio é mostrado na Figura 4 e está descrito em MICHALSKI (1998, p.57), nele vários inputs [entradas] $\mathbf{x i}$, cada qual ponderado pelo seu peso apropriado $\mathbf{W i}$, são então somados.

A somatória resultante é submetida a uma função do tipo degrau (atualmente outros tipos de funções são empregadas) de tal maneira que se o seu valor exceder um determinado limite $\theta$, o resultado da função será igual a 1 , caso contrário será igual a 0 . Estes valores poderiam ser fixados como sendo iguais $a+1 \mathrm{e}-1$, de maneira alternativa.

O mesmo modelo é apresentado por HAYKIN (1999) acrescentando ao mesmo um $v_{\text {viés }}{ }^{16}$ com peso conhecido e igual a 1 .

Atualmente esta função é conhecida como função de ativação e será abordada em detalhe na seqüência.

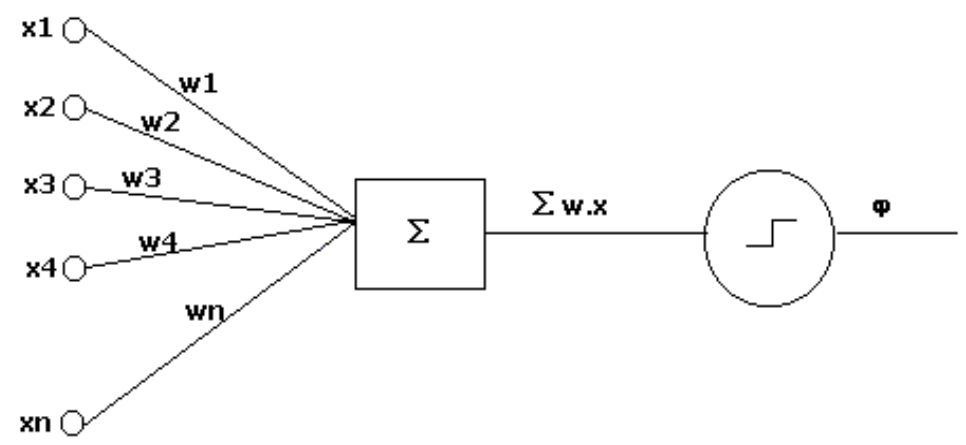

Figura 4 - Esquema geral de um perceptron.

Fonte: (MICHALSKI et al. 1998)

\subsubsection{Componentes de um modelo de Neurônio Artificial}

Um neurônio é uma unidade de processamento de informação que é fundamental na operação de uma Rede Neural. 
A partir da Figura 4 identificaremos os componentes do modelo de um neurônio.

São eles:

a) um conjunto de sinapses ou conecções sendo que cada qual é caracterizado por um peso, especificamente: um sinal ou estímulo $\mathbf{X} \mathbf{j}$ que chega à entrada $\mathbf{j}$ (sinapse) que está conectado ao neurônio $\mathbf{k}$ é multiplicado pelo peso $\mathbf{W k j}$;

b) um Soma que efetua a adição dos sinais ou estímulos de entrada, já devidamente ponderados conforme exposto em a); e

c) uma função de ativação, para limitar a amplitude de saída do neurônio. É também sua função atenuar possíveis ruídos(perturbações) nos sinais de entrada.

Na Figura 5 apresentamos um exemplo de função de ativação, a função logística.

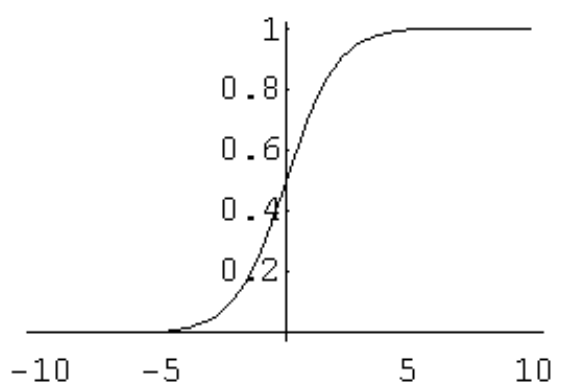

Figura 5 - Função de ativação do tipo logística. Fontes:(HAYKIN 1999; FREEMAN 1994).

\subsubsection{Rede Neural x Computação convencional}

STERGIOU \& SIGANOS (1999) citam que ... “Uma Rede Neural tem uma maneira diferente de resolver um problema do que a computação convencional,

${ }^{16}$ Êrro sistemático e não identificável. É também denominado vício. 
nesta, utilizam-se algoritmos, isto é, o computador segue um conjunto de instruções ordenadas para resolver o problema.

Caso todos os passos necessários para resolver o problema não sejam apresentados de maneira ordenada, ele não poderá resolver o mesmo. Este fato restringe a capacidade da computação convencional em resolver somente os problemas para os quais conhecemos a solução e sabemos como obtê-la"(sic).

FREEMAN (1994, p.2) apresenta o Paradigma da Rede Neural através de um exemplo bastante ilustrativo do reconhecimento do desenho de um cachorro tanto por um algoritmo convencional quanto por uma Rede Neural.

Teremos que face a uma simples ampliação do desenho original e o algoritmo convencional não mais reconhecerá a figura como sendo de um cachorro, fato este que não ocorre com uma Rede Neural, de fato, ela poderá inclusive identificar o desenho de um outro tipo de cachorro pela sua capacidade de reconhecimento de padrões.

SNIPES (1999) aponta que com o progresso na Tecnologia da Informação (TI), surgiu o computador com capacidade de processamento paralelo, dotado de múltiplos processadores alinhados (controlados pelo sistema operacional) para processar informações em paralelo.

Observamos então um enorme avanço na Computação Neural [Neurocomputing].

SNIPES (1999) descreve a Computação Neural como envolvendo o processamento de informações através da mudança de estados da rede formada por um número extremamente grande de interligações de elementos processantes (unidades), os quais interagem uns com os outros através de sinais (pulsos).

Redes com estas características são chamadas Redes Neurais Artificiais, no sentido dela representar um modelo simplificado da Rede Neural Natural. 


\subsubsection{Alguns Conceitos de Programação Paralela}

Programação paralela consiste em dividir um programa computacional ${ }^{17}$ em vários módulos gerenciáveis e integráveis. Devemos observar que nem sempre este requisito pode ser atendido e consequentemente o processamento paralelo aplicado em sua plenitude.

Estes módulos serão executados em diferentes estações, que podem ser diferentes processadores numa mesma máquina, simultaneamente, e visando a solução do problema para o qual o programa computacional foi elaborado.

Cada módulo é usualmente chamado de tarefa e esta trabalha em cima da parte de dados que lhe é conferida de acordo com a estrutura do programa. Há troca de resultados com outras tarefas ou com uma tarefa mestre ${ }^{18}$ durante o processamento.

Essa troca de resultados é feita através do processo denominado message passing [passagem de mensagens]. Este processo pode se dar entre CPU's ${ }^{19}$ de uma mesma máquina ou mesmo entre diferentes máquinas.

Ao desenvolver um programa paralelo, é fundamental termos em mente quais partes do código são passíveis de serem divididas e como as tarefas serão divididas entre as CPU's.

Em geral as partes do código passíveis de serem divididas são constituídas de funções do programa que não dependem umas das outras e que podem ser calculadas simultaneamente.

Um exemplo típico de código é o problema de calcular o valor da integral de uma função pelo método de somatória simples.

\footnotetext{
${ }^{17}$ Conjunto ordenado de instruções para resolução de um problema conhecido.

${ }^{18}$ Tarefa mestre é a responsável pela união dos resultados parciais e pelo gerenciamento das demais tarefas.

${ }^{19} \mathrm{CPU}$ - Unidade de processamento central
} 
A forma mais direta de resolver este programa em paralelo seria dividir a função em partições e passar para diferentes CPU's cada uma destas partições de modo que cada CPU calcule a integral em sua pequena região.

Ao final dos cálculos, cada CPU passaria o seu resultado para uma outra CPU, a que processa a tarefa mestre e esta se encarregaria de somar os valores parciais, obtendo assim o valor da integral.

Um importante indicador utilizado na programação paralela é o de speed-up [aumento de velocidade], que consiste na razão entre os tempos de execução do programa serial e da execução em paralelo.

No contexto de Redes Neurais o processamento paralelo desempenha um papel central pois este viabiliza a operacionalização do conceito de tolerância a falhas ${ }^{20}$ [fault tolerance].

Numa Rede Neural, se ocorre um problema com uma unidade de processamento, é desejável e necessário que as demais unidades assimilem a informação que estava sendo guardada naquela unidade e que todo o processo não seja afetado.

\subsubsection{Redes Neurais e as Técnicas Estatísticas}

Conforme observamos no site [SPSS 1999]: "Redes Neurais aprendem os padrões observando os dados enquanto as análises estatísticas assumem uma forma de modelo para os dados e então verificam, com base em testes, se os dados se ajustam a estrutura assumida."

As Redes Neurais tem como capacidade reproduzir diversas estatísticas ${ }^{21}$ e mesmo grande parte das próprias Técnicas Estatísticas. (SARLE 1997; SCHALKOFF 1997, p.25).

${ }^{20} \mathrm{Se}$ um problema ocorre com uma CPU a tarefa mestre redistribui dentre as demais CPU's operantes. 
Um resultado bastante significativo é relativo ao Teorema Universal da Aproximação $^{22}$ [Universal Approximation Theorem], ele garante que uma Rede Neural do tipo Função de Base Radial[Radial Basis Function] pode ser treinada para ajustar uniformemente qualquer função contínua definida num conjunto fechado, (HAYKIN 1999, p.290).

Entretanto, as Redes Neurais não eliminam a necessidade de aplicação de técnicas estatísticas, basta observar que a própria avaliação da qualidade do ajuste de um modelo baseado em Redes Neurais é feita a partir de Técnicas Estatística.

Mesmo num trabalho comparativo entre Redes Neurais e Metodologia de Box \& Jenkins para identificação e ajuste de Modelos de Série Temporal, o ganho obtido pelos autores na identificação da topologia da rede é graças ao processo de identificação da sazonalidade da série temporal, (KAO \& HUANG 2000).

O inverso também é verdadeiro conforme podemos observar no resultado do trabalho de REYNOLDS et al. (1995) no qual fica evidenciado o poder das Redes Neurais na própria especificação de modelos do tipo ARIMA não sazonais.

HAYKIN (1999, p.84) expõe a natureza Estatística do processo de aprendizado [learning process], evidenciando assim a contribuição desta ciência para a técnica de Redes Neurais.

Temos ainda que as Redes Neurais dependem fortemente dos conceitos matemáticos empregados nas Ciências Estatísticas.

Um exemplo é conceito de Inversa Generalizada ou Pseudo Inversa ${ }^{23}$ de uma matriz é largamente empregado nos procedimentos de cálculo das Redes Neurais conforme observamos em SCHALKOFF (1999, p.45).

${ }^{21}$ Qualquer função aplicada aos dados é encarada aqui como estatística.

22 (PARK \& SANDBERG 1991).

${ }^{23} \mathbf{G}$ é a Pseudo Inversa de $\mathbf{A}$ se: $\mathbf{A G A}=\mathbf{A}$ e $\mathbf{G A G}=\mathbf{G}$ e $(\mathbf{A G})^{\mathbf{T}}=\mathbf{A G}$. 
A relação inversa também é verdadeira, ou seja, com base em achados de uma Rede Neural podemos otimizar a aplicação de Técnicas Estatísticas. No trabalho de REYNOLDS et al. (1995) encontramos um exemplo desta afirmação onde Redes Neurais são empregadas para identificação de Modelos do tipo ARIMA ${ }^{24}$ para séries temporais estacionárias.

CANON \& LORD (2000) utilizaram a técnica de Bootstrap [re-amostragem] visando obter diferentes conjunto de dados para a fase de treinamento da Rede Neural construída para efetuar as previsões das concentrações máximas de ozônio na atmosfera. Através deste procedimento foi possível avaliar a estabilidade ${ }^{25}$ e o desempenho do modelo ajustado pela Rede Neural.

Com base nestas constatações nos parece claro que o emprego combinado de técnicas usuais e de Redes Neurais é o mais indicado.

Encontramos no site [SPSS 1999] uma orientação racional: “as Redes Neurais fornecem informações no mínimo tão boas quanto e usualmente melhores que os métodos tradicionais estatísticos ${ }^{26}$. Entretanto, não há garantia de quando os resultados serão melhores usando uma Rede Neural. Em geral, os resultados das Redes Neurais são superiores quando os dados tem comportamento não linear ou afetados por perturbações [noise]. Redes Neurais constituem mais uma ferramenta para o analista de dados no desenvolvimento do seu trabalho”.

\subsubsection{Taxonomia $^{27}$ das Redes Neurais Artificiais}

GARDNER \& DORLING (1998) apresentaram em seu trabalho um esquema ilustrativo da taxonomia das arquiteturas das Redes Neurais Artificiais, esta figura foi complementada com dados de SARLE (1997), especificamente no tocante aos

\footnotetext{
${ }^{24}$ Auto Regressivo Integrados e de Médias Móveis.

${ }^{25}$ Pequenas variações nos dados devem levar a também pequenas variações nas respostas do modelo.

${ }^{26} \mathrm{O}$ quanto melhor depende da efetividade da fase de treinamento da Rede Neural.

${ }^{27}$ Taxonomia é empregada aqui como identificação das divisões de classes ou topologias das Redes Neurais.
} 
tipos de Redes Neurais devido a Kohonen. A taxonomia resultante apresentamos na Figura 6.

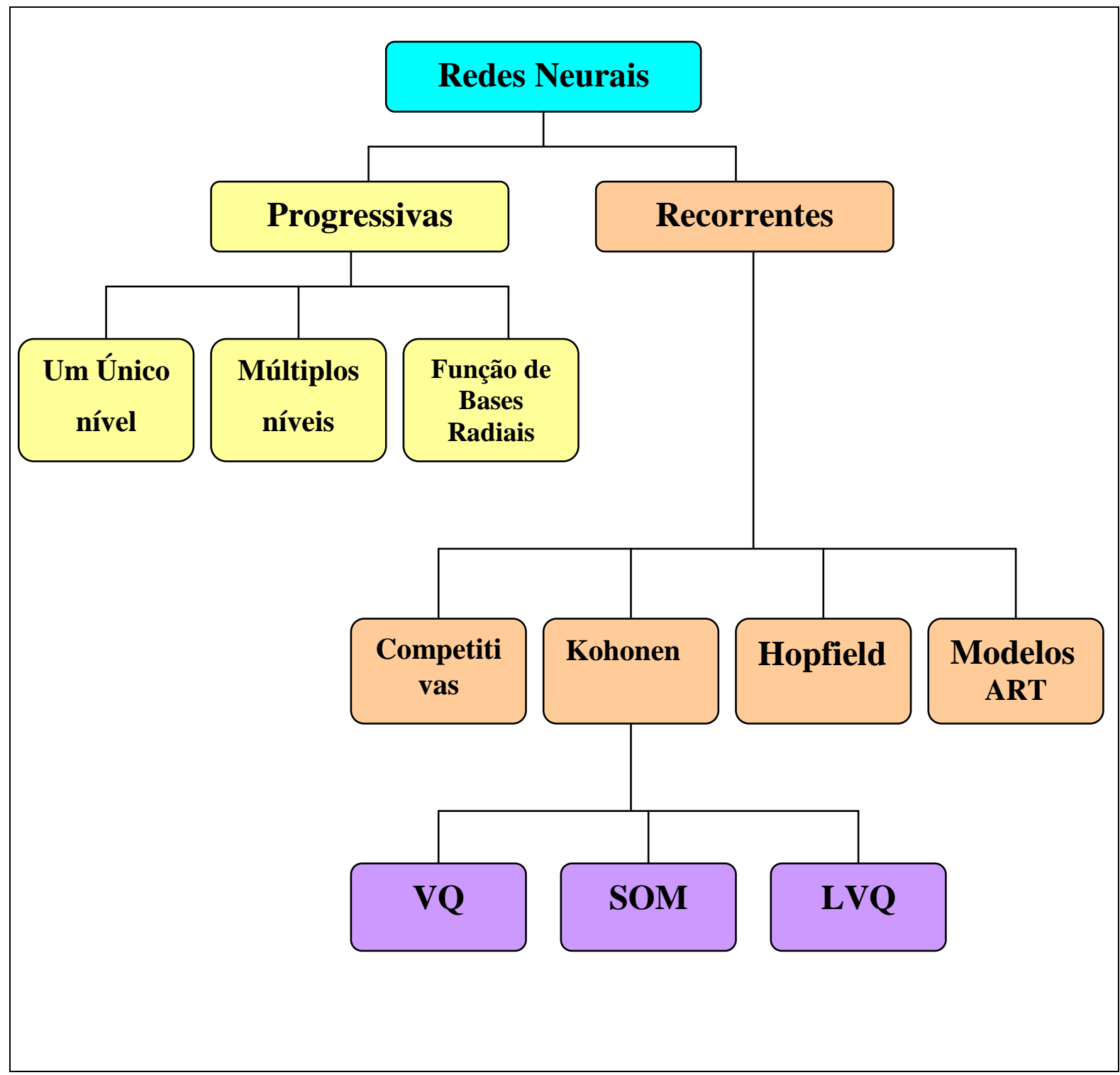

Figura 6 - Classes das Redes Neurais Artificiais. Fontes: (GARDNER \& DORLING 1998; SARLE 1997)

Cada classe apresentada na Figura 6 contém diversos modelos. É comum encontrarmos variações nas estruturas que apresentaremos e para muitas destas um nome específico foi atribuído. 
Para simplificar o entendimento apresentaremos as estruturas típicas de cada classe de Redes Neurais apontadas por GARDNER \& DORLING (1998) e adicionalmente apresentaremos a topologia de Redes Neurais que utilizam a componente temporal na sua estrutura conforme abordagem dada por HAYKIN (1999).

Para o perfeito entendimento dos conceitos, algumas informações preliminares precisam ser apresentadas. São elas:

As entradas [inputs] da Rede Neural são localizados no lado esquerdo das figuras;

As saídas [outputs] da Rede são colocados no lado direito das figuras;

Quando algum tipo de processamento é executado na unidade é feita uma indicação do tipo de função empregada, caso esta seja uma característica da rede.

Nas Figuras de 7 a 13 apresentamos um desenho esquemático das classes de Redes Neurais referenciadas na Figura 6.

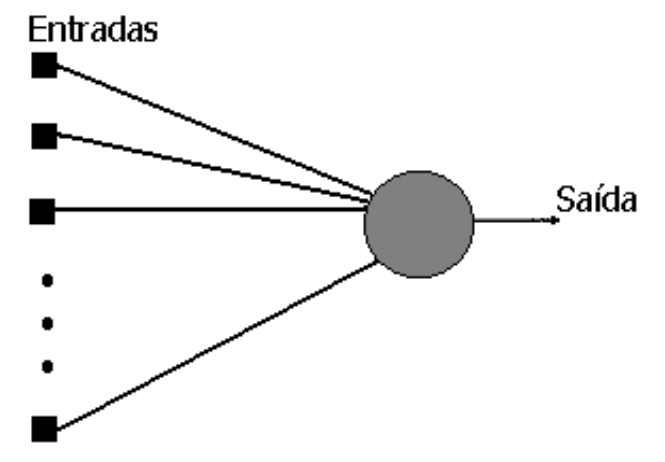

\section{Figura 7 - Rede Neural de Um único Nível [Single Layer]}

Fonte: (SCHALKOFF 1999, p. 70)

Um importante resultado associado a esta topologia é o Teorema da Convergência do Perceptron que localizamos em SCHALKOFF (1999, p.105) o qual afirma: 
"Se existe um conjunto de ponderações das conecções $\underline{w}^{*}$ que é capaz de executar uma transformação $T$, então a regra de aprendizado do perceptron convergirá para uma solução $\underline{w}$ ( não necessariamente igual a $\underline{w}^{*}$ ) em um número finito de passos para qualquer escolha da ponderação inicial."

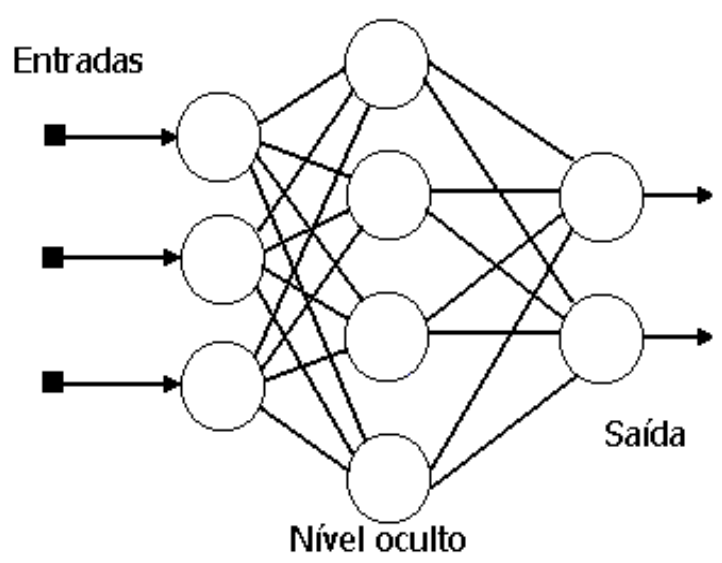

Figura 8-Redes Neurais tipo Perceptron de Vários Níveis [Multilayer Perceptron] Fonte: (HAYKIN 1999, p.159)

Este tipo de Rede admite mais de um nível oculto, dependendo somente da complexidade do problema que desejamos modelar e da qualidade dos resultados obtidos pelo modelo ajustado.

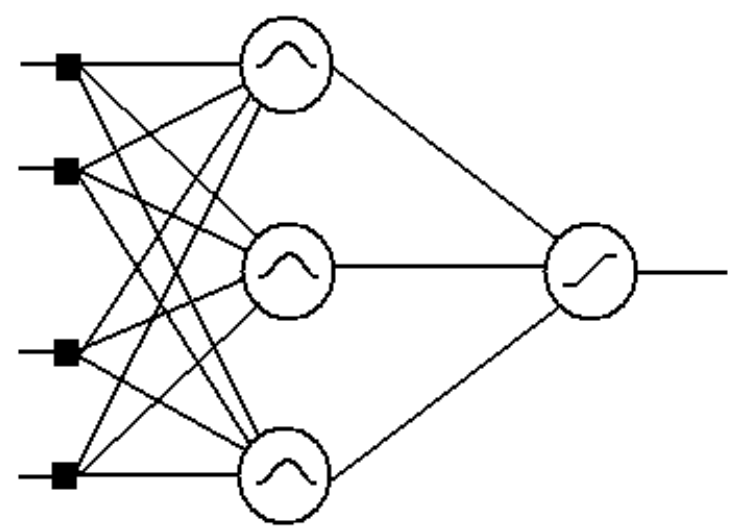

Figura 9 - Redes Neurais tipo Função de Bases Radiais [Radial Basis Function] Fonte: (HAYKIN 1999, p. 278) 
O número de entradas, o número de unidades no nível oculto e o número de unidades no nível de saída da rede podem assumir diferentes valores. Ela pode inclusive ter mais de um nível oculto, entretanto, usualmente só possui somente um.

Devemos observar que há o processamento de funções de transferência simétricas ( sigmóide $^{28}$ ) nas unidades e que na saída há uma função linear de avaliação de amplitude (SCHALKOFF 1997, p.339). Esta é a característica que define esta classe de redes.

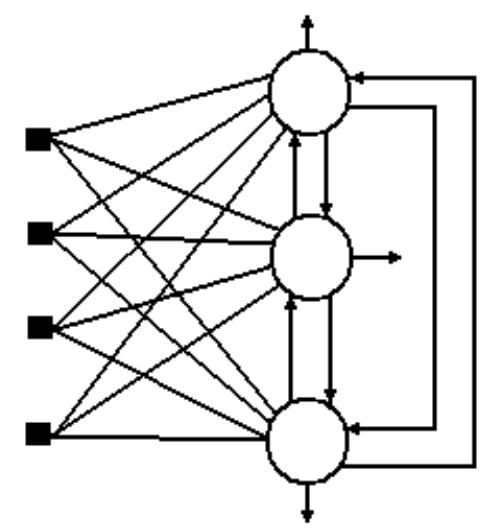

\section{Figura 10 - Redes Neurais do tipo Competitivas}

Fonte: (SCHALKOFF 1997, p.315)

Nesta arquitetura de Rede Neural há competição entre as unidades, ela está representada pelas ligações laterais ${ }^{29}$ inibitórias (sinal negativo) existentes entre os neurônios.

\footnotetext{
${ }^{28}$ Função Gaussiana.

${ }^{29}$ Ligações entre unidades do mesmo nível
} 


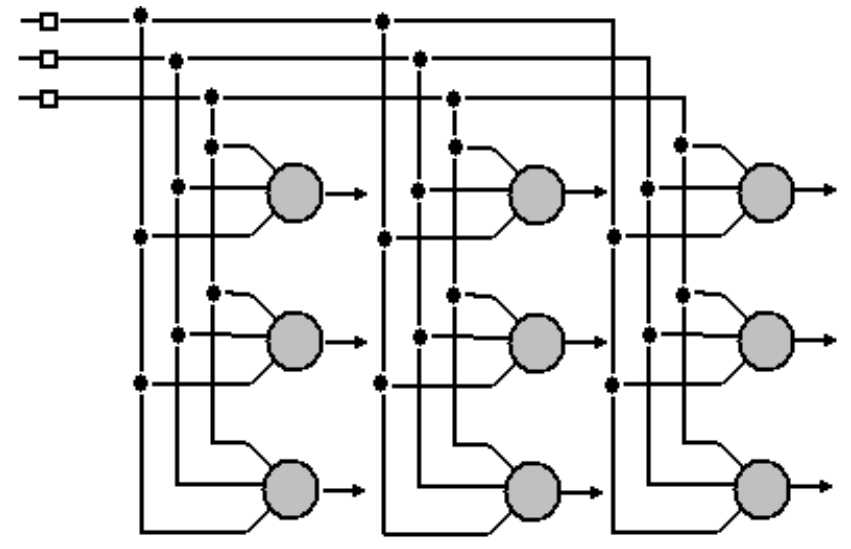

Figura 11 - Rede Neural de Kohonen tipo SOM - Self Organizing Map

Fonte: (HAYKIN 1999, p. 447)

A Rede apresentada na Figura 11 é denominada Bidimensional por ser constituída de linhas e colunas. Quando a rede for formada apenas por uma coluna ela é denominada Unidimensional.

O principal objetivo deste tipo de rede é transformar um padrão de sinal de entrada, de dimensão arbitrária, em um mapa discreto uni ou bidimensional e conduzir esta transformação de maneira adaptativa e de maneira ordenada (HAYKIN 1999, p.446). 


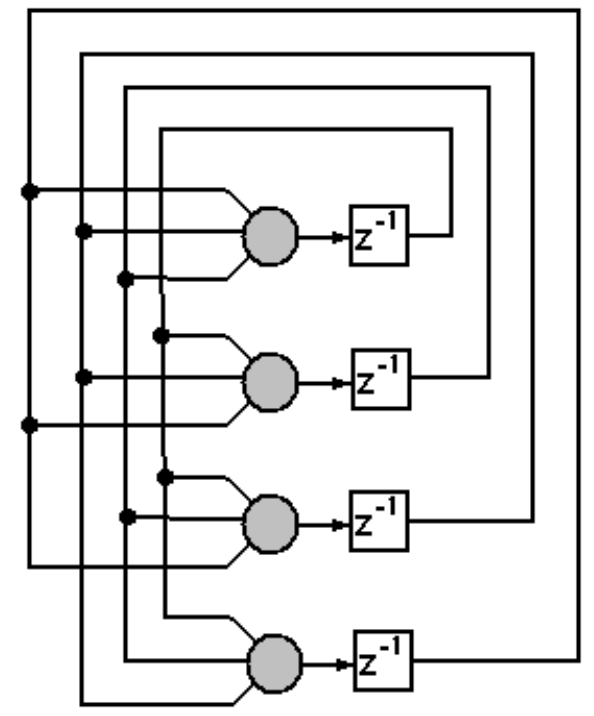

Figura 12 - Redes Neurais do tipo Hopfield

Fonte: (HAYKIN 1999, p.681)

Neste tipo de topologia de redes cada neurônio excita os demais através da unidade de defasagem temporal ${ }^{30}$ [delay unit] formando assim diversos loops [voltas].

O parâmetro característico deste tipo de rede é o número de neurônios. Na Figura 12 apresentamos uma arquitetura de uma Rede Hopfield de quatro unidades.

Este tipo de rede pode operar de maneira contínua ou discreta, dependendo do modelo adotado para descrever os neurônios.

${ }^{30}$ Trata-se de um operador que remete para a unidade de tempo anterior (passo anterior). 


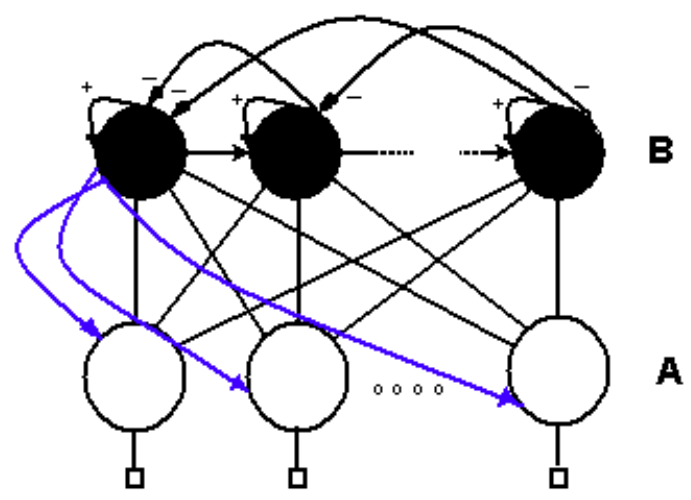

Figura 13 - Modelo de Redes Neurais do tipo ART1

Fonte: (SCHALKOFF 1997, p.328)

Segundo KOSKO (1997, p. 471), Stephen Grossberg introduziu a Teoria da Ressonância Adaptativa como uma teoria para representar o processamento cognitivo humano.

Essa teoria tem aplicações em Redes Neurais e nos Sistemas Fuzzy.

Uma rede tipo $\mathrm{ART}^{31}$ consiste de um par de subsistemas de neurônios (A e B) que interagem conforme mostramos na Figura 13.

Nesta arquitetura todos os neurônios do subsistema A estão ligados a todos os neurônios do subsistema B. Esta característica possibilita a competitividade entre os neurônios ${ }^{32}$.

A interatividade é expressa nesta arquitetura através da conecção entre os dois blocos de neurônios nomeados A e $\mathbf{B}$ na Figura 13.

Competitividade e interatividade são as características principais deste tipo de Rede Neural.

\footnotetext{
${ }^{31}$ ART : Adaptive Resonance Theory

${ }^{32}$ Veja a Figura 10 que apresenta uma arquitetura de redes competitivas.
} 
Devemos ainda observar que há no subsistema $\mathbf{B}$ um auto estímulo por parte de todos os seus neurônios.

Uma restrição das Redes tipo ART1 é que elas só trabalham com variáveis binárias $^{33}$. A topologia equivalente que trabalha com variáveis de outros tipos é denominada ART2.

\subsubsection{Redes Neurais Recorrentes e Dinâmicas}

Face a importância deste tipo de Redes Neurais apresentaremos um item específico expondo as mesmas.

As mais conhecidas que executam processamento temporal são as do tipo Time

Delay Neural Networks - TDNN [Redes Neurais com retrocesso temporal] (HAYKIN 1999, p.641).

A topologia deste tipo de rede é basicamente uma Recorrente de Multi-níveis e o objetivo básico é o reconhecimento de padrões temporais, ao contrário das topologias de Multi-níveis e Funções de Bases Radiais que tem capacidade de reconhecer padrões fixos. (HAYKIN 1999, p.643).

Na Figura 14 apresentamos uma típica Rede Neural com esta propriedade.

${ }^{33}$ Variável binária é aquela que assume somente os valores 0 e 1. 


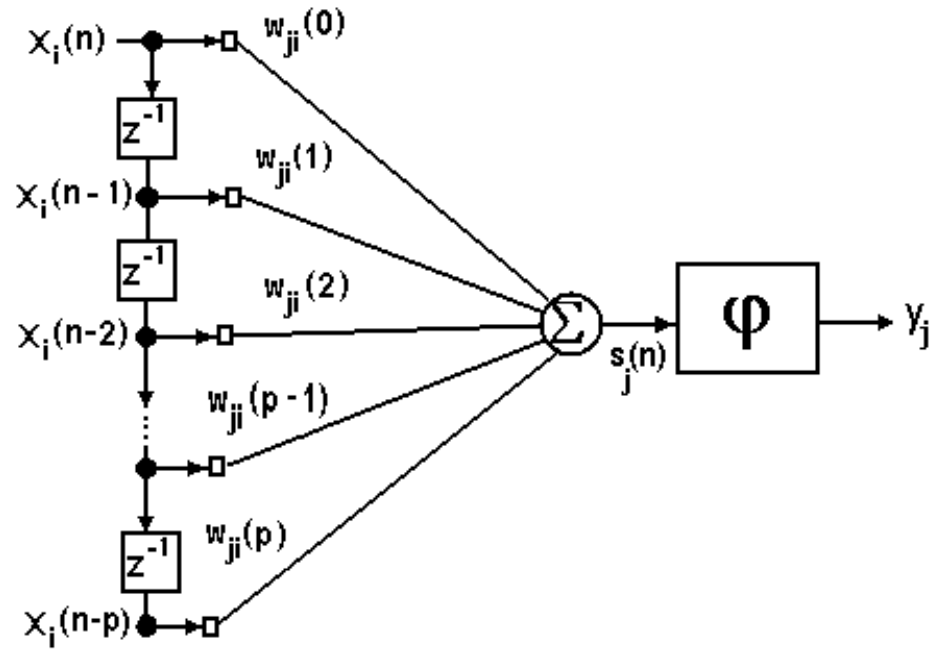

\section{Figura 14 - Topologia do tipo Filtro Neuronal Focado} Fonte: (HAYKIN 1999, p.644)

À topologia de rede que apresentamos na Figura 14 podemos acrescentar na sequência das entradas um nível oculto com o mesmo número de unidades que a entrada para obtermos uma nova topologia de redes, a Time Lagged Feedforward Network- TLFN [Rede Progressiva com Retardamento Temporal].

HAYKIN (1999, p.648) propõe que o modelo da Figura 14 seja visto como um Filtro de resposta a impulsos de duração finita - $\operatorname{FIR}^{34}$ [finite duration impulse response filter] de ordem $\mathbf{p}$.

A partir deste enfoque e do emprego de múltiplas entradas sendo que estas seriam associadas à componente espacial. Teremos então uma topologia de Redes Neurais contemplando as componentes de espaço e tempo que um modelo ambiental necessitam.

${ }^{34}$ Tipo de filtro com larga aplicação em processamento de sinais digitais. 


\subsubsection{Processo de Aprendizado de uma Rede Neural Artificial}

No site do Instituto de Ciências Matemáticas de São Carlos [ICMSC 2000] encontramos atestado que "a propriedade mais importante das Redes Neurais é a habilidade de aprender de seu ambiente".

(HAYKIN 1999, p.50) define aprendizado [learning], no contexto de Redes Neurais, como: “um processo através do qual os parâmetros livres de uma Rede Neural são adaptados por um processo de estimulação do ambiente no qual a Rede Neural está sustentada. O tipo de aprendizado é determinado pela maneira na qual as mudanças nos parâmetros se processam."

A partir desta definição, segundo o autor, temos três consequiências diretas:

1. A Rede Neural é estimulada por um ambiente;

2. A Rede Neural induz mudanças nos seus parâmetros livres como resultado destes estímulos;

3. A Rede Neural responde de uma nova maneira ao ambiente devido às mudanças ocorridas na sua estrutura interna.

(FREEMAN 1994, p. 28) deixa claro que "aprendizado em Redes Neurais envolve o problema de encontrar um conjunto de ponderações tal que a rede executará corretamente qualquer que seja a função que desejarmos (sic)". Na realidade isto vale para as funções contínuas definidas num intervalo fechado.

Vários são os procedimentos para se obter matematicamente estes valores. Estes procedimentos utilizam alguns conceitos e definições básicas sobre o aprendizado de Redes Neurais os quais apresentamos para clareza dos processos. Eles foram extraídos de (HAYKIN 1999): 
Algoritmo de Aprendizado [Learning algorithm] : Um conjunto prescrito de regras bem definidas para a solução de um problema de aprendizado de uma Rede Neural é denominado algoritmo de aprendizado. Não é único o algoritmo de treinamento para uma dada Rede Neural.

Paradigmas de Aprendizado [Learning Paradigms] : Se refere ao modelo de ambiente no qual a Rede Neural opera. Ele trata da relação entre a Rede Neural (máquina inteligente) e o ambiente no qual está inserida e como este afeta os parâmetros da rede. Os paradigmas de aprendizado são: Aprendizado Supervisionado e Não Supervisionado, este último se subdividindo em Reforço [Reinforcement] e Programação Neurodinâmica.

Tarefas de aprendizado [Learning tasks] : são seis os tipos de tarefas que fazem parte do processo de aprendizado de uma Rede Neural: associação de padrões [ pattern association], reconhecimento de padrões [pattern recognition], aproximação de funções [function approximation], controle [control], filtragem [filtering] e beamforming, que é um tipo especial de filtragem que compara o sinal com o ruído de fundo [background noise].

$>$ Memória : memória e aprendizado são intrinsicamente relacionados. A memória pode ser dividida em dois tipos: memória de curto prazo e de longo prazo, dependendo do tempo de retenção da informação (HAYKIN 1999, p.75).

Adaptação: freqüentemente o ambiente não é estacionário e então a Rede Neural tem que se adaptar a novas características. Uma rede faz esta adaptação através de um processo de ajuste dos parâmetros livres face aos sinais de entrada, isto é feito em tempo real.

Aprendizado Supervisionado: o aprendizado supervisionado ou aprendizado com um professor é aquele que utiliza um agente externo (professor) para indicar à Rede Neural a resposta desejada para uma entrada conhecida, na Figura 15 podemos observar este processo de aprendizado; 
Aprendizado Não supervisionado: quando o processo de aprendizado não é assistido por um agente externo (professor), a própria Rede Neural é obrigada a se auto organizar para efetivar o aprendizado;

Reforço: É quando no processo de Aprendizado Não Supervisionado há um crítico cuja função é de ampliar e reforçar as entradas ${ }^{35}$ de uma Rede Neural.

Programação Neurodinâmica: é uma técnica que lida com situações onde as decisões são tomadas em estágios. As decisões tomadas em estágios anteriores são levadas em consideração na tomada de decisão atual. Nas Redes Neurais ela possibilita que o sistema aprenda como tomar boas decisões através da observação do seu próprio comportamento.

Na Figura 15 esquematizamos o processo de aprendizado de uma Rede Neural que conta com a presença de um professor, ou seja o aprendizado é supervisionado.

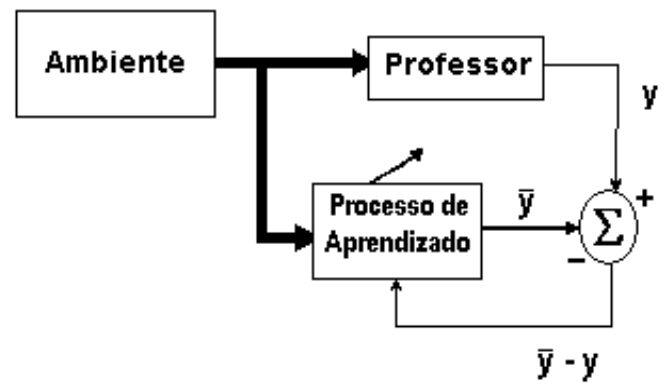

Figura 15 - Processo de Aprendizado Supervisionado Fonte: (HAYKIN 1999, p.63)

A partir da Figura 15 podemos observar que o professor alimenta o processo de aprendizado da Rede Neural através do fornecimento do valor verdadeiro de saída para a entrada recebida (estímulo) a partir do ambiente.

${ }^{35}$ A entrada é normalmente um sinal e, neste caso, é conhecido como sinal heurístico de reforço. 
Na Figura 16 apresentamos o processo de aprendizado de uma Rede Neural baseado em reforço, nele observamos o papel de um crítico, o qual recebe estímulo do ambiente e enfatiza para o processo de aprendizado da Rede Neural.

O aprendizado se processa então baseado em dois tipos de estímulos, um proveniente do ambiente (os estados) e outro proveniente do crítico.

Este tipo de aprendizado é o que mais se aproxima da programação dinâmica.

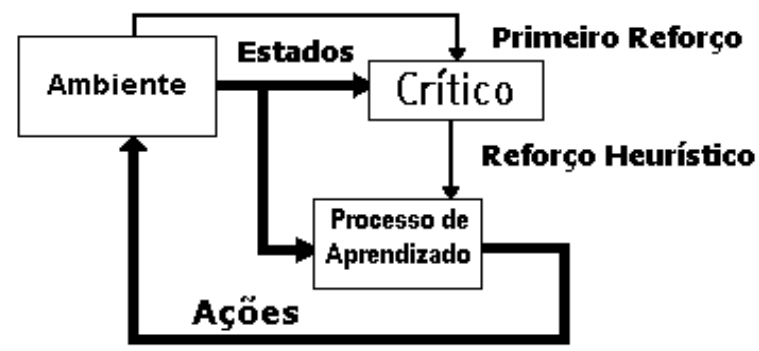

Figura 16 - Processo de Aprendizado com Reforço Fonte : (HAYKIN 1999, p.64)

A maioria das arquiteturas de Redes Neurais emprega apenas um dos modos de treinamento, as Redes Neurais do Tipo Função de Bases Radiais ${ }^{36}$ [Radial Basis Function] entretanto utilizam uma solução híbrida: as ponderações dos níveis ocultos da rede são obtidos através de um treinamento sem supervisão e na seqüência as ponderações das unidades de saída da rede são obtidas através de um treinamento supervisionado (SARLE 1997).

\subsubsection{1 Áreas com aplicação de Redes Neurais ${ }^{37}$}

Dentre as diversas áreas onde há aplicações de Redes Neurais podemos citar:

exploração de petróleo;

$>$ previsão de vendas e análise de mercado;

\footnotetext{
${ }^{36} \mathrm{Na}$ Figura 9 apresentamos este tipo de arquitetura de rede neural.
} 
previsão de fluxo de caixa;

$>$ análise de dados em Botânica;

reconhecimento de partículas;

$>$ otimização de matérias primas;

> previsão de indicadores econômicos;

CAD/CAM [desenho e manufatura assistidos por computador];

análise de produtividade, custos;

$>$ estratégias legais;

$>$ diagnóstico em circuitos eletrônicos e previsão de falhas;

controle de qualidade;

$>$ Help desk [Balcão de ajuda];

$>$ processo seletivo de empregados;

> identificação de componentes químicos e análise química analítica;

$>$ análise espectral;

$>$ análises médicas e diagnóstico de doenças;

qualidade da água subterrânea;

$>$ avaliação de crédito;

$>$ identificação de bactérias;

$>$ controle de processos produtivos na indústria;

$>$ modelagem de sistemas físicos;

- gerenciamento de bacias hidrográficas/ recursos hídricos;

$>$ diagnóstico psiquiátrico e testes mentais.

As Redes Neurais podem ajudar a aumentar o desempenho das tecnologias convencionais empregadas para:

$>$ reconhecimento de padrões (voz e imagem inclusive);

$>$ na filtragem de sinais;

$>$ na segmentação de dados;

> na compressão de dados;

${ }^{37}$ BUSHEY H. A survey of Neural Networks in business forecasting, 1998 
$>$ em Data Mining ${ }^{38}$ [análise exploratória de dados];

$>$ no controle adaptativo;

> em otimização;

$>$ na reserva de passagens; e

$>$ em mapeamento complexo.

${ }^{38}$ Análise exploratória de dados visando reconhecer padrões e apontar estruturas ocultas nos dados. 


\section{OBJETIVOS}

\subsection{Objetivos Gerais}

Conceituar Inteligência Artificial e apresentar suas principais técnicas relacionadas com Redes Neurais.

Apresentar os conceitos utilizados nas técnicas de Redes Neurais, suas características, os tipos de topologias e os processos de aprendizado das redes.

Apontar as principais áreas onde as Redes Neurais estão sendo aplicadas dando ênfase à área de poluição do ar.

Apresentar e discutir as principais Técnicas Estatísticas hoje utilizadas na interpretação de dados ambientais e apresentar, quando disponível, os resultados dos estudos comparativos entre estas técnicas e as Redes Neurais.

\subsection{Objetivos Específicos}

Apresentar aplicações de Redes Neurais na interpretação de dados ambientais dando maior ênfase nas ciências atmosféricas.

Apresentar a grande abrangência das aplicações de Redes Neurais em poluição do ar.

Efetuar um levantamento dos software [aplicativos] comerciais que lidam com Redes Neurais apontando suas características, fornecedores, preços etc.

Propor uma topologia de Redes Neurais visando prever episódios críticos de poluição do ar devido ao monóxido de carbono na Cidade de São Paulo. 


\section{METODOLOGIA}

Conduzimos um Estudo Exploratório baseado em Pesquisa Bibliográfica focado no escopo definido para a Dissertação, ou seja, aplicações de Redes Neurais nas Ciências Atmosféricas.

Conforme encontramos em GIL (1996), "Pesquisa Exploratória ou Estudo Exploratório é aquele que têm por objetivo um melhor conhecimento de determinado assunto”, no caso aplicações de Redes Neurais nas ciências atmosféricas.

As principais características do Estudo Exploratório são a flexibilidade, a utilização de instrumentos não padronizados, ter como base levantamentos bibliográficos, comunicação com especialistas (realizada via correio eletrônico), estudos de casos e propiciar uma análise crítica daquilo que foi levantado na revisão bibliográfica.

A pesquisa bibliográfica foi conduzida com base nos acervos das bibliotecas da FSP/USP - Faculdade de Saúde Pública da Universidade de São Paulo, do IME/USP - Instituto de Matemática e Estatística da Universidade de São Paulo, da CETESB Companhia de Tecnologia de Saneamento Ambiental, da FFLCH/USP - Faculdade de Filosofia, Letras, Ciências e História da Universidade de São Paulo, da EPUSP Escola Politécnica da Universidade de São Paulo, e no acervo particular do autor.

Para conceituar a técnica de Redes Neurais Artificiais alguns livros básicos foram adquiridos pelo autor, HAYKIN (1999) e SCHALKOFF (1997).

Poucos são os livros que contém aplicações de Redes Neurais na área ambiental, dentre eles MICHALSKI (1998), também adquirido pelo autor.

Para operacionalizar a tecnologia de Redes Neurais utilizando um software comercial, citamos o livro do FREEMAN (1994), o qual utiliza o aplicativo Mathematica ${ }^{\circledR}$ 
A abordagem das Redes Neuro-fuzzy foi extraída de PAL \& MITRA (1999) e de SCHALKOFF (1997). O primeiro é um livro básico tratando somente do tema e no segundo há um capítulo específico sobre este tipo de Redes Neurais Artificiais.

A referência básica sobre aplicações de Sistemas $\boldsymbol{F u z z y}$ que empregamos foi a do KOSKO (1997).

Os periódicos da área ambiental pesquisados foram: Atmospheric Environment, Journal of Air and Waste Management Association, Environmental Pollution, Journal of Environmental Engineering e Environmental Science and Technology e estão disponíveis nas bibliotecas citadas.

O periódico AI EXPERT foi pesquisado para apresentarmos a abordagem dos especialistas em Inteligência Artificial, sobre a comparação entre as Redes Neurais e as Técnicas Estatísticas de previsão. A referência localizada foi REYNOLDS et al. (1995).

Como os artigos envolvendo a tecnologia de Redes Neurais na área ambiental começaram a aparecer a partir da metade da década de 90 , pesquisamos os números referentes aos anos de 1996 a 2000. Quando alguma referência relevante estava fora deste período ela também foi pesquisada e integrada à Revisão Bibliográfica.

Os artigos foram então analisados com respeito à contribuição que poderiam dar ao desenvolvimento do tema, seja pela aplicação de Técnicas Estatísticas na interpretação dos dados (procuramos aqui a maior diversidade de técnicas possível), seja pelo esforço de Modelagem Matemática dos processos envolvidos na poluição do ar, seja por apontarem variáveis intervenientes no comportamento dos poluentes atmosféricos, seja por aplicar a tecnologia de Redes Neurais ou ainda aqueles que fizeram estudos comparativos envolvendo Redes Neurais. 
Este estudo também incluiu consultas a sites $^{l}$ específicos da Internet que são ligados ao tema Inteligência Artificial, Redes Neurais, Sistemas Fuzzy, Algoritmos Genéticos etc.

Contatos com especialistas no assunto de instituições de ensino e pesquisa no Brasil e no exterior através da Internet também puderam ser efetivados.

Foram ainda consultados alguns sites [endereços] de empresas que comercializam aplicativos para trabalhar com Redes Neurais. Estas empresas foram localizadas na rede através de consulta ao site de busca da Altavista ${ }^{\circledR}$ - http://www.altavista.com, onde procuramos por Neural Network [Rede Neural] dentro de Software [Aplicativo].

Para a especificação da topologia da Rede Neural para efetuar a previsão das concentrações futuras de monóxido de carbono na Cidade de São Paulo foram consultadas as listagem dos dados gerados pela Rede Telemétrica de monitoramento da qualidade do ar da CETESB e os Relatórios de avaliação da qualidade do ar.

O material relativo ao tema poluição do ar, divulgado no site da $\mathrm{CETESB}^{2}$, também foi consultado para subsídios.

\footnotetext{
${ }^{1}$ Endereços na Internet

${ }^{2}$ http://www.cetesb.br/Diversos/cet0601.htm
} 


\section{REVISÃO BIBLIOGRÁFICA}

\subsection{Redes Neurais aplicadas ao controle de processos}

ZHANG \& STANLEY (1999) utilizaram uma Rede Neural Artificial para controlar os sistemas de coagulação, floculação e sedimentação de um Sistema de Tratamento de Água, operando em tempo real.

YAGI \& SHIBA (1999) empregaram controle baseado em lógica Fuzzy e Algoritmos Genéticos ${ }^{3}$ para controlar o funcionamento de uma estação combinada de bombeamento de esgoto.

SCHÜTZE et al. (1999) também empregaram Algoritmos Genéticos para otimização das estratégias de controle para sistemas para água residuárias urbanas numa estação de tratamento, a abordagem dada foi integrada, isto é, envolveu o sistema de tratamento de esgoto, a estação de tratamento e o corpo receptor.

REIFMAN \& FELDMAN (1998) aplicaram duas classes de Redes Neurais para identificação e controle de um sistema dinâmico não linear. As redes foram treinadas para identificar e controlar a formação de $\mathrm{NO}_{\mathbf{x}}$ (óxidos de Nitrogênio) num forno que utiliza carvão como combustível numa instalação de geração de energia.

Os resultados observados comprovaram o valor da técnica no desenvolvimento de sistemas digitais avançados para controle de processos dinâmicos.

REIFMAN et al. (2000) utilizaram Redes Neurais para otimizar o desempenho de uma nova tecnologia de re-incineração, o FLGR - Fuel Lean Gas Reburn [Otimização do combustível gasoso através de re-incineração]. A topologia adotada foi a de Multi-níveis [ multilayer], sendo empregados três níveis.

\footnotetext{
${ }^{3}$ Algoritmo Genético é uma ferramenta de Inteligência Artificial utilizada em otimização. Pode ser empregada na fase de aprendizado de uma Rede Neural. Em 1.2.2 apresentamos este algoritmo.
} 
Um dos pontos positivos associado à tecnologia e apontado pelos autores é a possibilidade de que seja desenvolvido um modelo matemático empírico com relacionamentos complexos e não lineares entre as entradas e saídas do sistema, isto em tempo real e sem a necessidade de conhecimento dos fenômenos físicos envolvidos no processo.

Duas Redes Neurais foram aplicadas, uma para modelar os óxidos de nitrogênio NOx, na saída do processo e outra acoplada a esta servindo como controlador do processo, neste caso foi utilizada uma rede Multi-níveis do tipo (2 / 6 / 4): duas entradas, seis unidades no nível oculto e quatro saídas.

A função deste controlador foi a de prover a distribuição ótima para injeção de gás nas câmaras de combustão de tal forma que a geração de NOx fosse minimizada.

Os autores apontam que apesar do sistema FLGR, em termos práticos, não poder atingir uma solução teórica ótima, o sistema produziu uma significativa redução nas emissões de NOx.

Exemplificando, se o controlador pode reduzir 0,02 lbm/Mbtu em um queimador de 200 MW, então a redução total de NOx será de 60 ton. para o período de maior insolação.

\subsection{Redes Neurais nas Ciências Atmosféricas}

O trabalho de GARDNER \& DORLING (1998) apresenta as Redes Neurais como alternativa para as técnicas tradicionais de modelagem estatística, na verdade, conforme aponta SARLE (1997) ${ }^{4}$, elas se equivalem em muitos casos e se complementam na interpretação de dados, conforme expusemos em 1.3.7.

GARDNER \& DORLING (1998) apresentam e discutem algumas das recentes aplicações desta metodologia nas ciências atmosféricas, oferecem ainda uma revisão

\footnotetext{
${ }^{4}$ Diversos trabalhos científicos apontando a equivalência das técnicas são referenciados.
} 
dos conceitos para o entendimento de Redes Neurais e tiveram por objetivo elaborar um guia para orientação para o emprego desta ferramenta.

Uma das interessantes observações dos autores é que " funções não lineares são aproximadas sem a necessidade de conhecimento prévio a respeito da natureza da relação entre as variáveis”. Esta é uma importante propriedade das Redes Neurais.

\subsubsection{Reconhecimento, classificação e caracterização de aerosóis ${ }^{5}$}

Os pesquisadores canadenses Eugene Yee e Jim Ho de Alberta, treinaram uma Rede Neural para reconhecer, classificar e caracterizar aerosóis de origem desconhecida com um alto grau de precisão.

Os resultados por eles observados constituem uma considerável promessa para rapidamente termos aplicações para o monitoramento do ar em tempo real, com impacto nas áreas de Saúde Ocupacional e padrões de qualidade do ar.

$\mathrm{Na}$ pesquisa eles aplicaram um Rede Neural para reconhecer e classificar bactérias e aerosóis artificiais no ar ambiente com base na distribuição do tamanho aerodinâmico das partículas.

Segundo os autores esta é uma difícil tarefa para as técnicas usuais de reconhecimento de padrões devido à variabilidade existente.

\subsubsection{Classificação de partículas e fontes de poluição do ar}

XIE et al. (1994) analisaram partículas do ar ambiente usando escaneamento com microscópio eletrônico controlado por computador. O estudo demonstrou que o

\footnotetext{
${ }^{5}$ Informações extraídas do site da Brain Maker: http://www.calsci.com/air.html
} 
recente sistema de Ressonância Adaptativa baseada em Rede Neural Artificial $\left(\mathrm{ART}_{2} \mathrm{~A}^{6}\right)$ tem um alto valor potencial na classificação de partículas.

RAGE \& TOCK (1996) usaram Rede Neural para estimar a taxa de emissão de $\mathrm{H}_{2} \mathrm{~S}$ (gás sulfídrico) e $\mathrm{NH} 3$ (amônia) emitidos por uma fonte pontual. Como destaque os autores observam que com Redes Neurais não é necessário o conhecimento de diversos parâmetros e medidas precisas de diversas variáveis que os modelos tradicionais requerem.

REICH et al. (1999) também aplicaram Redes Neurais Artificiais para identificar fontes não conhecidas de poluição do ar.

Uma importante propriedade da Rede Neural é que o sistema pode identificar novos agrupamentos (clusters) para partículas desconhecidas e atualizar, dinamicamente, a biblioteca de classes de partículas. O sistema possibilita então uma maneira de identificar e posteriormente investigar novas fontes de partículas lançadas na atmosféricas.

\subsubsection{Balanço Químico de Massas e Redes Neurais}

SONG \& HOPKE (1996) propuseram uma Rede Neural Artificial com ajustes dos parâmetros (ponderações) utilizando o algoritmo de propagação retroativa (back propagation) de erros, como um método alternativo para resolver o problema de determinação da participação das fontes na técnica de Modelo Receptor.

Uma importante constatação foi que quando uma nova fonte, que não constou do conjunto de treinamento da Rede Neural, aparece no estudo, a rede é capaz de identificar e quantificar esta nova fonte e a sua contribuição.

${ }^{6}$ Analog Adaptive Resonance Theory 
Outra importante observação é que a Rede Neural lida, sem problemas, com fontes que apresentam o problema de colinearidade ${ }^{7}$ e LIPFERT \& WYZGA (1999) apontam que "colinearidade é uma situação comum com dados de poluição do ar".

Esta é uma importante característica das Redes Neurais e justifica o esforço de emprego desta técnica ao equacionamento dos problemas de poluição do ar.

SONG et al. (1999) apresentaram uma metodologia baseada na combinação de Redes Neurais e Microscopia e escaneamento eletrônico assistido por computador para quantificar a participação de fontes em amostras de solo.

\subsubsection{Interpretação de dados de poluentes atmosféricos}

GUARDANI et al. (1999) estudaram a formação do ozônio atmosférico através de um modelo baseado em Rede Neural e concluíram ser esta uma ferramenta promissora para a previsão de concentrações deste poluente na Região Metropolitana de São Paulo.

Uma Rede Neural do tipo Multi-níveis com oito entradas, oito unidades no nível oculto e uma saída $(8,8,1)$, foi treinada com base em concentrações dos precursores do ozônio disponíveis na rede de monitoramento (hidrocarbonetos menos metano, óxido de nitrogênio e dióxido de nitrogênio) e dos parâmetros meteorológicos também disponíveis (velocidade e direção do vento de superfície, temperatura ambiente e radiação solar). Dados de outros poluentes também foram utilizados como entradas para a rede.

Foi observada uma boa aderência entre os valores observados e as previsões efetuadas pela Rede Neural.

\footnotetext{
${ }^{7}$ Alto coeficiente de correlação ou seja, em módulo, próximo de 1;
} 
A abordagem usual para este tipo de problema é baseada no ajuste e adequação de modelos matemáticos que contenham o equacionamento dos processos físicoquímicos envolvidos, como exemplo citamos o trabalho de MILDFORD et al. (1994).

Neste trabalho os autores avaliaram os níveis dos precursores do ozônio e a resposta à redução das emissões através da aplicação do Modelo Regional para Oxidantes - ROMNET ${ }^{8}$ desenvolvido pela Environmental Protection Agency - EPA.

A abordagem dada pelos autores foi a de modelagem matemática dos processos físico-químicos envolvidos. A complexidade da modelagem, neste caso, está intimamente ligada à não linearidade do processo, conforme descrito no livro de GRAEDEL \& CRUTZEN (1993, p.342) e no trabalho de KLEY et al. (1999).

Fatores meteorológicos, dentre eles os padrões de escala sinótica, conforme exposto por ANEJA et al. (1994) em seu trabalho, também influenciam o processo.

O comportamento sazonal das concentrações do ozônio, é influenciado pela escala de abordagem. CASADO et al. (1994) discutem esta influência em seu trabalho.

FOWLER et al. (1999) além de abordarem todos estes aspectos também enfocam o impacto na saúde devido ao ozônio.

Como podemos observar, é um comportamento bastante complexo para se modelar, e neste sentido caso a ferramenta adotada fosse o ajuste de uma Rede Neural que incorporasse o conhecimento já adquirido na definição da sua topologia, muito do esforço para obter o resultado desejado seria minimizado.

A conclusão do trabalho de HARREMOËS \& MADSEN (1999) é a de que “o melhor modelo é aquele que oferece simulações apropriadas da realidade com o mínimo de complexidade e com um conjunto apropriado de dados de calibração".

${ }^{8}$ A referência deste modelo é U.S. EPA, 1991, EPA-450/4-91-002a 
Como disse Mackay, citado em WANIA (1999, p.235) “Don't make models more complicated than necessary. " [Não faça modelos mais complicados que o necessário].

Uma estratégia razoável para futuras aplicações seria então o emprego de Redes Neurais incorporando na definição da sua topologia todo o conhecimento disponível sobre o tema.

\subsubsection{Previsão de concentrações de poluentes atmosféricos}

BOZNAR et al. (1993) empregaram uma Rede Neural para efetuar previsões a curto prazo de concentrações ambientais de dióxido de enxofre - $\mathrm{SO}_{2}$ numa área altamente poluída e de topografia complexa. Os resultados encontrados foram promissores apesar de toda a adversidade imposta pelas condições do estudo.

A topologia da Rede Neural adotada foi uma do tipo Multi-níveis com o seguinte número de unidades - $(37,150,1)$. O grande número de unidades no modelo é devido ao fato dos autores terem utilizado esta alternativa para introduzir dados observados em diversas localidades.

Segundo os autores "o método desenvolvido, com algumas modificações pode ser empregado para outros poluentes atmosféricos", como de fato ocorreu.

As principais atividades apontadas pelos autores para o emprego de Redes Neurais com finalidade preditiva são:

1. Determinar o objetivo da aplicação da Rede Neural, o que ela oferecerá ou possibilitará;

2. Determinar o que será a entrada e qual será a saída esperada;

3. Determinar e selecionar o conjunto de dados para treinamento da Rede Neural no processo de aprendizado;

4. Determinar e selecionar o conjunto de dados para teste de padrões; 
5. Determinar e selecionar dados para os novos padrões desejados.

Como sugestões para aperfeiçoar o método os autores apontam a "melhoria no critério de escolha do conjunto de treinamento e aprendizado da Rede Neural e definição de princípios gerais”.

YI \& PRYBUTOK (1996) usaram uma Rede Neural para obter um modelo de previsão das concentrações máximas diárias de ozônio na atmosfera. O modelo aplicado foi uma Rede Neural do tipo Multi-níveis com nove entradas, quatro unidades no nível oculto e uma saída - $(9,4,1)$.

Eles compararam os resultados com outros tipos de metodologias: regressão linear e modelos ARIMA ajustados com base na metodologia de Box \& Jenkins.

As previsões observadas com o modelo da Rede Neural foram superiores às demais abordagens.

Estudo similar foi conduzido por COMRIE, em 1997, também objetivando a previsão de concentrações de ozônio.

Neste trabalho, uma primeira tentativa de equacionamento da componente temporal foi feita através da introdução de uma entrada específica da rede contendo a concentração máxima do dia anterior.

Os resultado observados também apontaram para uma superioridade da metodologia de Redes Neurais para efetuar as previsões desejadas.

A topologia da Rede Neural adotada também foi a de Multi-níveis contendo cinco entradas, sete unidades no nível oculto e uma saída - $(5,7,1)$. 
SOJA \& SOJA (1999) compararam modelos de regressão e Redes Neurais na previsão de índices de ozônio baseando-se apenas em parâmetros meteorológicos: temperatura máxima diária e duração diária da radiação solar.

Consideraram um período de três anos de dados como base para o estudo.

A topologia da Rede Neural adotada foi de Multi-níveis contendo duas unidades de entrada, duas unidades no nível oculto e uma saída - $(2,2,1)$.

A preferência dos autores, face os resultados observados com os dados de entrada, foi pela técnica de regressão linear.

GARDNER \& DORLING (1999) em seu trabalho apontaram o motivo desta preferência discutindo os dados e indicadores utilizados.

Indicam que foi devido à natureza dos dados de entrada para o treinamento da Rede Neural, que não representaram o comportamento real e não-linear da relação entre os parâmetros meteorológicos e as concentrações do ozônio.

No trabalho de SOJA \& SOJA (1999) foram considerados somente os dados do período das 7:00 às 16:00 horas e a variável estudada foi a concentração média de ozônio neste período.

Quanto ao dado de radiação solar, o melhor indicador apontado em MILANCHUS et al. (1998) é a quantidade de radiação horária, pois esta é função do ângulo de incidência solar.

Há trabalhos que inclusive estudam o comportamento da radiação UV-B ${ }^{9}$ (ultravioleta banda B) durante episódios de poluição atmosférica, como o trabalho realizado por REPAPIS et al. (1998) para a Cidade de Atenas.

\footnotetext{
${ }^{9}$ Faixa de comprimento de onda entre 290 e $320 \mathrm{~nm}$.
} 
Outros dois poluentes atmosféricos, dióxido de nitrogênio - NO2 e óxidos de nitrogênio - NOx , presentes na área urbana de Londres e originários de diversos tipos de fontes, foram modelados utilizando-se Redes Neurais por GARDNER \& DORLING em 1999.

O objetivo era o de obter previsões para as concentrações horárias destes poluentes baseadas em parâmetros meteorológicos. Os resultados obtidos, quando comparados com os obtidos empregando a técnica de regressão, foram superiores, isto é, apresentaram menor erro quadrático médio - EQM.

Neste trabalho a topologia da Rede Neural adotada também foi a de Multi-níveis.

\subsection{Técnicas Estatísticas em uso na Interpretação de dados ambientais}

LIU et al. (1997) introduziram a técnica de seleção de modelos baseada em dados censurados ${ }^{10}$ na análise de dados ambientais. A área de aplicação abordada no trabalho foi a de águas subterrâneas e o objetivo era a determinação de fatores que influenciam significativamente o risco de contaminação da água subterrânea por pesticidas.

Como resultado do trabalho é apontada a aplicabilidade da metodologia para análise de outros dados ambientais com o problema de dados censurados.

\subsubsection{Análise de Séries Temporais}

Para definirmos Série Temporal precisamos previamente definir um Processo Estocástico, conforme MORETTIN \& TOLOI (1981, p.18) “Um Processo Estocástico é uma família $Z=\{Z(t), t \in T\}$, tal que, para cada $t \in T, Z(t)$ é uma variável aleatória. Té um conjunto arbitrário, normalmente o conjunto dos

\footnotetext{
${ }^{10}$ Valores abaixo do limite de detecção pelo método de análise levam a uma distribuição truncada.
} 
inteiros." Com base nesta definição temos que uma Série Temporal é uma realização ou trajetória de um Processo Estocástico.

MILANCHUS et al. (1998) apresentam uma metodologia baseada em Análise de Séries Temporais para quantificar a influência de parâmetros meteorológicos no comportamento das concentrações de ozônio na atmosfera.

Os autores utilizaram para tanto um Modelo Sazonal Aditivo, conforme definição disponível em MORETTIN \& TOLOI (1981). Neste modelo, a concentração de ozônio é expressa pela soma de duas componentes básica: tendência e sazonalidade [periodicidade], algebricamente:

$$
\mathrm{C}(\mathrm{t})=\mathrm{T}(\mathrm{t})+\mathrm{S}(\mathrm{t})+\varepsilon(\mathrm{t})
$$

A concentração $C(t)$ é a soma da tendência naquele instante, $T(t)$, da componente sazonal para o mesmo instante, $\mathrm{S}(\mathrm{t})$ e de uma componente aleatória não controlável, $\varepsilon(\mathrm{t})$ denominada ruído branco.

Este modelo foi originalmente proposto por RAO \& ZURBENKO (1994) e novamente foi aplicado por ANH et al. (1997b), neste último, num contexto mais amplo, o de modelagem de tendência da qualidade do ar.

A componente $\mathrm{T}(\mathrm{t})$ também é conhecida como Nível da série temporal e aponta para a tendência temporal dos dados, podendo ela ser crescente, decrescente ou nula.

A componente sazonal, $\mathrm{S}(\mathrm{t})$, visa neste caso aglutinar a informação devida às variáveis cíclicas e intervenientes no processo, em poluição do ar teremos a radiação solar, a umidade específica, dentre outras variáveis.

Este tipo de modelo é apresentado na literatura estatística como Modelos de decomposição com componentes Não observáveis ${ }^{11}$.

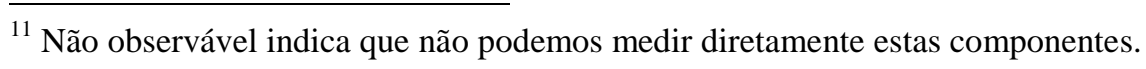


O modelo aditivo é adequado, segundo MORETTIN \& TOLOI (1981, p38), quando a componente $\mathrm{S}(\mathrm{t})$ não depende das demais, caso contrário, isto é: as amplitudes sazonais variam com a tendência, o modelo mais adequado para descrever o comportamento da Série Temporal é o Modelo multiplicativo, ou seja:

$$
\mathrm{C}(\mathrm{t})=\mathrm{T}(\mathrm{t}) * \mathrm{~S}(\mathrm{t}) * \varepsilon(\mathrm{t})
$$

Como resultado da aplicação do modelo aditivo, MILANCHUS et al. (1998) obtiveram uma explicação ${ }^{12}$ de aproximadamente $70 \%$ da variação das concentrações do ozônio.

SCHLINK et al. (1997) usaram a metodologia de séries temporais para modelar os dados de concentrações de dióxido de enxofre. Eles empregaram uma variante do modelo (1) introduzindo uma nova componente sazonal. Os dados sofreram uma transformação logarítmica previamente.

\subsubsection{Modelos de Box \& Jenkins - ARIMA}

BRUNI \& KIRA (1985, p.2) apresentam a metodologia de Box \& Jenkins informando que esta é baseada num ciclo interativo no qual a escolha do modelo é baseada nos próprios dados.

Os estágios do ciclo iterativo foram apresentados pelos autores, são eles:

Especificação, onde uma classe geral de modelos é considerada para análise;

Identificação, onde é feita a identificação de um ou mais modelos com base na análise das funções de Autocorrelação e Autocorrelação parcial, conforme definições apresentadas em MORETTIN \& TOLOI (1981);

Estimação, os parâmetros dos modelos identificados são estimados;

\footnotetext{
${ }^{12}$ Coeficiente de explicação ou de determinação $-r^{2}$
} 
Verificação, é feita a verificação da validade dos modelos ajustados através da análise dos resíduos observados.

MILLER \& SAGER (1994) ajustaram um modelo Auto-Regressivo de ordem 1 AR(1), para apontar a redundância das medidas de ozônio em duas dentre as seis estações de monitoramento que operavam em Harris County -Texas. As séries temporais de oito anos de observações das concentrações máximas diárias de ozônio foram analisadas.

YI \& PRYBUTOK (1996) também empregaram a metodologia de Box \& Jenkins para ajustar um modelo ARIMA para previsão das concentrações máximas diárias de ozônio em áreas urbanas. Neste trabalho os autores adicionalmente ajustaram um modelo de regressão linear e uma Rede Neural visando comparar a qualidade das previsões.

Como conclusão, observaram que "o modelo de Rede Neural é superior ao modelo de regressão e ao modelo ARIMA".

SALCEDO et al. (1999) aplicaram diferentes abordagens para tratar séries temporais de acidez (dióxido de enxofre) e fumaça preta, dentre elas usaram modelos tipo ARIMA e Análise de Fourier.

CHEN et al.(1998) comparam em seu trabalho o modelo de espaço de fase (Fourier) contra o modelo auto-regressivo. Os resultados apontaram uma pequena superioridade do modelo de espaço de fase para a previsão das concentrações máximas diárias de ozônio em Cincinatti.

Finalizando o estudo os autores sugerem a incorporação de outras séries, criando assim um modelo multidimensional, incluindo poluentes como o $\mathrm{NO}_{\mathrm{x}}$ e os Compostos Orgânicos Voláteis - COV, além, é claro, de alguns parâmetros meteorológicos dominantes. 
KAO \& HUANG (2000) empregaram duas técnicas para efetuar a previsão de concentrações de dióxido de enxofre e ozônio em três estações de monitoramento da qualidade do ar em Taiwan objetivando a comparação das mesmas quanto à qualidade das previsões efetuadas.

A técnica usualmente empregada para previsão temporal é a de Séries Temporais e, neste caso, empregaram a metodologia de Box \& Jenkins. Como método alternativo empregaram Redes Neurais do tipo Multi-níveis.

Os dados analisados foram as concentrações médias horárias destes poluentes e o objetivo era efetuar a previsão para a próxima hora e para 24 horas adiante, face a sazonalidade identificada no comportamento das séries de dados de concentrações pela metodologia de Box \& Jenkins.

A topologia de Rede Neural utilizada pelos autores foi a $(24, \mathbf{n}, 1)$ tendo analisados os seguintes números de unidades no nível oculto: 2,5,8,11,14,17,20,23,26,29,32,35 e 38 .

A Figura 17 apresenta esta topologia e mostra o enfoque dado ao problema temporal. Um número superior não foi analisado face ao sugerido por Weigend et al., citado em KAO \& HUANG (2000), que limita em 10\% dos padrões usados na fase de treinamento da Rede Neural.

O aplicativo utilizado para a Rede Neural foi o Xerion ${ }^{\circledR}$. Para emprego da metodologia de Box \& Jenkins foi usado o aplicativo comercial $\boldsymbol{S A S} \AA^{\circ}$

Foram utilizados os dados de quatro semanas consecutivas na fase de treinamento da Rede Neural, cada dia, 24 horas, foi considerado como uma amostra.

Este procedimento, devemos observar, limita a operacionalidade da rede em efetuar previsões pois devemos apresentar como entrada 24 horas (um dia) e não hora a hora como seria recomendável. 
KAO \& HUANG (2000) além de reportar os resultados superiores em qualidade de previsão (menor erro médio) as Redes Neurais ainda atestam que estas são capazes de auto-aprendizagem, auto-adaptação e processamento paralelo, estas características levam esta tecnologia a ser amplamente utilizada no desenvolvimento de sistemas automáticos de previsão da qualidade do ar.

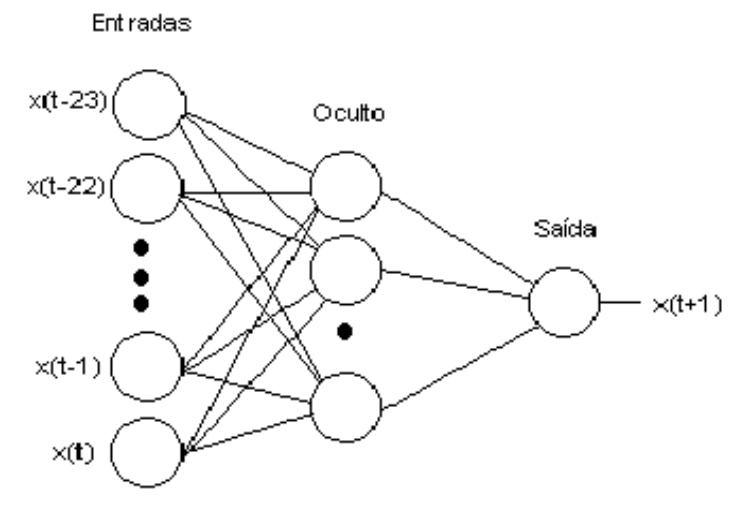

Figura 17 - Topologia da Rede Neural utilizada para previsão da concentração de poluentes atmosféricos.

Fonte: (KAO \& HUANG 2000)

KAO \& HUANG (2000) apontam que "na literatura relacionada a previsão em poluição do ar, análise de séries temporais não é prevalente”, citam Kappor \& Terry ${ }^{13}$ para justificar este fato associando-o à necessidade de consideráveis conhecimentos de estatística para o emprego deste tipo de metodologia, apontam ainda que aplicativos que ajustam automaticamente modelos em séries temporais na maioria dos caso não existe.

O aplicativo comercial SAS®, segundo os autores, provê boa assistência na identificação de modelos.

\footnotetext{
${ }^{13}$ A comparation of two automatic systems for building vector time-series models in air pollution research. In Time Series Analysis : Theory and Pratice, vol 7; Anderson, O.D., Ed.;Elsevier Science Publishers: Cincinatti, OH, 1985.
} 
Alguns trabalhos, como o de GARDNER \& DORLING (2000b) já optaram por empregar uma Rede Neural do tipo Perceptron de Multi-níveis - MLP [Multilayer Perceptron], ao invés de usar metodologias de séries temporais para remover a influência meteorológica na série temporal das concentrações de ozônio em cinco diferentes locais da Inglaterra. Para um dos locais a série compreendia o período de 1979 a 1998, as demais são do começo da década de 80.

O objetivo do trabalho foi o de avaliar possíveis variações temporais e/ou espaciais nas concentrações de ozônio face às alterações no quadro de emissões dos precursores deste poluente.

A topologia de Rede Neural foi adotada, face a ela poder representar relações funcionais complexas entre as diversas variáveis preditoras.

O período de um ano de dados, de todos os locais, foi empregado na fase de treinamento da Rede Neural.

Um importante achado foi que a explicação obtida pelo modelo será tão melhor quanto mais próxima a estação meteorológica se encontrava da estação de monitoramento da qualidade do ar (duas fontes de dados forma usadas pelos autores no trabalho).

Como resultado geral os autores apontam para uma redução nas concentrações de ozônio a partir de 1994, as taxas variam de $-0,7$ a $-2,3$ ppb/ano dependendo do local considerado.

Anteriormente REYNOLDS et al. (1995) já haviam feito uma comparação similar usando uma abordagem Estatística.

Eles construíram duas Redes Neurais do tipo Multi-níveis com três níveis (somente um nível oculto). A primeira identificava e eliminava a tendência da série temporal, a 
segunda identificava o modelo apropriado à série tratada ${ }^{14}$ pela primeira Rede Neural.

Este procedimento é o mesmo empregado no ajuste de um modelo de Séries Temporais, entretanto, nesta técnica a identificação deverá ser feito de maneira interativa e conforme uma metodologia consagrada e não automática, como no caso das Redes Neurais.

Esta abordagem é válida para modelo de séries temporais do tipo ARIMA. Modelos mais complexos, segundo REYNOLDS et al. (1995) citando LIPPMAN (1987), podem ser ajustados se empregarmos uma Rede Neural com quatro níveis, ou seja, com dois níveis ocultos.

Os critérios de comparação adotados no trabalho de REYNOLDS et al. (1995) foram os originalmente aplicados em PANKRATZ (1983), são eles:

Parcimônia: emprego do menor número possível de parâmetros no modelo;

Estacionariedade : a ser determinada previamente com base na função de auto correlação e no erro padrão;

$>$ Inversibilidade : determinada a partir dos coeficientes das médias móveis [moving averages - MA];

> Qualidade dos coeficientes: Num modelo ARIMA $(1,0,1)$ os coeficientes podem ser significantes ${ }^{15}$ e não podem ser correlacionados significativamente;

Resíduos não correlacionados: testado através do teste de Portmanteau;

$>$ Previsões satisfatórias: julgamento feito a partir da análise do erro quadrático médio [root mean square error - RMSE] obtido com base nos dados do período de validação do modelo.

\footnotetext{
${ }^{14}$ série livre de tendência

${ }^{15} \mathrm{p}<\alpha$, usualmente adota-se $\alpha$ como sendo igual a $5 \%$.
} 
O resultado do trabalho de REYNOLDS et al. (1995) indicou que as Redes Neurais são efetivas para identificar modelos do tipo Box \& Jenkins ARIMA para séries não sazonais. Os modelos identificados pelas Redes Neurais foram sistematicamente melhores em termos de qualidade que os indicados pelos sistemas especialistas ${ }^{16}$ [expert system package].

\subsubsection{Método de simulação de Monte Carlo}

CSETE (2000) define Método de Monte Carlo como sendo o conjunto de métodos numéricos que envolvem amostragem a partir de números aleatórios. É também conhecido como Método de Simulação Estatística.

Historicamente o Método de Simulação de Monte Carlo passou a ser conhecido devido a sua aplicação no Projeto Manhattan na Segunda Guerra Mundial.

O método possibilita, em muitas aplicações, a simulação do processo físico sem a necessidade de conhecimento das equações diferenciais que descrevem o mesmo. As Redes Neurais também apresentam esta capacidade.

O único requisito é que o processo físico (ou matemático) possa ser descrito por uma função densidade de probabilidade. ${ }^{17}$

Uma outra metodologia é a de simulação do comportamento dos poluentes a partir do conhecimento do comportamento de uma única partícula isoladamente (quantum).

O trabalho de SCHICHTEL \& HUSAR (1997) aponta que esta metodologia teve ampla aplicação na década de 1990, principalmente para as simulações de média escala.

\footnotetext{
${ }^{16}$ É citado do trabalho o aplicativo Forecast Pro.

${ }^{17}$ Função que possibilita o cálculo de probabilidade de ocorrências de eventos.
} 
WAGNER (1999) também utilizou simulação pelo método de Monte Carlo para obter probabilidades de ocorrência de eventos meteorológicos extremos, o tipo de evento estudado foi o de ocorrência de altas temperaturas ${ }^{18}$ em Berlim.

\subsubsection{Bootstrap $^{19}$}

CHAN \& HWANG (1996) empregaram a técnica de bootstrap [re-amostragem] ou de replicação de amostras para avaliar a representatividade ${ }^{20}$ de uma estação de monitoramento da qualidade do ar em área urbana.

Os autores reportam que para obter resultados confiáveis usando a técnica é preciso escolher amostras aleatórias a partir dos dados e garantir a presença de todos os meses do ano.

COX \& CHU (1993) aplicaram a técnica de bootstrap para estimar o erro padrão das estimativas dos parâmetros do modelo.

Considerações sobre a localização dos pontos de amostragem onde se localizam os monitores não são abordadas no trabalho.

Para os interessados nos aspectos relativos à localização dos analisadores, pois ela pode determinar o comportamento viciado nas medidas do parâmetros, o trabalho de CROXFORD \& PENN (1998) discute o tema.

CANNON \& LORD (2000) empregaram a técnica de bootstrap [re-amostragem] para gerar diferentes conjuntos de dados para efetuar o treinamento de uma Redes Neurais criadas para efetuar previsões de concentrações de ozônio na atmosfera durante o período de maior insolação [summertime].

\footnotetext{
${ }^{18}$ Temperaturas máximas diárias superiores ou iguais a $33^{\circ} \mathrm{C}$.

${ }^{19}$ Emprego de subconjunto de dados de uma amostra original visando estimar a variabilidade.

${ }^{20}$ Qual é o raio de cobertura da estação.
} 
A topologia da Rede Neural utilizada foi a de Multi-níveis com um único nível oculto.

\subsubsection{Análise de Regressão}

As técnicas estatísticas de regressão visam obter um modelo simplificado para explicar, ajustar ou prever valores de uma variável aleatória ${ }^{21}$ em função do conhecimento dos valores de outras variáveis independentes ou preditivas.

A variável que desejamos obter estimativas é denotada por $\mathbf{Y}$ e é denominada variável resposta ou variável dependente. As variáveis independentes ou preditivas são denotadas por $\mathbf{X}_{1}, \mathbf{X}_{2}, \ldots \mathbf{X}_{\mathbf{n}}$.

O modelo é da seguinte forma:

$$
Y=f\left(X_{1}, X_{2}, \ldots X_{n}\right)+\varepsilon
$$

As técnicas de regressão se subdividem em Regressão Linear e Não linear. O conceito de linearidade está associado aos parâmetros [coeficientes] do modelo e não à função f, apontada na equação (3), propriamente dita.

A técnica possibilita o teste de significância ${ }^{22}$ dos parâmetros que compõem o modelo e como medida de ajuste é empregado o coeficiente de determinação ou de explicação, ou seja, qual porcentagem da variabilidade dos dados é explicada pelo modelo ajustado.

O procedimento utilizado para obtenção das estimativas dos parâmetros do modelo é o de Mínimos Quadrados [Least Squares].

\footnotetext{
${ }^{21}$ Se num experimento controlado, diversas repetições do mesmo podem levar a diferentes valores da variável analisada dizemos que esta é uma variável aleatória.

${ }^{22} \mathrm{Se}$ é estatisticamente diferente de zero.
} 
Em DRAPER \& SMITH (1991, p.11) podemos encontrar o procedimento de Mínimos Quadrados e suas variações. São descritas ainda diversas técnicas de obtenção do melhor ${ }^{23}$ modelo.

BLOOMFIELD et al. (1996) construíram um modelo usando técnicas de regressão para compor, variável por variável, um modelo não linear para prever as concentrações de ozônio na área urbana.

Os fatores que compuseram o modelo foram: meteorologia do ar superior (700 mbar) e a história passada mais recente. O modelo final, composto por 20 parâmetros, obteve um coeficiente de explicação $\left(\mathrm{r}^{2}\right)$ de 80,42\%.

HUBBARD \& COBOURN (1998) empregaram a técnica de regressão linear múltipla para obter um modelo preditivo das concentrações, ao nível do solo, do ozônio em Louisville, KY.

A explicação obtida com base nos dados do período de 1993 a 1996 foi de $\mathrm{r}^{2}=$ 0,705. As variáveis analisadas foram: temperatura máxima diária(+), velocidade média do vento no período das 7 as 10 hs (-), velocidade média do vento no período das 13 às 16 hs. (-), umidade relativa no período das 10 às 16 hs.(-), cobertura de nuvens (-), e altura da mistura no período da manhã.

SHI \& HARRISON (1997) ajustaram modelos de regressão via método de mínimos quadrados e também modelos auto-regressivos. Os poluentes estudados foram os óxidos de nitrogênio e o dióxido de nitrogênio.

MILIONIS \& DAVIES (1994a, 1994b) fazem uma revisão dos modelos de regressão aplicados em poluição do ar e discutem e fazem sugestões quanto a suas aplicações.

${ }^{23}$ Aquele que maximiza o coeficiente de explicação, $\mathbf{r}^{2}$, com o menor número de parâmetros. 
Comparam ainda os modelos obtidos via regressão com os modelos estocásticos ou de análise de séries temporais usando Box \& Jenkins e concluem pela superioridade destes últimos.

\subsubsection{Regression Trees $\mathrm{x}$ Redes Neurais}

Na literatura esta técnica é usualmente denominada Classification Regression Trees - CART [Classificação via regressão hierárquica]. O procedimento criador por Breiman et. al. em 1984 podemos encontrar em HAYKIN (1999, p.374).

A técnica de Regression trees [Regressão hierárquica]é recomendada por HAYKIN (1999, p.375) para efetuar a inicialização de Redes Neurais do tipo Mistura Hierárquica de modelos especialistas [Hierarchical Mixture of Experts Models].

O trabalho de GARDNER \& DORLING (2000a) compara três diferentes técnicas de modelagem: Regressão linear, Regression trees e Rede Neural (perceptron de Multi-níveis).

Dados horários de ozônio e dados horários de parâmetros meteorológicos sinópticos provenientes de cinco estações de amostragem na Inglaterra formaram a base de dados do trabalho.

Apesar de sabidamente associado ao ozônio, a radiação solar não fez parte da base de dados, devido à não disponibilidade de dados.

Cobertura de nuvens, altura da base das nuvens baixas, visibilidade, temperatura de bulbo seco, pressão de vapor, velocidade e direção do vento foram analisadas.

O modelo baseado em Redes Neurais apresentou melhores resultados, entretanto, os autores apontam que a técnica de Regression trees é uma Técnica Estatística alternativa. Ela tem por qualidade apresentar um modelo de fácil interpretação física, ao contrário do modelo de Redes Neurais que se apresenta com uma caixa preta. 
Entretanto, os autores apontam que "visando efetuar previsões podemos optar por um bom modelo tipo caixa preta do que um modelo de qualidade inferior, embora interpretável".

\subsubsection{Análise Fatorial [Factor Analysis]}

A técnica de Análise Fatorial consiste em considerar as variáveis observáveis como combinação de fatores não observáveis (entes matemáticos). O perfeito casamento da teoria com a prática ocorre quando estes fatores são interpretáveis.

Em poluição atmosférica a técnica de Balanço Químico de Massas em Modelo Receptor [Receptor Model] é um exemplo na qual a interpretação dos fatores tem interpretação física (MALM \& GEBHART 1997).

Esta técnica visa basicamente obtermos uma redução no número de variáveis originais a serem analisadas, passando então a análise a ser conduzida com base nas cargas fatoriais.

O modelo na sua forma matricial pode ser escrito como:

$$
\mathbf{x}=\Lambda \mathbf{y}+\varepsilon
$$

onde:

x é o vetor que contém as observações das variáveis;

y é o vetor que contém os fatores;

$>\Lambda$ é a matriz que relaciona os fatores com as observações, é a matriz que contém as cargas fatoriais. É uma matriz positiva e definida ${ }^{24}$, e

$>\boldsymbol{\varepsilon}$ é o vetor de erros associado às variáveis.

${ }^{24}$ Tipo de matriz cujos determinantes menores existem e são positivos. 
As definições e a notação que utilizamos na apresentação da técnica estão conforme as apresentadas em MORRISON (1967, p.261).

HUANG et al. (1999) aplicaram uma nova proposta que otimiza a técnica de análise fatorial tradicional, a Fatoração de Matrizes Positivas, eles aplicaram aos dados de elementos observados nos aerosóis em Narragansett, RI - USA. Essa abordagem técnica foi comparada pelos autores à técnica de Análise Fatorial na identificação de fontes conhecidas de poluição do ar.

MALM \& GEBHART (1997) mostram explicitamente o resultado da Análise Fatorial na metodologia de Modelos Receptores.

É a partir do resultado da Análise Fatorial que se obtém as indicações das fontes através da interpretação dos fatores observados.

Uma breve descrição sobre Modelo Receptor, podemos encontrar no trabalho de SONG \& HOPKE (1996).

\subsubsection{Componentes Principais}

A técnica de Componentes Principais nos fornece uma maneira de transformar os dados originais em novas variáveis, estas são combinações lineares das variáveis originais e são denominadas componentes principais.

Várias condições são impostas a estas componentes por esta técnica: as componentes devem ser ortogonais ${ }^{25}$ e as componentes são ordenadas de acordo com a variabilidade dos dados por ela explicada, (MORRISON 1961, p.221).

STATHEROPOULOS et al. (1998) aplicaram várias técnicas multivariadas de análise de dados para a cidade de Atenas, dentre elas, Componentes Principais e

${ }^{25}$ Duas componentes são ortogonais se o produto interno delas é nulo. 
Correlação Canônica ${ }^{26}$ para examinar os dados de poluição do ar e dados meteorológicos.

Os autores interpretaram as componentes observadas como sendo associadas a: combustão de gasolina, óleo combustivel e oxidantes. As componentes meteorológicas apontaram para o período de verão, refletindo a estação seca da cidade.

Correlação Canônica foi empregada para avaliar a estrutura de dependência entre os dois conjuntos de variáveis, os dados de poluição do ar e os dados de parâmetros meteorológicos observados no mesmo período.

DEININGER \& SAXENA (1997) aplicaram Componentes Principais na validação das trajetórias das massas de ar medindo as concentrações de íons nas nuvens de vapor d'água. Através do estudo provaram que a ferramenta tem aplicabilidade na investigação da relação entre a química da água das nuvens e a história das massas de $\operatorname{ar}$.

\subsubsection{Análise de Agrupamentos [Cluster Analysis].}

Análise de Agrupamentos está associada ao processo de classificação. Abordagens numéricas para este problema começaram a ser publicadas na década de 70 .

CLIFFORD \& STEPHENSON (1975) apresentam o emprego destas técnicas de classificação numérica para a área biológica. Os diferentes métodos de agrupamento são apresentados pelos autores.

Aplicações na área ambiental são mais recentes.

${ }^{26}$ Correlação Canônica avalia o grau de dependência entre dois subconjuntos de variáveis. 
Em poluição do ar, DAVIS et al. (1998) modelaram os efeitos meteorológicos nas concentrações do ozônio em Huston usando a técnica multivariada de clusters [análise de agrupamento].

Vinte e dois anos de dados meteorológicos observados no período de 1981 a 1992 foram analisados e sete diferentes regimes meteorológicos foram identificados para melhor compreender o comportamento das concentrações máximas diárias de ozônio.

Os autores sugerem o uso desta metodologia para o estudo de episódios agudos de poluição por ozônio e também para a finalidade de modelagens visando a previsão de concentrações futuras do poluente.

Vale aqui observarmos que as Redes Neurais programadas para reconhecimento de padrões podem executar os métodos de análise de agrupamentos, (SARLE 1997).

\subsubsection{Semivariogramas ${ }^{27}$}

A técnica teve sua motivação na área de Geologia e tem poucas aplicações na área de poluição do ar por suas características e propriedades físicas de difusão.

No trabalho de SEN (1995) é proposto o uso de Semivariogramas Cumulativos em poluição atmosférica.

O autor aplicou a técnica aos dados de três poluentes: fumaça, dióxido de enxofre e material particulado em suspensão (sic).

O principal objetivo do trabalho foi o de apresentar uma alternativa de como quantificar, a partir de medidas irregulares ${ }^{28}$, como é a distribuição regional da poluição do ar.

\footnotetext{
${ }^{27}$ Função de correlação espacial

${ }^{28}$ Medidas não eqüidistantes.
} 
A influência meteorológica não foi tratada pelo autor.

Dois anos mais tarde, ANH et al. (1997a) apresentam um trabalho sobre a variabilidade da qualidade do ar Região de Sidney, Austrália.

Neste trabalho os autores afirmam que "para representar a variabilidade espacial das concentrações de poluentes atmosféricos com base em Semivariogramas é preciso que a influência meteorológica seja eliminada”.

No trabalho de ANH et al. (1997a) eles utilizaram médias mensais das máximas concentrações diárias de ozônio para minimizar a componente meteorológica e obtiveram a distância de $17 \mathrm{~km}$ como o raio de influência para as características de Sidney.

Outro problema existente e não apontado pelos autores é devido à topografia e demais características geográficas.

Uma outra forma de atender ao mesmo tipo de demanda é através de modelagem matemática, McNAIR et al. (1998) discutem a distribuição espacial das concentrações de poluentes atmosféricos e suas implicações na avaliação de Modelos da Qualidade do Ar.

\subsubsection{Abordagem Probabilística}

COX \& CHU (1998) fizeram uma abordagem probabilística para ajustar a tendência das concentrações de ozônio em áreas urbanas face à influência meteorológica.

Com base nos dados observados em 43 áreas urbanas dos Estados Unidos para o período de 1981 a 1991, concluíram que as concentrações máximas diárias de 1 hora estão decrescendo com uma taxa de $-1,1 \%$ ao ano. 
WAGNER (1999) usou uma abordagem probabilística para acessar a probabilidade de ocorrência de eventos extremos de meteorologia e seus efeitos potenciais de grandes conturbações.

Simulação de Monte Carlo e Modelos Auto-regressivos também foram aplicados na abordagem do autor.

\subsection{Sistemas especialistas: a tendência futura.}

Sistemas especialistas são aqueles que incorporam componentes ${ }^{29}$ de Inteligência Artificial para oferecer ao usuário apoio à tomada de decisões ou auxiliar nas tarefas introduzindo automação nos processos.

Na maioria dos casos os Sistemas Especialistas [Expert Systems] tem que lidar com incertezas, devendo pois, incorporar medidas de incerteza e manter a capacidade de inferência, (SCHALKOFF 1997, p.381).

LAM et al. (1994) criaram um protótipo de um Sistema de Informação para gerenciamento e planejamento de uma Bacia Hidrográfica, este sistema especialista contou com uma Rede Neural, uma rede tipo Multi-níveis com as seguintes unidades, $(6,4,2,1)^{30}$, tendo dois níveis ocultos. Segundo os autores "este método foi escolhido pela capacidade que tem de reconhecer padrões sejam espaciais ou temporais".

Como podemos observar o equacionamento dos padrões espaciais e temporais é necessário e deve ser incorporado nas futuras propostas de topologias de Redes Neurais para o equacionamento de problemas ambientais.

Os aplicativos comerciais utilizados neste protótipo foram: RAISON® e ArcInfo®.

\footnotetext{
${ }^{29}$ Redes Neurais, Sistemas Fuzzy, Algoritmos Genéticos etc.

${ }^{30}$ Seis entradas, 4 neurônios no primeiro nível oculto, 2 neurônios no segundo nível oculto e uma saída.
} 
Pelas suas funcionalidades, as Redes Neuro-Fuzzy e os Sistemas Especialistas $\boldsymbol{F u z z y}$ constituem a tendência para as aplicações na área ambiental.

Encontramos em PAL \& MITRA (1999) diversos exemplos comparativos deste tipo de sistemas e a superioridade é notória.

O Projeto SIENA - Stimulation Initiative for European Neural Network Applications [Estímulo à iniciativa de aplicação de Redes Neurais na Europa] reflete esta tendência e já tem como resultado diversas aplicações de sucesso envolvendo as técnicas de Inteligência Artificial. Há inclusive aplicações na área ambiental. [SIENA 1997]. 


\section{Aplicativos comerciais para Redes Neurais}

Em SARLE (1997) encontramos a descrição de diversos aplicativos comerciais que lidam com a tecnologia de Redes Neurais Artificiais.

As descrições dos produtos e demais dados foram obtidas a partir dos próprios desenvolvedores e ou distribuidores dos aplicativos.

Os seguintes aplicativos são apresentados:

\section{BrainMaker}

2. SAS Enterprise Miner Software

3. NeuralWorks

4. MATLAB Neural Network Toolbox

5. Propagator

6. NeuroForester

7. Products of NESTOR, Inc.

8. Ward Systems Group (NeuroShell)

9. NuTank

10. Neuralyst

11. NeuFuz4

12. Cortex-Pro

13. Partek

14. NeuroSolutions $v 3.0$

15. Qnet for Windows Version 2.0

16. NeuroLab, A Neural Network Library

17. Hav.Software

18. IBM Neural Network Utility

19. NeuroGenetic Optmizer - NGO Version 2.0

20. WAND

21. The Dendronic Learning Engine

22. TDL v. 1.1

23. NeurOn-Line

24. NeuFrame, NeuroFuzzy, NeuDesk and NeuRun 
25. OWL Neural Network Library

26. Neural Connection

27. Patter Recognition Workpench Expo/PRO/PRO+

28. PREVia

29. Neural Bench

30. Trajan 2.1 Neural Network Simulator

31. DataEngine

32. Machine Consciousness Toolbox

33. Professional Basis of AI Backprop

34. STATISTICA : Neural Networks

35. Braincel (Excel add-in)

36. DESIRE/NEUNET

37. BioNet Simulator

38. Viscovery SOMine

39. NeuNet Pro

40. Neuronics

Não Anexo apresentamos as demais informações sobre estes produtos, dentre elas a identificação do fornecedor, as características operacionais e preço.

Existem poucos estudos comparativos entre os produtos para trabalhar com Redes Neurais, um deles foi elaborado pela empresa Logical Designs Consulting, Inc. e pode ser acessado na Internet através do seguinte endereço http://www.logicaldesigns.com.

Um exemplo de quadro comparativo de alguns dos produtos que trabalham com Redes Neurais é apresentado a seguir. A autoria é da empresa Logical Designs Consulting, Inc. e devemos nãos ater principalmente aos indicadores empregados na comparação dos produtos. 
Tabela 6 - Exemplo de comparação de produtos para Redes Neurais.

\begin{tabular}{|c|c|c|c|c|c|c|}
\hline Empresa & $\begin{array}{l}\text { Logical } \\
\text { Designs }\end{array}$ & $\begin{array}{l}\text { Logical } \\
\text { Designs }\end{array}$ & NeuralWare & $\begin{array}{l}\text { Ward } \\
\text { Systems }\end{array}$ & $\begin{array}{l}\text { California } \\
\text { Scientific }\end{array}$ & $\begin{array}{l}\text { Math } \\
\text { Works }\end{array}$ \\
\hline $\begin{array}{l}\text { Nome do } \\
\text { Produto }\end{array}$ & $\begin{array}{l}\text { THINKS } \\
\text { Ver } 1.03\end{array}$ & ThinksPro & $\begin{array}{l}\text { NeuralWorks } \\
\text { Professional }\end{array}$ & NeuroShell2 & $\begin{array}{l}\text { BrainMaker } \\
\text { Professional }\end{array}$ & $\begin{array}{l}\text { Neural Net } \\
\text { Tool Kit }\end{array}$ \\
\hline Preço & $\$ 295$ & $\$ 1,495$ & $\$ 1,995-3,995$ & $\$ 495$ & $\$ 795$ & $\begin{array}{l}\$ 2,590 \\
\text { (MatLab) }\end{array}$ \\
\hline Windows & Sim & Sim & Não & Sim & Não & Sim \\
\hline Editor & Sim & Sim & Não & Sim & Sim & Sim \\
\hline Validação & Sim & Sim & Não & Sim & Sim & Não \\
\hline Neurônios & RAM limit & RAM limit & 10000 & 32767 & 8192 & RAM \\
\hline $\begin{array}{l}\text { Níveis que } \\
\text { opera }\end{array}$ & 5 & 5 & 30 & 32 & 8 & $\begin{array}{l}\text { RAM } \\
\text { limits }\end{array}$ \\
\hline $\begin{array}{l}\text { Algoritmos } \\
\text { disponíveis } \\
\text { não } \\
\text { aplicativo }\end{array}$ & $\begin{array}{l}\text { BPN, QP, } \\
\text { JACOBS, } \\
\text { KOH, } \\
\text { LVQ, SA, } \\
\text { CC, RTRL }\end{array}$ & $\begin{array}{l}\text { BPN, QP, } \\
\text { JACOBS, } \\
\text { KOH, LVQ, } \\
\text { SA, CC, } \\
\text { RTRLSimpl } \\
\text { exSA, } \\
\text { Powell, CG, } \\
\text { TD,PNN, } \\
\text { GRNN, } \\
\text { Lev-Marq. }\end{array}$ & $\begin{array}{l}\text { BPN, QP, } \\
\text { JACOBS, } \\
\text { MaxProp, } \\
\text { LVQ, LPN, } \\
\text { PNN, GRNN, } \\
\text { SOM, Fuzzy } \\
\text { ART, } \\
\text { historical nets }\end{array}$ & $\begin{array}{l}\text { BPN, } \\
\text { KOH, } \\
\text { PNN, } \\
\text { GRNN, } \\
\text { WardNets }\end{array}$ & BPN & $\begin{array}{l}\text { BPN, Lev- } \\
\text { Marq, } \\
\text { LVQ, } \\
\text { RBF, SOM } \\
\text { recurrent, } \\
\text { associative }\end{array}$ \\
\hline $\begin{array}{l}\text { Análise de } \\
\text { sensibilidade }\end{array}$ & Não & Sim & Sim & Sim & Sim & Não \\
\hline $\begin{array}{l}\text { Possibilidade } \\
\text { de Expansão }\end{array}$ & Sim & Sim & Sim & Não & Sim & Não \\
\hline $\begin{array}{l}\text { Processador } \\
\text { matemático }\end{array}$ & 64bit Float & $\begin{array}{l}64 \text { bit } \\
\text { Float }\end{array}$ & 32bit Float & 32bit Float & 16bit Int & 32bit Float \\
\hline $\begin{array}{l}\text { Ajuda on- } \\
\text { line }\end{array}$ & Sim & Sim & Não & Sim & Não & Sim \\
\hline $\begin{array}{l}\text { Formatos de } \\
\text { importação e } \\
\text { exportação }\end{array}$ & ASCII & ASCII & $\begin{array}{l}\text { ASCII, } \\
\text { BIN, } \\
\text { Excel }\end{array}$ & $\begin{array}{l}\text { ASCII, } \\
\text { BIN, } \\
\text { MetaStock, } \\
\text { Excel }\end{array}$ & $\begin{array}{l}\text { ASCII,BIN, } \\
\text { MetaStock, } \\
\text { Computrac, } \\
\text { CSI, Lotus, } \\
\text { dBase, } \\
\text { Excel }\end{array}$ & $\begin{array}{l}\text { ASCII, } \\
\text { MatFile }\end{array}$ \\
\hline $\begin{array}{l}\text { Series } \\
\text { temporais }\end{array}$ & Não & Sim & Não & Sim & Sim & Não \\
\hline $\begin{array}{l}\text { Pre- } \\
\text { Processamen } \\
\text { to }\end{array}$ & $\begin{array}{l}\text { Mean/Std, } \\
\text { Min/Max, } \\
\text { Vect. } \\
\text { Norm. }\end{array}$ & $\begin{array}{l}\text { Mean/Std, } \\
\text { Min/Max, } \\
\text { Vect.Norm., } \\
\text { Added } \\
\text { Noise, } \\
\text { Disabling } \\
\end{array}$ & $+\$ 495$ & $\begin{array}{l}\text { Mean/Std, } \\
\text { Min/Max }\end{array}$ & NetMaker & não \\
\hline $\begin{array}{l}\text { Indicadores } \\
\text { financeiros }\end{array}$ & Não & $\begin{array}{l}\text { Time Series } \\
\text { Window }\end{array}$ & Não & $\begin{array}{l}\text { +\$590 pelo } \\
\text { Módulo }\end{array}$ & $\begin{array}{l}\text { Oscillators, } \\
\text { Moving } \\
\text { averages }\end{array}$ & Não \\
\hline $\begin{array}{l}\text { Suporte } \\
\text { durante } \\
\text { execução }\end{array}$ & net files & $\begin{array}{l}\text { net files, } \\
\text { DLL }\end{array}$ & C code & $\begin{array}{l}\text { DLL, } \\
\text { C code }\end{array}$ & C code & M-Files \\
\hline $\begin{array}{l}\text { Função de } \\
\text { erros do } \\
\text { usuário }\end{array}$ & Não & Sim & Não & Não & Não & Não \\
\hline $\begin{array}{l}\text { Tipos de } \\
\text { Erros }\end{array}$ & 5 & 8 & 1 & 1 & 1 & 1 \\
\hline
\end{tabular}

Fonte: Logical Designs Consulting, Inc. 
Analisando as informações apresentadas na Tabela 6 chegamos à conclusão de que a escolha do melhor aplicativo dependerá do objetivo específico do pesquisador.

Exemplificando, caso fossemos trabalhar com análise de Séries Temporais deveríamos fazer nossa escolha entre os aplicativos: ThinksPro, NeuroShell 2 e BrainMaker Professional optando neste caso pelo de menor custo.

Existem ainda disponíveis na Internet diversos aplicativos freeware [gratuitos] e shareware [paga-se uma taxa pelo uso] para trabalharmos com Redes Neurais. Os dois grandes inconvenientes associado são a falta de suporte e a necessidade de conhecimento da linguagem de programação na qual o aplicativo foi desenvolvido.

O site da Environmental Molecular Sciences Laboratory - EMSL contém uma extensa relação de aplicativos e aponta as seguintes informações sobre os produtos:

Descrição do produto;

Algoritmos disponíveis não aplicativo;

As plataformas ${ }^{31}$ suportadas

$>\mathrm{O}$ tipo (freeware ou shareware);

$>$ Referência do responsável pelo desenvolvimento do aplicativo; e

$>$ Informações adicionais sobre a facilidade de acesso pela rede.

As informações são disponibilizadas para o site pelos próprios desenvolvedores dos aplicativos.

O endereço do site que contém estas informações é: http://www.emsl.pnl.gov:2080/proj/neuron/neural/systems/shareware.html

Quando consultamos em 06/08/1999 a relação dispunha de 59 aplicativos.

\footnotetext{
${ }^{31}$ Conjunto formado pelo tipo de hardware [máquina] e o sistema operacional.
} 
Localizamos ainda na Internet outros aplicativos através de consulta formulada não Altavista ${ }^{\circledR}$, são eles:

PathFinder Neural Network System ${ }^{\text {TM }}$ da Z-Solutions ${ }^{\circledR}$, informações disponíveis em http://www.zsolutions.com/pathfinder.htm;

DynaMind ${ }^{\circledR} 4.0$ e DynaMind ${ }^{\circledR}$ Developer Pro 5.0 da NeuroDynamX, informações disponíveis em http://www.neurodynamx.com;

$>$ THINKS e ThinksPro da Logical Designs Consulting, Inc., informações disponíveis em http://www.logicaldesigns.com;

Netlab Neural Network software oferecido pelo Neural Computing Research Group para quem possui o MATLAB®, informações disponíveis em http://www.ncrg.aston.ac.uk/netlab/index.html; 


\section{TOPOLOGIA DE UM SISTEMA INTELIGENTE PARA PREVISÃO DAS CONCENTRAÇÕES DE CO NA CIDADE DE SÃO PAULO}

\subsection{Informações preliminares e dados existentes}

Discutiremos no item 6.1.1, com maior detalhe, o trabalho de KAO \& HUANG (2000) por ser este o único dentre os levantados que apresentou uma preocupação explicita de abordam o aspecto temporal do comportamento dos poluentes refletida na topologia da rede neural.

Em 6.1.2 oferecemos informações sobre os dados disponíveis para a Cidade de São Paulo e apresentamos alguns conceitos que serão utilizados na abordagem e especificação do sistema inteligente proposto no item 6.3.

\subsubsection{Abordagem temporal e Redes Neurais}

A abordagem temporal para o comportamento das concentrações de poluentes ambientais é considerada desde o começo da década de 70. Os trabalhos de MERZ, PAINTE \& RYASON (1972) e CHOCK, TERREL \& LEVITT (1975) citados em KAO \& HUANG (2000), são exemplos.

A técnica usualmente empregada nas abordagem era a de Séries Temporais, a qual apresentamos no item 4.3.1. No começo da década de 90, as Redes Neurais começaram a ser utilizadas, sem contudo haver incorporação do fator temporal na topologia da rede.

O primeiro trabalho, no universo pesquisado, onde identificamos esta preocupação foi o de KAO \& HUANG (2000), nele a componente temporal ficou explicita na topologia da rede neural conforme apresentamos anteriormente na Figura 17. 
Temos então que a definição do número de entradas da rede (24) é devido à periodicidade diária no comportamento das concentrações dos poluentes modelados pelos autores (dióxido de enxofre e ozônio).

A topologia de Rede Neural utilizada pelos autores foi a de multi níveis do tipo (24, n, 1) tendo sido analisados os seguintes números de unidades no nível oculto:

2,5,8,11,14,17,20,23,26,29,32,35 e 38. Segundo os autores, não há teoria específica sobre a otimização deste dimensionamento. Uma única referência sobre o tema é citada pelos autores, é o trabalho de WEIGEND et al. (1990), o qual norteou a escolha dos números de unidades, nele há a sugestão de não adotar mais do que $10 \%$ do número de padrões utilizados na fase de treinamento da rede.

O aspecto espacial não foi incorporado ao modelo. Os autores optaram por ajustar modelos específicos para cada uma das estações de monitoramento, foram analisadas três estações na região de Taiwan de um total de 27 que monitoram toda a região.

As estações são categorizadas em cinco tipos quanto ao tipo de emissões a que estão predominantemente sujeitas: gerais, transporte, industriais, parques nacionais e de referência [background].

Previamente ao ajuste dos coeficientes da Rede Neural, os dados foram padronizados simplesmente dividindo-se pelo máximo valor observado na série de dados (uma dada estação e um dado poluente). Outras padronizações foram feitas mas o melhor resultado foi observado com a padronização linear baseada no valor máximo.

O algoritmo de propagação retroativa [back propagation] foi utilizado na fase de treinamento da rede.

O período do estudo foi de 1 de setembro de 1993 a 31 de aosto de 1994. Foram consideradas quatro semanas consecutivas de dados horários na fase de treinamento da Rede Neural e a semana seguinte foi utilizada para previsão. A nosso entender, 
um período muito curto para contemplar a real periodicidade do comportamento destes poluentes, período de verão para o ozônio (CETESB 1999, p. 19) e para os demais poluentes o período de inverno (CETESB 1999, p. 18).

Nossa sugestão para esta abordagem seria a de ajustar uma Rede Neural visando a previsão das concentrações dos poluentes quando alguma condição meteorológica desfavorável para a região estivesse atuando, neste caso, os dados para o treinamento poderiam ser reduzidos aos dias onde forma observados estes episódios na região estudada.

Como há cinco categorias de estações devido a diferentes características de fontes de emissão seria importante que esta componente fosse incorporada ao estudo, ou seja ao invés de somente três, deveria haver pelo menos uma de cada categoria no estudo. Poderiam neste caso serem ajustadas redes para cada uma delas ou um sistema mais amplo enfocando todas simultaneamente, conforme propomos no item 6.3.1.

Para otimização do algoritmo de ajuste dos coeficientes foram utilizados três métodos baseados em gradiente ${ }^{32}$ :

1. Gradiente conjugado;

2. Gradiente conjugado de Rudi Mathon ${ }^{33}$; e

3. Conjugado com reinicialização [restarts]

O resultado do estudo apontou a superioridade das Redes Neurais para efetuar as previsões futuras (1 hora e 24 horas) quando comparados aos modelos de Séries Temporais ajustadas segundo a metodologia de Box \& Jenkins.

\footnotetext{
${ }^{32}$ Operador matemático que aplicado a uma função é definido como um vetor cujas componentes são as derivadas parciais da função

${ }^{33}$ Méto integrante do aplicativo XERION
} 
Os autores apontam a capacidade de auto aprendizado e de auto adaptação das Redes Neurais a novas condições como fator importantíssimo para modelar cenários dinâmicos como os grandes centros urbanos.

Finalizando, os autores apontam que as Redes Neurais tem sido extensivamente aplicadas no processamento de informações como, por exemplo, no reconhecimento de voz [já dispomos de telefone celular que obedece comando de voz do seu proprietário], reconhecimento de caracteres escritos manualmente, no processamento de imagens (compactação principalmente), no controle de eletrodomésticos [geladeiras, ar condicionado etc.], em processadores de textos [você dita ele escreve o texto automaticamente]. Entretanto, aplicações na área de poluição do ar tem recebido uma limitada atenção.

Em nosso levantamento bibliográfico observamos que, apesar de haver poucas aplicações e a maioria delas utilizando somente um tipo de topologia (multi-níveis), as áreas englobam praticamente todos os segmentos da poluição do ar. Há, pois, que se estimular e difundir este potencial para que novas aplicações e produtos surjam.

Este é um dos objetivos desta dissertação.

\subsubsection{Dados existentes e outras informações correlatas}

Encontramos no site da Cia. de Tecnologia de Saneamento Ambiental [CETESB 2000, p.9] a lista dos principais objetivos do monitoramento da qualidade do ar, são eles:

fornecer dados para ativar ações de emergência durante períodos de estagnação atmosférica quando os níveis de poluentes na atmosfera possam representar risco à saúde pública;

avaliar a qualidade do ar à luz de limites estabelecidos para proteger a saúde e o bem estar das pessoas; 
acompanhar as tendências e mudanças na qualidade do ar devidas a alterações nas emissões dos poluentes.

A CETESB avalia a qualidade do ar de maneira contínua através do emprego de uma Rede Telemétrica de monitoramento. Os locais onde o monóxido de carbono é monitorado são apresentados na Tabela 7 assim como os demais parâmetros analisados na estação remota.

A primeira fase do desenvolvimento de um modelo é a de levantamento dos dados disponíveis para o objetivo pretendido.

A base de dados que deveremos trabalhar, para o efetivo ajuste da Rede Neural está então definida, são as concentrações horárias dos poluentes monitorados nas estações listadas na Tabela 7 assim como os dados relativos aos parâmetros meteorológicos. Devemos observar que estes são em bem menor número. 
Tabela 7 - Locais com monitoramento contínuo de CO na Cidade de São Paulo

\begin{tabular}{|c|c|c|}
\hline $\mathbf{E R}^{34}$ & Local & Parâmetros analisados na estação \\
\hline 01 & $\begin{array}{l}\text { Parque Dom Pedro II } \\
\text { Parque D. Pedro II, } 319 . \\
\text { Centro }\end{array}$ & $\begin{array}{l}\text { Partículas inaláveis, Dióxido de Enxofre, Óxido de } \\
\text { Nitrogênio, Dióxido de Nitrogênio, Oxidos de } \\
\text { Nitrogênio, Monóxido de Carbono, Metano, } \\
\text { Hidrocarbonetos Menos Metano, Ozônio, Umidade } \\
\text { relativa, Temperatura, Velocidade e direção dos ventos. }\end{array}$ \\
\hline 05 & $\begin{array}{c}\text { Ibirapuera } \\
\text { Parque Ibirapuera, } 1985 . \\
\text { (setor 25) - São Paulo } \\
\text { Próximo à Av. IV } \\
\text { Centenário - Ibirapuera } \\
\end{array}$ & $\begin{array}{l}\text { Partículas inaláveis, Dióxido de Enxofre, Óxido de } \\
\text { Nitrogênio, Dióxido de Nitrogênio, Oxidos de } \\
\text { Nitrogênio, Monóxido de Carbono, Ozônio, Umidade } \\
\text { relativa, Temperatura, Velocidade e direção dos ventos, } \\
\text { Pressão atmosférica e Radiação total e ultravioleta }\end{array}$ \\
\hline 08 & $\begin{array}{r}\text { Congor } \\
\text { Al. dos Tupiniq } \\
\text { Congon } \\
\end{array}$ & $\begin{array}{l}\text { Partículas inaláveis, Dióxido de Enxofre, Óxido de } \\
\text { Nitrogênio, Dióxido de Nitrogênio, Óxidos de } \\
\text { Nitrogênio, Monóxido de Carbono, Ozônio. }\end{array}$ \\
\hline 09 & $\begin{array}{r}\text { Lal } \\
\text { Av. Embaixa } \\
\text { Soares, } 799\end{array}$ & $\begin{array}{l}\text { Partículas inaláveis, Dióxido de Enxofre, Óxido de } \\
\text { Nitrogênio, Dióxido de Nitrogênio, Oxidos de } \\
\text { Nitrogênio, Monóxido de Carbono, Ozônio, Velocidade } \\
\text { direção dos ventos. }\end{array}$ \\
\hline $\mathbf{1 0}$ & $\begin{array}{l}\text { Cerqueir } \\
\text { Av. Dr Arn } \\
\text { Cerqueir }\end{array}$ & $\begin{array}{l}\text { Partículas inaláveis, Dióxido de Enxofre, Óxido de } \\
\text { Nitrogênio, Dióxido de Nitrogênio, Óxidos de } \\
\text { Nitrogênio, Monóxido de Carbono. }\end{array}$ \\
\hline 12 & $\begin{array}{l}\text { Centro de São Paulo } \\
\text { Av. São Luiz esquina com } \\
\text { a Rua da Consolação }\end{array}$ & $\begin{array}{l}\text { Partículas inaláveis, Dióxido de Enxofre, Óxido de } \\
\text { Nitrogênio, Dióxido de Nitrogênio, Óxidos de } \\
\text { Nitrogênio, Monóxido de Carbono. }\end{array}$ \\
\hline 16 & $\begin{array}{l}\text { Santo Amaro } \\
\text { Av. Padre José Maria, } 355 . \\
\text { Santo Amaro }\end{array}$ & $\begin{array}{l}\text { Partículas inaláveis, Monóxido de carbono e Velocidade } \\
\text { e direção dos ventos. }\end{array}$ \\
\hline
\end{tabular}

Fonte: [CETESB 2000].

Como há sazonalidade anual no comportamento dos poluentes atmosféricos, minimamente um ano de dados deve ser utilizado no estudo. O ideal, caso factível, seria trabalharmos com uma série histórica mínima de três anos de dados.

As Redes Neurais, pelo que apresentamos neste trabalho, podem ajudar e muito no atendimento destes objetivos mesmo com uma base mais restrita de dados.

${ }^{34}$ Número de identificação da Estação Remota da CETESB. 


\subsection{A qualidade do ar na Cidade de São Paulo}

Para efetuarmos a avaliação da qualidade do ar precisamos nos valer de valores de referência ou de padrões.

O padrão de qualidade do ar define legalmente um limite máximo para a concentração de um componente atmosférico que garanta a proteção da saúde e do bem estar das pessoas.

Os padrões de qualidade do ar são baseados em estudos dos efeitos produzidos por poluentes específicos. Eles são fixados em níveis que propiciem uma margem adequada de segurança. [CETESB 2000].

A Portaria Normativa n 348 de 14/03/90 do IBAMA - Instituto Brasileiro de Meio Ambiente e dos Recursos Naturais Renováveis, estabeleceu os padrões nacionais de qualidade do ar (VENTURA \& RAMBELLI 1999, p. 844-847).

Os padrões estabelecidos através dessa portaria foram submetidos ao CONAMA em 28.06.90 e transformados na Resolução CONAMA n 03/90 (VENTURA \& RAMBELLI 1999, p. 1256-1260).

São estabelecidos dois tipos de padrões de qualidade do ar: os primários e secundários.

São padrões primários de qualidade do ar as concentrações de poluentes que, se ultrapassadas, poderão afetar a saúde da população. Podem ser entendidos como níveis máximos toleráveis de concentração de poluentes atmosféricos, constituindose em metas de curto e médio prazo.

São padrões secundários de qualidade do ar as concentrações de poluentes atmosféricos abaixo das quais se prevê o mínimo efeito adverso sobre o bem estar da população, assim como o mínimo dano à fauna e à flora, aos materiais e ao meio 
ambiente em geral. Podem ser entendidos como níveis desejados de concentração de poluentes, constituindo-se em meta de longo prazo.

Para o monóxido de carbono os padrões primário e secundário são iguais, conforme apresentamos na Tabela 8.

Os parâmetros regulamentados são os seguintes: partículas totais em suspensão, fumaça, partículas inaláveis, dióxido de enxofre, monóxido de carbono, ozônio e dióxido de nitrogênio.

Tabela 8 - Padrões Nacionais de Qualidade do Ar (Resolução CONAMA nº 3 de 28/06/90).

\begin{tabular}{c|c|c|c|c}
\hline POLUENTE & $\begin{array}{c}\text { TEMPO DE } \\
\text { AMOSTRAGEM }\end{array}$ & $\begin{array}{c}\text { PADRÃO } \\
\text { PRIMÁRIO ppm }\end{array}$ & $\begin{array}{c}\text { PADRÃO } \\
\text { SECUNDÁRIO } \\
\text { ppm }\end{array}$ & $\begin{array}{c}\text { MÉTODO DE } \\
\text { MEDIÇÃO }\end{array}$ \\
\hline $\begin{array}{c}\text { Monóxido de } \\
\text { Carbono }\end{array}$ & $\begin{array}{c}1 \text { hora } \\
8 \text { horas }\end{array}$ & 35 & 35 & $\begin{array}{c}\text { Infravermelho } \\
\text { não } \\
\text { dispersivo }\end{array}$ \\
\hline
\end{tabular}

Fonte: [CETESB 2000]

A mesma resolução estabelece ainda os critérios para episódios agudos de poluição do ar. Esses critérios são apresentados na Tabela 9.

Tabela 9 - Critérios para Episódio Agudo de Poluição do Ar por monóxido de carbono. (Resolução CONAMA nº 3 de 28/06/90)

\begin{tabular}{c|c|c|c}
\hline \multirow{2}{*}{ PARÂMETRO } & \multicolumn{3}{|c}{ NÍVEIS } \\
\cline { 2 - 4 } & ATENÇÃO & ALERTA & EMERGÊNCIA \\
\hline $\begin{array}{c}\text { Monóxido de Carbono } \\
\text { (ppm) Média de 8 hs. }\end{array}$ & 15 & 30 & 40 \\
\hline
\end{tabular}

Fonte: [CETESB 2000] 
A declaração de um episódio depende também das condições meteorológicas para a dispersão dos poluentes.

As relações envolvendo as concentrações dos poluentes, a previsão meteorológica para a dispersão dos poluentes atmosféricos e a caracterização do episódio, apresentamos no item 1.2.1 - Sistemas $\boldsymbol{F u z z y}$, quando da definição das regras no processo de fuzzilização.

\subsubsection{O monóxido de carbono na Cidade de São Paulo}

O monóxido de carbono ( $\mathrm{CO}$ ) possui como principal fonte de emissão os veículos automotores, principalmente os veículos leves. A contribuição dos veículos no total das emissões deste poluente na Região Metropolitana de São Paulo é de 98\%. A taxa de emissão é estimada em 1652 mil t/ano para uma frota de 5,5 milhões de veículos leves (CETESB,2000).

Esta emissão, entretanto, depende de outros fatores, dentre eles:

$>\quad$ Número de veículos em circulação;

$>$ Composição da frota circulante no local (veículos a álcool, gasolina, diesel, motos etc.);

$>$ Distribuição da frota segundo a idade dos veículos (fator de deterioração); e

$>\quad$ Velocidade média do fluxo de veículos.

Estes fatores por sua vez dependem de outros numa reação em cadeia. O número de veículos em circulação depende da política de transportes e oferta destes, depende de fatores econômicos pois um aquecimento da economia como o observado no Plano Cruzado levou as pessoas a circularem muito mais com seus veículos.

O preço dos combustíveis, por si só, pode levar ao aumento ou a diminuição do número de veículos em circulação. 
Atualmente, já em caráter emergencial, temos para a Cidade de São Paulo o Rodízio de Veículos restringindo a circulação dos veículos de acordo com o final de placa e dia da semana no período das 7:00 às 10:00 e das 17:00 às 20:00 hs. Esta medida também causa impacto nas emissões caso se observe uma aumento na velocidade média do fluxo de veículos.

FRUEHAUF e SZWARC (1991, p.11) apontaram, baseados em trabalhos internacionais, que a diminuição da velocidade média do fluxo de $31,5 \mathrm{~km} / \mathrm{h}$ para $14,0 \mathrm{~km} / \mathrm{h}$ acarreta num aumento de $50 \%$ nas emissões de poluentes, assim, o crescimento da frota ou o aumento no número de viagens levará a um aumento nas emissões devido à redução da velocidade média do tráfego.

MURGEL \& SZWARC (1989) também estudaram este tema e publicaram um estudo avaliando a influência da velocidade nas emissões dos poluentes para veículos nacionais e obtiveram resultados similares aos observados internacionalmente.

Temos então que a diminuição da velocidade média do tráfego implica no aumento significativo das emissões de poluentes atmosféricos.

A composição da frota circulante depende fortemente da política do Governo com relação à matriz energética ou mesmo da política associada à Balança de Pagamentos, como ocorrido com os veículos movidos a álcool: um incentivo no IPVA e no preço levou ao aumento do número de veículos movidos com este combustível (resultado do Pró-álcool - Programa Nacional do Álcool), já o desabastecimento dos postos de venda levou a uma quase total retração da produção dos veículos movidos a álcool.

A distribuição da frota segundo a idade dos veículos é fortemente afetada pelo fator econômico e pelas políticas e incentivos do Governo, como a ocorrida para os veículos até 1000 cilindradas. 
O estado de manutenção dos veículos também é influenciado pelo fator econômico e apresenta impacto direto nas emissões veiculares.

O PROCONVE - Programa de Controle da Poluição do ar por Veículos Automotores, instituído em 1986 através da Resolução 18/86 do CONAMA Conselho Nacional do Meio Ambiente - também representou um papel decisivo no comportamentos das emissões de poluentes de origem veicular (VENTURA \& RAMBELLI 1999, p. 1202-1211).

Segundo a CETESB, órgão técnico conveniado do IBAMA para acompanhar este programa, "os fabricantes de veículos vêm cumprindo exigências legais, tendo-se atingido a redução média da ordem de $90 \%$ na emissão de poluentes dos veículos leves novos de 1998, em relação ao início do programa" (CETESB, 2000, p.34).

O limite inicial fixado pelo PROCONVE foi de $24 \mathrm{~g} / \mathrm{km}$ de CO para os veículos leves fabricados a partir de 1989, este limite foi reduzido para apenas $2 \mathrm{~g} / \mathrm{km}$ para os veículos produzidos após Janeiro de 1997 através da Lei Federal 8723 de Outubro de 1993 (VENTURA \& RAMBELLI 1999, p. 345-348).

Os dados de acompanhamento do PROCONVE divulgados pela CETESB apontam para uma taxa de emissão média dos veículos modelo 1999 da ordem de 0,74 g/km para os veículos movidos a gasolina ${ }^{35}$ e de $0,60 \mathrm{~g} / \mathrm{km}$ para os veículos movidos a álcool.

Adicionalmente temos o importante e significativo efeito das condições meteorológicas para a dispersão dos poluentes atmosféricos, influenciando o comportamento das concentrações atmosféricas dos poluentes. Dentre as variáveis meteorológicas FRUEHAUF e SZWARC (1991, p.30) citam as seguintes: presença de anticiclone, baixas velocidades dos ventos, presença de inversão de subsidência com altura da base próxima à superfície ( 150 m). Estas condições foram observadas durante o episódio agudo de 11 de Agosto de 1987 no qual a concentração média de 8 horas ultrapassou o nível de Alerta (35 ppm) durante 6 horas consecutivas. 
Com base nestas informações evidenciamos a grande complexidade para se modelar matematicamente o comportamento das concentrações deste poluente.

O único trabalho do gênero em São Paulo foi devido a FRUEHAUF e SZWARC (1991) onde os autores aplicaram o modelo APRAC - Air Pollution Research Advisory Commitee da Environmental Protection Agency - EPA, com as devidas correções para o novo cenário - Centro de São Paulo, objetivando avaliar a aplicabilidade do mesmo para previsões de concentrações do monóxido de carbono e o seu emprego na prevenção dos episódios críticos.

Este trabalho evidencia a necessidade de extensa base de dados sobre o fluxo de veículos nas vias, dados sobre as condições meteorológicas etc.

O Programa de Inspeção e Manutenção dos veículos em uso- I/M é complementar ao PROCONVE pois visa garantir que os resultados atingidos por este programa sejam efetivamente mantidos. O CONAMA regulamentou este programa através da Resolução 07/93 (VENTURA \& RAMBELLI 1999, p. 1289-1295), complementada pela Resolução 18/95 (VENTURA \& RAMBELLI 1999, p. 1388-1388) e alterada pela Resolução 227/97.

\subsubsection{O monóxido de carbono em São Paulo e a Saúde Pública}

Os efeitos tóxicos do monóxido de carbono vem sendo analisados desde o século passado quando foi comprovado que este gás causa a hipoxemia ao combinar-se com a hemoglobina, diminuindo assim a capacidade destas de transportar o oxigênio através do sangue, ROJAS (1981), citado em KUNO et al. (1991, p.1).

KUNO et al. analisaram as concentrações de Carboxiemoglobina - $\mathrm{COHb}$ presentes no sangue de diversos trabalhadores fixos na região central da Cidade de São Paulo. Foram amostrados, jornaleiros, engraxates, vendedores e outras ocupações. Fizeram

\footnotetext{
${ }^{35}$ Na verdade gasool : 76\% de gasolina e 24\% de álcool, conforme MP 1662-3 de 25/08/1998.
} 
parte da amostra os indivíduos com mais de seis meses de trabalho no local, sexo masculino e não fumantes. Dois períodos foram avaliados: 07/02/1990 a 23/03/1990 e 21/06/1990 a 14/08/1990.

Como conclusões do levantamento os autores apontaram:

Os indivíduos expostos nos locais com maior densidade de trafego apresentaram maiores níveis de $\mathrm{COHb}$ no sangue, indicando assim uma associação positiva;

A taxa média de $\mathrm{COHb}$ observada no amostra foi de $1,28 \%$ sendo que foram observados casos com valores acima de $2 \%$, que é o limite associado ao Padrão de Qualidade do ar para o monóxido de carbono de 9 ppm, média de 8 horas.

Encontramos no trabalho de KUNO et al. (1991, p.2) a citação do período crítico para este poluente na Região Central de São Paulo, que até a época do estudo, foram os anos de 1986 e 1987.

De fato, foram observados cinco episódios agudos devido ao monóxido de carbono no Centro de São Paulo em 1987 na Praça do Correio, são eles:

$>\quad 06$ de Agosto, as 17 hs observou-se 30,2 ppm;

$>\quad 11$ de Agosto, as 21 hs observou-se 38,6 ppm;

$>12$ de Agosto, a 1 h observou-se 34,2 ppm;

$>10$ de Setembro, as $21 \mathrm{hs}$ observou-se 32,1 ppm;

$>\quad 15$ de Setembro, as 24 hs observou-se 31,0 ppm;

> 16 de Setembro, as 2 hs observou-se 33,0 ppm;

$>\quad 30$ de Setembro, as 23 hs observou-se 38,6 ppm; e

$>\quad 01$ de Outubro, a 1 h observou-se 34,1 ppm.

Vale aqui comentar que os valores observados ficaram muito próximos ao nível de emergência que é de 40 ppm e por conseguinte nestes anos os valores de $\mathrm{COHb}$, se observados, seriam muito superiores. 


\subsubsection{Situação atual e perspectivas}

Dados do Departamento Estadual de Trânsito - DETRAN, apresentados no relatório da CETESB (2000), apontam para uma frota de mais de 5 milhões de veículos licenciados na $\mathrm{RMSP}^{36}$.

Os veículos movidos a álcool representam hoje menos de $20 \%$ do total da frota. Em 1989 eles representavam $50 \%$ e a tendência de crescimento neste ano foi drasticamente alterada pois no período de 1983 a 1989 praticamente todos os veículos produzidos eram movido a álcool.

A forte redução nas taxas de emissão dos veículos devido ao PROCONVE levou a uma gradativa melhora na qualidade do ar. Na cidade de São Paulo este impacto pode ser claramente observado nos níveis de concentração do monóxido de carbono que hoje observamos nas estações de monitoramento da CETESB.

Em 1999 a qualidade do ar na Cidade de São Paulo devido ao monóxido de carbono aponta para o seguinte quadro:

Foram observadas duas ultrapassagens do padrão no Parque Dom Pedro II com a máxima de 10,4 ppm;

> Uma ultrapassagem no Parque do Ibirapuera atingindo 9,6 ppm;

Seis ultrapassagens em Congonhas, com máxima de 12,0 ppm;

No Centro da Cidade foram observadas cinco ultrapassagens e máxima de 13,6 ppm.

Valores estes sensivelmente inferiores aos observados nos episódios de 1987. Vale observarmos que a frota em 1999 era duas vezes e meia maior.

Duas alternativas foram adotadas pelas montadoras para atendimento aos limites impostos pelo PROCONVE a partir de 1992, o emprego de catalisadores e a injeção eletrônica de combustível.

${ }^{36}$ Baseado nos registros do cadastro do DETRAN em Janeiro/2000. 
A natural degradação dos componentes destes sistemas pode levar a uma alteração nas taxas de emissões originalmente projetadas, assim sendo, o Programa de Inspeção e Manutenção dos veículos em uso (I/M), tem importância estratégica para a manutenção dos resultados obtidos pelo PROCONVE, infelizmente até a presente data ele ainda não foi implantado na RMSP.

\subsection{Proposta de modelos inteligentes ${ }^{37}$ com enfoque espaço-temporal}

O problema de previsão, no contexto de Redes Neurais, está associado à decisão sobre quais variáveis iremos fazer as previsões e quais as variáveis serão utilizadas adicionalmente no modelo.

No caso do monóxido de carbono podemos desejar prever episódios críticos (valor da concentração média móvel de 8 horas acima de 30 ppm), ou podemos estar interessados em prever as concentrações horárias deste poluente para as próximas 24 horas.

Avaliamos que a segunda abordagem é a mais prática para a efetiva tomada de decisões e possibilita o acompanhamento das concentrações observadas do poluente contra as estimativas feitas pelo modelo da Rede Neural.

O tipo de topologia da Rede Neural também deve levar em consideração o aspecto espacial/temporal do poluente analisado.

\subsubsection{Proposta de Modelo Espaço-temporal}

Um tipo de modelo que leva estes aspectos em consideração é apresentado na Figura 18, é o modelo de Filtro de resposta a impulso de duração finita [finiteduration impulse response filter], este modelo é conhecido na literatura pela sigla FIR e está sempre associado a sua ordem $\mathbf{p}^{\mathbf{3 8}}$.

\footnotetext{
${ }^{37}$ Modelos que incorporam técnicas de Inteligência Artificial

${ }^{38}$ Período da sazonalidade
} 


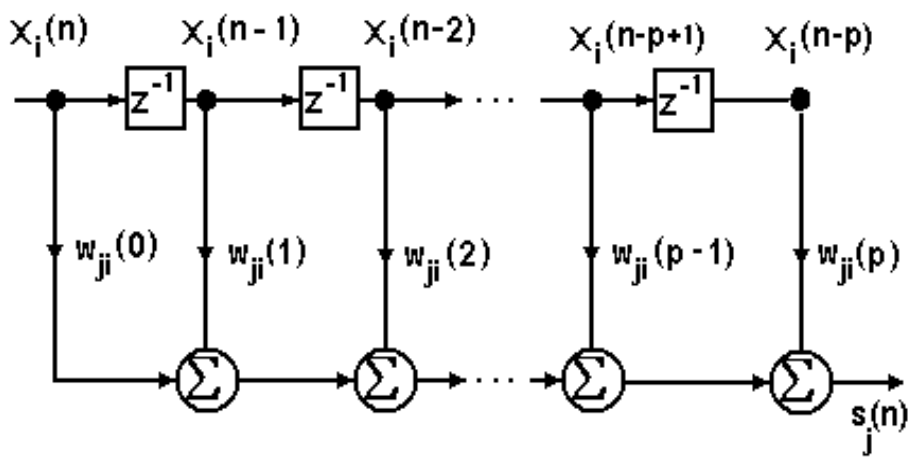

Figura 18 - Modelo Espaço-temporal de um neurônio de ordem p. Fonte: (HAYKIN 1999, p. 648)

O modelo da Figura 18 é conhecido na literatura como Filtro FIR, nomenclatura que adotamos neste trabalho.

O valor da saída deste modelo podemos obter através da seguinte fórmula:

$$
\mathrm{s}_{j}(n)=\sum_{k=0}^{\mathrm{p}} w_{i j} x_{i}(n-k)
$$

Onde:

p é a periodicidade identificada no comportamento do poluente; (no nosso caso 24 horas);

$n$ é o instante de tempo atual (horas);

$>\boldsymbol{x}$ é a concentração horária dos poluentes. A estação de monitoramento (localidade) é representada neste modelo pela letra $\mathbf{i}$. A letra $\mathbf{j}$ é indicativa da j-ésima variável de saída da rede.

É fácil deduzir que a expressão de saída é um índice obtido a partir das ponderações observadas na fase de treinamento.

Este índice deve refletir o comportamento dos poluentes naquela localidade 
Na sequiência estes índices de saída deverão ser tratados por uma Rede Neural com a topologia que apresentamos na Figura 19.

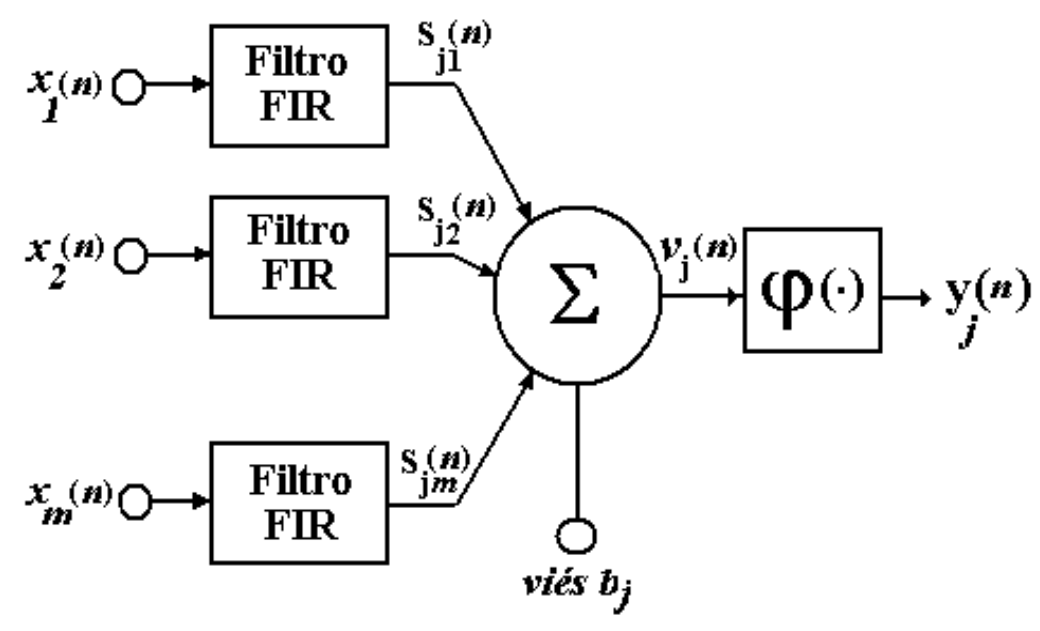

Figura 19 - Filtro Neuronal Distribuído

Fonte: (HAYKIN 1999, p. 648)

O Filtro FIR é o que apresentamos na Figura 18.

O cálculo dos valores de saída deste modelo podemos obter pela seguinte fórmula:

$$
y_{j}(n)=\varphi\left(\sum_{i=1}^{\mathrm{m}} \mathrm{s}_{j}(n)+b_{j}\right)
$$

A função de ativação que sugerimos para o modelo é a logística.

Nossa proposição é que esta topologia tenha somente duas saídas, uma refletindo a condição da poluição atmosférica e outra carreando as condições dos parâmetros meteorológicos. Essas saídas, uma vez estudadas, poderiam servir de entrada para um sistema Neuro-fuzzy conforme proposta a seguir.

Devemos observar que o modelo proposto não pode ser ajustado com base em dados hipotéticos pois desta maneira a Rede Neural não corresponderia à realidade dos dados e o modelo final seria abstrato. 


\subsubsection{Proposta de Sistema Fuzzy-Neural}

Previamente à apresentação da proposta iremos apresentar este tipo de sistemas pois o mesmo até a presente data não constou de nenhum trabalho científico na área ambiental.

Costumamos empregar esta denominação genérica aos sistemas híbridos que empregam ambas tecnologias, entretanto, esses sistemas se dividem em dois grupos distintos: os sistemas Neuro-Fuzzy e os Fuzzy-Neurais (PAL \& MITRA 1999, p.59).

As Redes Fuzzy-Neurais são aquelas equipadas com a facilidade de tratar informações fuzzilizadas.

Explicitando, as Redes Fuzzy-Neurais podem:

incorporar dados de entrada oriundos de procedimento de fuzzilização;

$>$ utilizar variáveis lingüisticas para rotular conjuntos de dados usados na fase de treinamento;

$>$ fuzzilizar o procedimento de treinamento;

$>$ oferecer dados de saída na forma de conjuntos fuzzy;

$>$ mudar as características de processamento dos neurônios de uma rede, ampliando os tipos de cálculos executados nestes. Os neurônios poderão ser programados para fazer união, interseção ou agregação.

modelar os erros a partir de processos de fuzzilização;

$>$ serem totalmente fuzzilizadas, ou seja: as entradas e saídas são conjuntos fuzzy, os neurônios da rede executam operações ${ }^{39}$ de lógica $\boldsymbol{F u z z y}$.

${ }^{39}$ As operações de lógica são: E, OU e Negativa. 
O grupo das Redes Neuro-Fuzzy é formado pelas aplicações de Redes Neurais a sistemas $\boldsymbol{F u z z y}$. Estas aplicações visam ampliar algumas das características deste sistema, seja sua flexibilidade, a velocidade de processamento ou sua adaptabilidade.

Este tipo de rede pode projetar Redes Neurais visando implementar lógica Fuzzy e processo de decisão Fuzzy [Fuzzy decision making].

Face aos conceitos apresentados, apresentamos nossa proposta de Sistema Fuzzy Neural para previsão de episódios críticos de monóxido de carbono na Cidade de São Paulo.

Neste caso, a abordagem é dada em função do tipo de qualificação do ar e não simplesmente para previsão das concentrações futuras de monóxido de carbono, uma rede que efetua previsões poderá ser operada em conjunto a este sistema.

Necessidades para implementação deste tipo de modelo:

Empregar uma topologia para identificação de padrões ${ }^{40}$ em função da qualificação associada ao índice de qualidade observado para o monóxido de carbono, sendo elas: Boa, Regular, Inadequada, Má, Péssima e Crítica;

$>$ Deve-se incorporar as condições meteorológicas predominantes em cada um dos padrões sendo que estas deverão ser apresentas à Rede Neural após passarem pelo processo de fuzzilização conforme apresentado na Figura 19;

Utilizar a base de dados disponível para escolher os conjuntos de padrões que treinarão a Rede Neural. Caso necessário poderá ser empregada uma técnica de Agrupamentos [Cluster Analysis] para classificar os conjuntos de dados;

Caso seja pouco representativo o número de conjuntos de treinamento para um dado tipo de padrão sugerimos a aplicação da técnica de bootstrap;

- Alguns conjuntos de dados deverão ser previamente separados para a fase de teste do modelo. Estes dados não poderão fazer parte do processo de treinamento da rede.

O Sistema Inteligente que propomos está esquematizado na Figura 20.

${ }^{40}$ Dias típicos e representativos de cada qualificação do ar. 


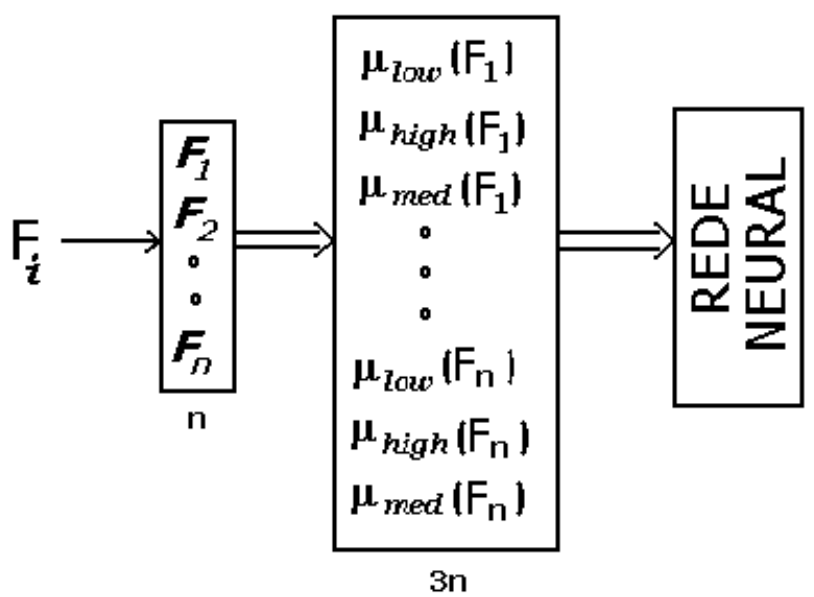

Figura 20 - Diagrama de blocos do sistema inteligente do tipo Fuzzy-Neuro. Fonte: (PAL \& MITRA 1999, p.111).

Conforme apresentamos na Figura 20, os padrões de entrada no processo passam pelo processo de fuzzilização e somente então são apresentados nas entradas da Rede Neural.

Nesta proposta o procedimento de fuzzilização foi construído com base numa função de agrupamento de três níveis (high, medium e low), o tipo de função normalmente adotada devido à facilidade de interpretação dos seus parâmetros é a função $\pi$ (PAL \& MITRA 1999, p. 32).

O Processo de desenvolvimento do modelo é compreendido pelas seguintes $\operatorname{etapas}^{41}$ :

1. Seleção e organização dos conjuntos de dados para as fases de treinamento e teste do sistema inteligente;

2. Os conjuntos de dados que irão compor a fase de treinamento deverão ser submetidos à rede de maneira aleatória ${ }^{42}$;

\footnotetext{
${ }^{41}$ Não listamos as atividades de aquisição do software e respectivo treinamento. No projeto para implementação do modelo estas atividades devem estar previstas.

${ }^{42}$ Devemos associar números aos conjuntos e sortear ao acaso a ordem destes para apresentação à rede.
} 
3. Estabelecimento do processo de treinamento. Para o modelo proposto deverá ser o treinamento com professor pois os padrões são conhecidos.

4. Determinação da topologia da Rede Neural (número de níveis, unidades por nível etc.).

5. Estabelecimento do processo de fuzzilização dos dados de entrada da Rede Neural, incluindo o tipo de função de agrupamento, definição das variáveis lingüisticas associadas a cada uma das variáveis utilizadas pelo modelo.

6. Executar o treinamento da Rede Neural a partir das entradas neuronais ${ }^{43}$.

7. Efetuar os testes utilizando os conjuntos de dados previamente selecionados para esta fase do processo. Este processo também deve ser casual, ou seja, os conjuntos de dados devem ser submetidos à Rede Neural de maneira aleatória;

8. Avaliação dos resultados utilizando técnicas estatísticas;

9. Incorporação do modelo na rotina operacional.

${ }^{43}$ Saídas obtidas a partir do processo de fuzzilização dos dados originais. 


\section{CONCLUSÕES E RECOMENDAÇÕES}

\subsection{Conclusões}

> As Redes Neurais podem ser aplicadas com facilidade onde outras técnicas visando a interpretação de dados não tiveram sucesso, seja pela falta de informações ou devido a problemas operacionais com os cálculos envolvidos;

As Redes Neurais já foram aplicadas em praticamente todas as áreas das Ciências Atmosféricas, desde o reconhecimento das partículas, até a análise dos riscos à saúde;

> Existe um número considerável de aplicativos comerciais que lidam com as técnicas de Redes Neurais, facilitando desta maneira a aplicação das mesmas;

A escolha do aplicativo mais adequado dependerá do objetivo pretendido, das funcionalidades desejadas, da plataforma na qual o mesmo irá operar e do custo;

As Redes Neurais oferecem resultados minimamente equivalentes aos obtidos por outras técnicas estatísticas, em geral os resultados são superiores;

As Redes Neurais devem ser encaradas como mais uma ferramenta que visa facilitar o trabalho do pesquisador na interpretação dos dados. Seu emprego, combinado com as demais técnicas estatísticas, garante melhores resultados;

$>$ É comum o uso combinado das Redes Neurais e outra técnica de Inteligência Artificial;

Como as Redes Neurais aprendem a partir dos próprios dados, é importantíssimo que seja garantida a representatividade e a qualidade dos mesmos para o objetivo pretendido;

Apesar da poluição do ar ter características espaço-temporais determinantes no seu comportamento, todos os estudos realizados até o momento não utilizaram uma topologia de Rede Neural que contemplasse esta necessidade. 


\subsection{Recomendações}

Face a relevância do tema e dos poucos trabalhos desenvolvidos no Brasil, principalmente na área ambiental, sugerimos que crie um Projeto Piloto e que se busque fontes de financiamento para viabilizar o seu desenvolvimento;

Recomendamos como ponto de partida para o desenvolvimento de aplicações das Redes Neurais as propostas de modelos apresentadas neste trabalho assim como uma parceria com a CETESB seria altamente desejável;

Sugerimos que novos trabalhos sobre as Redes Neurais sejam incentivados pela Faculdade de Saúde Pública, tendo em vista sua importância para área ambiental e a necessidade da Faculdade se manter atualizada em relação ao tema. 


\section{Referências Bibliográficas}

[CETESB 1999] Cia. de Tecnologia de Saneamento Ambiental. Qualidade do ar no Estado de São Paulo - 1998. São Paulo: CETESB; 1999.

[CETESB 2000] Cia. de Tecnologia de Saneamento Ambiental. Qualidade do ar no Estado de São Paulo- 1999. São Paulo: CETESB; 2000.

[SBRN 1997] IV Simpósio Brasileiro de Redes Neurais [Home page] 1997. Disponível em http://www.ime.usp.br/ enec/eventos/sbrn97.html [15/10/1999]

[SIENA 1997] Stimulation Initiative for European Neural Applications [Home page] 1997. Disponível em http://www.mbfys.kun.nl/snn/Research/siena/cases/cy2.html [10/04/2000].

[SPSS 1999] Neural Connection [Home page] 1999. Disponível em http://www.spss.com/software/neuro/ncqa.html [11/04/2000]

[UFRGS 2000] Redes de Computadores e suas aplicações na Educação [Home page] 1999. Disponível em http://penta2.ufrgs.br/edu/bloom/domcogn.htm [30/03/2000].

[USP/FSP 1998] Universidade de São Paulo. Faculdade de Saúde Pública. Guia de Apresentação de Teses. São Paulo: Biblioteca / CIR; 1998.

ANEJA VP et al. Trends, seasonal variations and analysis of high-elevation surface nitric acid, ozone and hydrogen peroxide. Atmospheric Environment 28(10) : 17811790, 1994.

ANH V et al. Spatial variability of Sydney air quality by Cumulative Semivariogram. Atmospheric Environment 31(24): 4073-4080, 1997 .

ANH V et al. Modeling Anthropogenic trends in Air Quality data. J. Air \& Waste Manage. Assoc. 47(1): 66-71, $1997 \mathrm{~b}$. 
BLOOMFIELD P et al. Accounting for meteorological effects in measuring urban ozone levels and trends. Atmospheric Environment 30(17) : 3067-3077, 1996.

BOZNAR M et al. A Neural Network based method for short-term prediction of ambient $\mathrm{SO}_{2}$ concentrations in highly polluted industrial areas of complex terrain. Atmospheric Environment 27B(2) : 221-230, 1993.

BRUNI AC, KIRA E Modelos para previsão e ajuste da quantidade de precipitação mensal em Cubatão e Santos - Metodologia Box \& Jenkins. In: Congresso Brasileiro de Engenharia Sanitária e Ambiental, 13², Maceió - Alagoas, 1985, Anais, São Paulo, CETESB, 1985, 5p.

BURREL TD Neural Networks Implementations. [Home page] 1999 Disponível em http://holodeck.st.usm.edu/classes/ent650/nnreports/burrell/nn1.html [18/10/1999]

\section{BUSHEY H, FLETCHER D A survey of Neural Networks in business}

forecasting. [Home page] 1999 Disponível em

http://holodeck.st.usm.edu/classes/ent650/nnreports/bushey/nn1.html [18/10/1999]

CANON AJ, LORD ER Forecasting summertime surface-level ozone concentrations in the Lower Fraser Valley of British Columbia: An ensemble Neural Network Approach. J. Air \& Waste Manage. Assoc. 50(3): 322-339, 2000.

CASADO LS et al. Geostatistical analysis and visualization of hourly ozone data. Atmospheric Environment 28(12) : 2105-2118, 1994.

\section{CLIFFORD HT, STEPHENSON W. An Introduction to Numerical Classification.}

New York: Ed. Academic Press, Inc.; 1975.

CHAN CC, HWANG JS Site representativeness of Urban Air Monitoring Stations. $J$. Air \& Waste Manage. Assoc. 46(8): 755-760, 1996. 
CHEN JL et al. Nonlinear dynamics of hourly ozone concentrations: nonparametric short term prediction. Atmospheric Environment. 32(11): 1839-1848, 1998.

CHOCK DP, TERREL TR \& LEVITT SB. Time series analysis of Riverside, California air Quality. Atmos. Environ. 1975 (9) : 978-989, 1975.

COMRIE AC Comparing Neural Networks and Regression Models for Ozone forecasting. J. Air \& Waste Manage. Assoc. 47(6): 653-663, 1997.

COTTON A Computers and Neural Networks Applications. [Home page] 1999

Disponível em http://holodeck.st.usm.edu/classes/ent650/nnreports/cotton/nn1.html [18/10/1999]

COX WM, CHU SH Meteorologically adjusted Ozone trends in Urban areas: A probabilistic approach. Atmospheric Environment 27B(4) : 425-434, 1993.

CROXFORD B, PENN, A Siting considerations for urban pollution monitors. Atmospheric Environment 32(6): 1049-1057, 1998.

CSETE A The Monte Carlo Method to approximate Pi [Home page] Institute of Physics and Astronomy, University of Aarhus. Denmark. 1999. Disponível em http://www.daimi.aau.dk/ u951581/pi/MonteCarlo/prime.html [20/04/2000].

DAVIS, JM et al. Modeling the effect of meteorology on ozone in Houston using analysis and generalized additive models. Atmospheric Environment 32(14/15): 2505-2520, 1998.

DEININGER CK, SAXENA VK A validation of back trajectories of air masses by Principal Component Analysis of ion concentrations in cloud water. Atmospheric Environment 31(2): 295-300, 1997. 
DRAPER NR, SMITH H. Applied Regression Analysis. $2^{\text {nd }}$ Ed, New York:. John Willey \& Sons, Inc.; 1981.

FOWLER, D et al. Modelling photochemical oxidant formation, transport, deposition and exposure of terrestrial ecosystems. Environmental Pollution 100(1) : 43-45, 1999.

FREEMAN JA Simulating Neural Networks with Mathematica ${ }^{\circledR} 1^{\text {st }}$ ed. New York, Ed. Addison-Wesley Publishing Company, Inc., 1994.

FRUEHAUF GCL \& SZWARC A, Modelagem matemática das concentrações de monóxido de carbono no Centro de São Paulo, São Paulo: CETESB, 1991, 71p.

GARDNER MW, DORLING SR. Artificial Neural Network (the multilayer perceptron) - A review of applications in the atmospheric science. Atmospheric Environment 32(14/15) : 2627-2647, 1998.

GARDNER MW, DORLING SR Neural Network modelling and prediction of hourly $\mathrm{NO}_{x}$ and $\mathrm{NO}_{2}$ concentrations in urban air in London. Atmospheric Environment 33(5) : 709-719, 1999.

GARDNER MW, DORLING, SR Statistical surface ozone models: an improved methodology to account for non-linear behavior. Atmospheric Environment 34(1) : 21-34, 2000a.

GARDNER MW, DORLING SR Meteorologically adjusted trends in UK daily maximum surface ozone concentrations. Atmospheric Environment 34(2) : 171-176, 2000b.

GIL AC Como Elaborar Projetos de Pesquisa. $3^{\text {a }}$ ed. São Paulo: Editora Atlas; 1996. 
GRAEDEL TE, CRUTZEN PJ Atmospheric Change - An Earth System Perspective. $1^{\text {st }}$. ed. New York, Ed. W. H. Freeman \& Co., 1993.

GUARDANI R et al. Study of Atmospheric Ozone Formation by Means of a Neural Network-Based Model. J. Air \& Waste Manage. Assoc. 49(3): 316-323, 1999.

HAAS TC Statistical assessment of spatio-temporal pollution trends and meteorological transport models. Atmospheric Environment 32(11): 1865-1879, 1998.

HAYKIN S Neural Networks a comprehensive foundation . $2^{\text {nd }}$ ed. New Jersey, Ed. Prentice-Hall, Inc., 1999.

HOGREFE C et al. Detecting trends and biases in time series of ozone sonde data. Atmospheric Environment 32(14/15): 2569-2586, 1998.

HUANG PF, TURPIN B Reduction of sampling and analytical errors for electron microscopic analysis of atmospheric aerosols. Atmospheric Environment 30(24): 4137-4148, 1996.

HUANG S et al. Testing and optimizing two factor-analysis techniques on aerosol at Narragansett, Rhode Island. Atmospheric Environment 33(14) : 2169-2185, 1999.

HUBBARD MC, COBOURN WG Development of a Regression Model to forecast ground-level ozone concentration in Louisville, KY. Atmospheric Environment 32(14/15): 2637-2647, 1998.

KAO JJ, HUANG SS Forecasting using Neural Network versus Box-Jenkins Methodology for ambient air quality monitoring data. J. Air \& Waste Manage. Assoc. 50(2): 219-226, 2000. 
KLEY D et al. Photochemical oxidants: state of the science. Environmental Pollution 100(1) 19-42, 1999.

KOSKO B Fuzzy Engineering $1^{\text {st }}$. Ed., New Jersey: Prentice Hall, Inc; 1997. KUNO R et al. Níveis de carboxiemoglobina em grupos populacionais na Região Central da Cidade de São Paulo, São Paulo: CETESB, 1991, 16p.

LAM DCL et al. A prototype Information System for Watershed Management and Planing. J. Biol. Systems 2(4) : 499-517, 1994.

LIPFERT FW, WYZGA RE Statistical considerations in determining the health significance of constituents of airbone particulate matter. J. Air \& Waste Manage. Assoc. 49(9): PM - 182-191, 1999.

LIPPMAN RP. An Introduction to Computing with Neural Nets. IEEE ASSP Magazine 4: 4-22 (1987).

MALM WC, GEBHART KA Source apportionment of Sulfur and light extinction using Receptor Modeling Techniques. J. Air \& Waste Manage. Assoc. 47(3): 250268, 1997.

MAYER H Air pollution in cities. Atmospheric Environment 33(24/25) : 4029-4037, 1999.

McNAIR L A. et al. Spatial inhomogeneity in pollutant concentrations and their implications for Air Quality Model evaluation. Atmospheric Environment 30(24) : 4291-4301, 1996.

MERZ PH, PAINTE LJ \& RYASON PR. Aerometric data analysis - time-series analysis and forecast and atmospheric smog, Atmos. Environ. 1972, 6: 319-342; 1972. 
MICHALSKI RS et al. Machine Learning and Data Mining - Methods and Applications. $1^{\text {st }}$ ed. Chichester, Ed. John Wiley \& Sons Ltd., 1998.

MILANCHUS ML et al. Evaluating the effectiveness of Ozone management efforts in the presence of Meteorological variability. J. Air \& Waste Manage. Assoc. 48(3): 201-215, 1998.

MILFORD JB et al. Ozone precursor levels and response to emissions reductions: analysis of regional oxidant model results. Atmospheric Environment 28(12) : 20932104, 1994.

MILIONIS AE, DAVIES TD Regression and Stochastic Models for air pollution - I. Review, comments and suggestions. Atmospheric Environment 28(17) : 2801-2810, 1994a.

MILIONIS AE, DAVIES TD Regression and Stochastic Models for air pollution II. Application of stochastic models to examine the links between ground-level smoke concentrations and temperature inversions. Atmospheric Environment 28(17) : 2811-2822, 1994b.

MILLER AA, SAGER TW Site redundancy in Urban Ozone Monitoring. J. Air \& Waste Manage. Assoc. 44(9): 1097-1102, 1994.

MORETTIN PA, TOLOI CMC Modelos para previsão e ajuste de Séries Temporais - Vol.1. In: Colóquio Brasileiro de Matemática, 13 ${ }^{\circ}$, Poços de Caldas, Minas Gerais, 1981, Anais, Rio de Janeiro, Instituto de Matemática Pura e Aplicada - IMPA, 1981, $351 \mathrm{p}$.

MORRISON DF. Multivariate Statistical Methods, $1^{\text {st }}$ Ed. New York: McGraw Hill, Inc.; 1967. (Series in Probability and Statistics). 
MURGEL EM \& SZWARC A. Condições de tráfego e a emissão de poluentes. AMBIENTE 3 (1): 59-64, 1989.

\section{PAL SK, MITRA S. Neuro-Fuzzy Pattern Recognition: Methods in Soft}

Computing, $1^{\text {st }}$. Ed. New York: John Wiley \& Sons, Inc.; 1999. (Wiley Series on Intelligent Systems).

PARK J, SANDBERG IW. Universal approximation using Radial Basis Function Networks. Neural Computation 3: 246-257 (1991).

RAO ST, ZURBENKO IG Detecting and tracking changes in ozone air quality. $J$. Air \& Waste Manage. Assoc. 44(9): 1089-1092, 1994.

REGE MA, TOCK RW A simple Neural Network for estimating emission rates of hydrogen sulfide and ammonia from single point sources. J. Air \& Waste Manage. Assoc. 46(10): 953-962, 1996.

REICH SL et al. Artificial Neural Network for the identification of unknown air pollution sources. Atmospheric Environment 33(18) : 3045-3052, 1999.

REIFMAN J, FELDMAN EE Identification and control of $\mathrm{NO}_{\mathbf{x}}$ emission using Neural Networks. J. Air \& Waste Manage. Assoc. 48(5): 408-417, 1998.

REIFMAN J et al. An Intelligent Emissions Controller for Fuel Lean Gas Reburn in Coal-fired Power Plants. J. Air \& Waste Manage. Assoc. 50(2): 240-251, 2000.

REPAPIS CC et al. Case study of UV-B modification during episodes of urban air pollution. Atmospheric Environment 32(12): 2203-2208, 1998.

REYNOLDS SB, MELLICHAMP JM, SMITH RE. Box-Jenkins Forecast Model Identification. AI EXPERT, (1995) 6:15-28. 
ROJAS GS et al. Niveles de carboxiemoglobina em la poplación de Puebla y sus implicaciones. Sal. Públ. Méx., 23: 399-403, 1981.

SALCEDO RLR et al. Time-series analysis of air pollution data. Atmospheric Environment 33(15) : 2361-2372, 1999.

SARLE WS, ed. Neural Network FAQ, parts 1 to 7 [Periodic posting to the Usenet newsgroup comp.ai.neural-nets] 1997 Disponível no URL:

ftp://ftp.sas.com/pub/neural/FAQ.html [09/11/1999].

SCHALKOFF RJ Artificial Neural Networks. $1^{\text {st }}$ ed., Singapore, Ed. McGraw-Hill, 1997.

SCHICHTEL BA, HUSAR RB Regional simulation of Atmospheric pollutants with the CAPITA Monte Carlo Model. J. Air \& Waste Manage. Assoc. 47(3): 331-343, 1997.

SCHLINK U et al. A component Time-series model for $\mathrm{SO}_{2}$ data: forecasting, interpretation and modification. Atmospheric Environment 31(9) : 1285-1295, 1997.

SEN Z Regional air pollution assessment by Cumulative Semivariogram Technique. Atmospheric Environment 29(4) : 543-548, 1995.

SHI JP, HARRISON RM Regression modelling of hourly $\mathrm{NO}_{x}$ and $\mathrm{NO}_{2}$ concentrations in urban air in London. Atmospheric Environment 31(24): 4081-4094, 1997.

SILLMAN S The erroneous use of receptor modeling to diagnose $\mathrm{O}_{3}-\mathrm{NO}_{\mathbf{x}}-$ hydrocarbon sensitivity. Atmospheric Environment 33(14) : 2289-2291, 1999.

SILLMAN S The relation between ozone, $\mathrm{NO}_{\mathbf{x}}$ and hydrocarbons in the urban and polluted rural environments. Atmospheric Environment 33(12) : 1821-1845, 1999. 
SNIPES E Applications of Neural Networks. [Home page] 1999 Disponível em http://holodeck.st.usm.edu/classes/ent650/nnreports/snipes/nn1.html [18/10/1999]

SOJA G, SOJA AM Ozone indices based on simple meteorological parameters: potentials and limitations of regression and Neural Network models. Atmospheric Environment 33(26) : 4299-4307, 1999.

SONG XH, HOPKE PK Solving the chemical mass balance problem using an Artificial Neural Network. Environ. Sci. Technol., 30 (2) : 531-535, 1996.

SONG XH, HADJIISKI L, HOPKE K Source Apportionment of Soil Samples by Combination of Two Neural Networks Based on Computer-Controlled Scanning Electron Microscopy. J. Air \& Waste Manage. Assoc. 49(7): 773-783, 1999.

STATHEROPOULOS M et al. Principal Component and Canonical Correlation Analysis for examining air pollution and meteorological data. Atmospheric Environment 32(6): 1087-1095, 1998.

STERGIOU C, SIGANOS D Neural Networks. [Home page] 1999 Disponível em http://www-dse.doc.ic.ac.uk/ nd/surprise 96/journal/vol4/cs11/report.html [15/10/1999]

STIBER NA et al. Expert System methodology for evaluating reductive Dechlorination at TCE sites. Environ. Sci. Technol. 33(17) 3012-3020, 1999.

TREVIÑO C, MÉNDEZ F Simplified model for the prediction of ozone generation in polluted urban areas with continuous precursors species emissions. Atmospheric Environment 33(7) : 1103-1110, 1999.

VENTURA VJ \& RAMBELLI AM Legislação Federal sobre Meio Ambiente $3^{\text {a }}$ Ed. Taubaté/SP: Ed. Vana; 1999. 
WAGNER D Assessment of the probability of extreme weather events and their potential effects in large conurbations. Atmospheric Environment 33(24/25) : 41514155, 1999.

WAKAMATSU S et al. A study of the relationships between photochemical ozone and its precursor emissions of Nitrogen Oxides and Hydrocarbons in Tokyo and surrounding areas. Atmospheric Environment 33(19): 3097-3108, 1999.

WANIA F, MACKAY D The evolution of mass balance of persistent organic pollutant fate in the environment. Environmental Pollution 100(3) : 223-240, 1999.

WEIGEND AS, HUBERMAN BA \& RUMELHART DE. Predicting the future: a connectionism approach, Intl. J. Neural Systems 1990 (1) : 109-209; 1990.

WONGPHATARAKUL $\mathrm{V}$ et al. A comparative study of PM2.5 ambient aerosol chemical databases. Environ. Sci. Technol. 32 (24): 3926-3934, 1998.

XIE Y et al. Airbone particle classification with a combination of Chemical Composition and Shape index utilizing an Adaptive Resonance Neural Network. Environ. Sci. Technol., 28 (11) : 1921-1928, 1994.

YAGI S, SHIBA S Application of Genetic Algorithms and Fuzzy Control to a combined sewer pumping station. Wat. Sci. Tech. 39(9) : 217-224, 1999.

YI J, PRYBUTOK VRA Neural Network model forecasting for prediction of daily maximum ozone concentration in an industrialized Urban area. Environmental Pollution 92(3): 349-357, 1996.

ZHANG Q, STANLEY SJ Real-time Water Treatment Process Control with Artificial Neural Networks. Journal of Environmental Engineering 125(2) : 153-160, 1999. 
Anexos 


\section{Aplicativos comerciais para simulação de Redes Neurais}

\section{Observações:}

Os valores apresentados são em moeda estrangeira, normalmente em US\$ e não incluem taxas adicionais de importação e transporte do produto.

É aconselhável pedir ao fornecedor uma Fatura Pró Forma para que o custo total de importação seja explicitado.

A data de referência para estas informações é 28/09/1999, quando foi feita a última atualização.

A ordem na qual os produtos foram listados não reflete qualquer preferência pelo produto.

Estas informações podem ser reproduzidas, desde que citada a fonte original conforme segue.

Archive-name: ai-faq/neural-nets/part6 Last-modified: 1999-09-28

URL: ftp://ftp.sas.com/pub/neural/FAQ6.html

Maintainer: saswss@unx.sas.com (Warren S. Sarle)

The copyright for the description of each product is held by the producer or distributor of the product or whoever it was who supplied the description for the $F A Q$, who by submitting it for the FAQ gives permission for the description to be reproduced as part of the FAQ in any of the ways specified in part 1 (ftp://ftp.sas.com/pub/neural/FAQ1.html) of the FAQ.

This is part 6 (of 7 ) of a monthly posting to the Usenet newsgroup comp.ai.neural-nets. See the part 1 of this posting for full information what it is all about.

\section{Part 6: Neural Networks Commercial Software}

The following simulators are described below:

1. BrainMaker

2. SAS Enterprise Miner Software

3. NeuralWorks

4. MATLAB Neural Network Toolbox

5. Propagator

6. NeuroForecaster

7. Products of NESTOR, Inc. 
8. Ward Systems Group (NeuroShell, etc.)

9. NuTank

10. Neuralyst

11. NeuFuz4

12. Cortex-Pro

13. Partek

14. NeuroSolutions v3.0

15. Qnet For Windows Version 2.0

16. NeuroLab, A Neural Network Library

17. hav.Software: havBpNet++, havFmNet++, havBpNet:J

18. IBM Neural Network Utility

19. NeuroGenetic Optimizer (NGO) Version 2.0

20. WAND

21. The Dendronic Learning Engine

22. TDL v. 1.1 (Trans-Dimensional Learning)

23. NeurOn-Line

24. NeuFrame, NeuroFuzzy, NeuDesk and NeuRun

25. OWL Neural Network Library (TM)

26. Neural Connection

27. Pattern Recognition Workbench Expo/PRO/PRO+

28. PREVia

29. Neural Bench

30. Trajan 2.1 Neural Network Simulator

31. DataEngine

32. Machine Consciousness Toolbox

33. Professional Basis of Al Backprop

34. STATISTICA: Neural Networks

35. Braincel (Excel add-in)

36. DESIRE/NEUNET

37. BioNet Simulator

38. Viscovery SOMine

39. NeuNet Pro

40. Neuronics

\section{BrainMaker}

Name: BrainMaker, BrainMaker Pro

Company: California Scientific Software

Address: 10024 Newtown rd, Nevada City, CA, 95959 USA

Phone: 800 284-8112, 5304789040

Fax: 5304789041

URL: http://www.calsci.com/

Basic capabilities: train backprop neural nets

Operating system: Windows, Mac

System requirements: N/A

Approx. price: $\$ 195, \$ 795$

BrainMaker Pro 3.7 (DOS/Windows) \$795

Gennetic Training add-on \$250

BrainMaker 3.7 (DOS/Windows/Mac) $\$ 195$

Network Toolkit add-on $\$ 150$

BrainMaker 3.7 Student version (quantity sales only, about $\$ 38$ each)

BrainMaker Pro CNAPS Accelerator Board $\$ 8145$

Introduction To Neural Networks book $\$ 30$ 
30 day money back guarantee, and unlimited free technical support.

BrainMaker package includes:

The book Introduction to Neural Networks

BrainMaker Users Guide and reference manual

300 pages, fully indexed, with tutorials, and sample networks

Netmaker

Netmaker makes building and training Neural Networks easy, by

importing and automatically creating BrainMaker's Neural Network

files. Netmaker imports Lotus, Excel, dBase, and ASCII files.

BrainMaker

Full menu and dialog box interface, runs Backprop at 3,000,000 cps

on a $300 \mathrm{Mhz}$ Pentium II; $570,000,000 \mathrm{cps}$ on CNAPS accelerator.

Features ("P" means is available in professional version only):

MMX instruction set support for increased computation speed,

Pull-down Menus, Dialog Boxes, Programmable Output Files, Editing in BrainMaker,

Network Progress Display (P), Fact Annotation, supports many printers, NetPlotter,

Graphics Built In $(P)$, Dynamic Data Exchange $(P)$, Binary Data Mode, Batch Use Mode $(P)$,

EMS and XMS Memory (P), Save Network Periodically, Fastest Algorithms,

512 Neurons per Layer (P: 32,000), up to 8 layers, Specify Parameters by Layer $(P)$,

Recurrence Networks (P), Prune Connections and Neurons (P), Add Hidden Neurons In

Training, Custom Neuron Functions, Testing While Training,

Stop training when...-function $(P)$, Heavy Weights $(P)$, Hypersonic Training, Sensitivity Analysis $(P)$, Neuron Sensitivity $(P)$, Global Network Analysis $(P)$, Contour Analysis $(P)$, Data Correlator $(P)$, Error Statistics Report, Print or Edit Weight Matrices, Competitor $(P)$, Run Time System (P), Chip Support for Intel, American Neurologics, Micro Devices, Genetic Training Option (P), NetMaker, NetChecker, Shuffle, Data Import from Lotus, dBASE, Excel, ASCII, binary, Finacial Data (P), Data Manipulation, Cyclic Analysis (P), User's Guide quick start booklet, Introduction to Neural Networks 324 pp book.

\section{SAS Enterprise Miner Software}

$\begin{array}{cc}\begin{array}{c}\text { Name: SAS Enterprise Miner Software } \\ \text { In USA: }\end{array} & \text { In Europe: } \\ \text { Company: SAS Institute, Inc. } & \text { SAS Institute, European Office } \\ \text { Address: SAS Campus Drive } & \text { Neuenheimer Landstrasse 28-30 } \\ \text { Cary, NC } 27513 & \text { P.O.Box } 105340 \\ \text { USA } & \text { D-69043 Heidelberg } \\ & \text { Germany } \\ \text { Phone: (919) } 677-8000 & \text { (49) } 62214160 \\ \text { Fax: (919) } 677-4444 & \text { (49) } 6221474850\end{array}$

URL: http://www.sas.com/software/components/miner.html

Email: software@sas.sas.com

Operating systems: Windows NT

To find the addresses and telephone numbers of other SAS Institute offices, including those outside the USA and Europe, connect your web browser to

http://www.sas.com/offices/intro.html

Enterprise Miner is an integrated software product that provides an end-to-end business solution for data mining based on SEMMA (Sample, Explore, Modify, Model, Assess) methodology. Statistical tools include clustering, decision trees, linear and logistic regression, and neural networks. Data preparation tools include outlier detection, variable transformations, random sampling, and the partitioning of data sets (into training, test, and validation data sets). Advanced visualization tools enable you to quickly and easily examine large amounts of data in multidimensional histograms, and to graphically compare modeling results. 
The neural network tool includes multilayer perceptrons, radial basis functions, statistical versions of counterpropagation and learning vector quantization, a variety of built-in activation and error functions, multiple hidden layers, direct input-output connections, categorical variables, standardization of inputs and targets, and multiple preliminary optimizations from random initial values to avoid local minima. Training is done by state-ofthe-art numerical optimization algorithms instead of tedious backprop.

\section{NeuralWorks}

Name: NeuralWorks Professional II Plus (from NeuralWare)

Company: NeuralWare Inc.

Adress: RIDC Park West 202 Park West Drive

Pittsburgh, PA 15275

Phone: (412) 787-8222

FAX: (412) 787-8220

Email: sales@neuralware.com

URL: http://www.neuralware.com/

Distributor for Europe:

Scientific Computers GmbH.

Franzstr. 107, 52064 Aachen

Germany

Tel. (49) $+241-26041$

Fax. (49) +241-44983

Email.info@scientific.de

Basic capabilities:

supports over 30 different nets: backprop, art-1,kohonen, modular neural network, General regression, Fuzzy art-map, probabilistic nets, self-organizing map, Ivq, boltmann, bsb, spr, etc...

Extendable with optional package.

ExplainNet, Flashcode (compiles net in .c code for runtime), user-defined io in c possible. ExplainNet (to eliminate extra inputs), pruning, savebest,graph.instruments like correlation, hinton diagrams, rms error graphs etc..

Operating system : PC,Sun,IBM RS6000,Apple Macintosh,SGI,Dec,HP.

System requirements: varies. PC:2MB extended memory+6MB Harddisk space.

Uses windows compatible memory driver (extended).

Uses extended memory.

Approx. price : call (depends on platform)

Comments : award winning documentation, one of the market leaders in NN software.

\section{MATLAB Neural Network Toolbox}

Contact: The MathWorks, Inc. 24 Prime Park Way Natick, MA 01760

Phone: $508-653-1415$

FAX: 508-653-2997

email: info@mathworks.com

The Neural Network Toolbox is a powerful collection of MATLAB functions for the design, training, and simulation of neural networks. It supports a wide range of network architectures with an unlimited number of processing elements and interconnections (up to operating system constraints). Supported architectures and training methods include: supervised training of feedforward networks using the perceptron learning rule, Widrow-Hoff rule, several variations on backpropagation (including the fast Levenberg-Marquardt algorithm), and radial basis networks; supervised training of recurrent Elman networks; unsupervised training of associative networks including competitive and feature map layers; Kohonen 
networks, self-organizing maps, and learning vector quantization. The Neural Network Toolbox contains a textbook-quality Users' Guide, uses tutorials, reference materials and sample applications with code examples to explain the design and use of each network architecture and paradigm. The Toolbox is delivered as MATLAB M-files, enabling users to see the algorithms and implementations, as well as to make changes or create new functions to address a specific application.

(Comment from Nigel Dodd, nd@neural.win-uk.net): there is also a free Neural Network Based System Identification Toolbox available from

http://kalman.iau.dtu.dk/Projects/proj/nnsysid.html that contains many of the supervised training algorithms, some of which are duplicated in $\mathrm{C}$ code which should run faster. This free toolbox does regularisation and pruning which the costly one doesn't attempt (as of Nov 1995).

(Message from Eric A. Wan, ericwan@eeap.ogi.edu) FIR/TDNN Toolbox for MATLAB: Beta version of a toolbox for FIR (Finite Impulse Response) and TD (Time Delay) Neural

Networks. For efficient stochastic implementation, algorithms are written as MEX compatible $c$-code which can be called as primitive functions from within MATLAB. Both source and compiled functions are available. URL: http://www.eeap.ogi.edu/ ericwan/fir.html

\section{Propagator}

Contact: ARD Corporation, 9151 Rumsey Road, Columbia, MD 21045, USA propagator@ard.com

Easy to use neural network training package. A GUI implementation of backpropagation networks with five layers (32,000 nodes per layer). Features dynamic performance graphs, training with a validation set, and $\mathrm{C} / \mathrm{C}++$ source code generation.

For Sun (Solaris 1.x \& 2.x, \$499), PC (Windows 3.x, \$199) Mac (System 7.x, \$199)

Floating point coprocessor required, Educational Discount, Money Back Guarantee, Muliti User Discount

See http://www.cs.umbc.edu/ zwa/Gator/Description.html

Windows Demo on:

nic.funet.fi /pub/msdos/windows/demo

oak.oakland.edu /pub/msdos/neural_nets gatordem.zip pkzip $2.04 \mathrm{~g}$ archive file gatordem.txt readme text file

\section{NeuroForecaster \& VisuaData}

Name: NeuroForecaster(TM)/Genetica 4.1 a

Contact: Accel Infotech (S) Pte Ltd; 648 Geylang Road; Republic of Singapore 1438;

Phone: +65-7446863, 3366997; Fax: +65-3362833, Internet: accel@technet.sg, accel@singapore.com

Neuroforecaster 4.1a for Windows is priced at US\$1199 per single user license. Please email us (accel@technet.sg) for order form.

For more information and evaluation copy please visit http://www.singapore.com/products/nfga.

NeuroForecaster is a user-friendly ms-windows neural network program specifically designed for building sophisticated and powerful forecasting and decision-support systems (Time-Series Forecasting, Cross-Sectional Classification, Indicator Analysis)

\section{Features:}

- GENETICA Net Builder Option for automatic network optimization

- 12 Neuro-Fuzzy Network Models

- Multitasking \& Background Training Mode

- Unlimited Network Capacity 
- Rescaled Range Analysis \& Hurst Exponent to Unveil Hidden Market

- Cycles \& Check for Predictability

- Correlation Analysis to Compute Correlation Factors to Analyze the

- Significance of Indicators

- Weight Histogram to Monitor the Progress of Learning

- Accumulated Error Analysis to Analyze the Strength of Input Indicators

The following example applications are included in the package:

- Credit Rating - for generating the credit rating of bank loan applications.

- Stock market 6 monthly returns forecast

- Stock selection based on company ratios

- US\$ to Deutschmark exchange rate forecast

- US\$ to Yen exchange rate forecast

- US\$ to SGD exchange rate forecast

- Property price valuation

- Chaos - Prediction of Mackey-Glass chaotic time series

- SineWave - For demonstrating the power of Rescaled Range Analysis and significance of window size

\section{Techniques Implemented:}

- GENETICA Net Builder Option - network creation \& optimization based on Darwinian evolution theory

- Backprop Neural Networks - the most widely-used training algorithm

- Fastprop Neural Networks - speeds up training of large problems

- Radial Basis Function Networks - best for pattern classification problems

- Neuro-Fuzzy Network

- Rescaled Range Analysis - computes Hurst exponents to unveil hidden cycles \& check for predictability

- Correlation Analysis - to identify significant input indicators

- Companion Software - VisuaData for Windows A user-friendly data management program designed for intelligent technical analysis. It reads MetaStock, CSI, Computrac and various ASCII data file formats directly, generates over 100 popular and new technical indicators and buy/sell signals.

\section{Products of NESTOR, Inc.}

530 Fifth Avenue;

New York, NY 10036; USA;

Tel.: 001-212-398-7955

Founders:

Dr. Leon Cooper (having a Nobel Prize) and Dr. Charles Elbaum

(Brown University).

Neural Network Models:

Adaptive shape and pattern recognition (Restricted Coulomb Energy - RCE)

developed by NESTOR is one of the most powerfull Neural Network Model

used in a later products.

The basis for NESTOR products is the Nestor Learning System - NLS. Later are developed: Character Learning System - CLS and Image Learning System - ILS. Nestor Development System - NDS is a development tool in Standard C - a powerfull PC-Tool for simulation and development of Neural Networks.

NLS is a multi-layer, feed forward system with low connectivity within each layer and no relaxation procedure used for determining an output response. This unique architecture allows the NLS to operate in real time without the need for special computers or custom hardware.

NLS is composed of multiple neural networks, each specializing in a 
subset of information about the input patterns. The NLS integrates the

responses of its several parallel networks to produce a system response.

Minimized connectivity within each layer results in rapid training and efficient memory utilization- ideal for current VLSI technology. Intel has made such a chip - NE1000.

\section{Ward Systems Group (NeuroShell, etc.)}

Name: NeuroShell Predictor, NeuroShell Classifier,

NeuroShell Run-Time Server, NeuroShell Trader,

NeuroShell Trader Professional, NeuroShell 2,

GeneHunter, NeuroShell Engine

Company: Ward Systems Group, Inc.

Address: Executive Park West

5 Hillcrest Drive

Frederick, MD 21702

USA

Phone: $301662-7950$

FAX: $301662-5666$

Email:WardSystems@msn.com

URL: http://www.wardsystems.com/

Ward Systems Group Product Descriptions:

- NeuroShell. Predictor - This product is used for forecasting and estimating numeric amounts such as sales, prices, workload, level, cost, scores, speed, capacity, etc. It contains two of our newest algorithms (neural and genetic) with no parameters for you to have to set. These are our most powerful networks. Reads and writes text files.

- NeuroShell. Classifier - The NeuroShell Classifier solves classification and categorization problems based on patterns learned from historical data. The Classifier produces outputs that are the probabilities of the input pattern belonging to each of several categories. Examples of categories include \{acidic, neutral, alkaline\}, \{buy, sell, hold\}, and \{cancer, benign\}. Like the NeuroShell Predictor, it has the latest neural and genetic classifiers with no parameters to set. These are our most powerful networks. It also reads and writes text files.

- NeuroShell. Run-Time Server - The NeuroShell Run-Time Server allows you to distribute networks created with the NeuroShell Predictor or NeuroShell Classifier from either a simple interface, from your own computer programs, or from Excel spreadsheets.

- NeuroShell Trader. - This is the complete product for anyone trading stocks, bonds, futures, commodities, currencies, derivatives, etc. It works the way you think and work: for example, it reads open, high, low, close type price streams. It contains charting, indicators, the latest neural nets, trading simulations, data downloading, and walk forward testing, all seamlessly working together to make predictions for you. The NeuroShell Trader contains our most powerful network type.

- NeuroShell Trader. Professional - The Professional incorporates the original Trader along with the ability to optimize systems with a genetic algorithm even if they don't include neural nets! For example, you can enter a traditional trading strategy (using crossovers and breakouts) and then find optimal parameters for those crossovers and breakouts. You can also use the optimizer to remove useless rules in your trading strategy.

- NeuroShell. 2 - This is our classic general purpose system highly suited to students and professors who are most comfortable with traditional neural nets (not recommended for problem solving in a business or scientific environment). It contains 16 traditional neural network paradigms (algorithms) and combines ease of use and lots of control over how the networks are trained. Parameter defaults make it easy for you to get started, but provide generous flexibility and control later for experimentation. Networks can either predict or classify. Uses spreadsheet files, but can import other types. Runtime facilities include a source code generator, and there are several options for processing many nets, 3D graphics 
(response surfaces), and financial or time series indicators. It does not contain our newest network types that are in the NeuroShell Predictor, the NeuroShell Classifier and the NeuroShell Trader.

- GeneHunter. - This is a genetic algorithm product designed for optimizations like finding the best schedules, financial indicators, mixes, model variables, locations, parameter settings, portfolios, etc. More powerful than traditional optimization techniques, it includes both an Excel spreadsheet add-in and a programmer's tool kit.

- NeuroShell. Engine - This is an Active X control that contains the neural and genetic training methods that we have used ourselves in the NeuroShell Predictor, the NeuroShell Classifier, and the NeuroShell Trader. They are available to be integrated into your own computer programs for both training and firing neural networks. The NeuroShell Engine is only for the most serious neural network users, and only those who are programmers or have programmers on staff.

Contact us for a free demo diskette and Consumer's Guide to Neural Networks.

\section{NuTank}

NuTank stands for NeuralTank. It is educational and entertainment software. In this program one is given the shell of a 2 dimentional robotic tank. The tank has various I/O devices like wheels, whiskers, optical sensors, smell, fuel level, sound and such. These I/O sensors are connected to Neurons. The player/designer uses more Neurons to interconnect the I/O devices. One can have any level of complexity desired (memory limited) and do subsumptive designs. More complex design take slightly more fuel, so life is not free. All movement costs fuel too. One can also tag neuron connections as "adaptable" that adapt their weights in acordance with the target neuron. This allows neurons to learn. The Neuron editor can handle 3 dimention arrays of neurons as single entities with very flexible interconect patterns.

One can then design a scenario with walls, rocks, lights, fat (fuel) sources (that can be smelled) and many other such things. Robot tanks are then introduced into the Scenario and allowed interact or battle it out. The last one alive wins, or maybe one just watches the motion of the robots for fun. While the scenario is running it can be stopped, edited, zoom'd, and can track on any robot.

The entire program is mouse and graphicly based. It uses DOS and VGA and is written in TurboC++. There will also be the ability to download designs to another computer and source code will be available for the core neural simulator. This will allow one to design neural systems and download them to real robots. The design tools can handle three dimentional networks so will work with video camera inputs and such. Eventualy I expect to do a port to UNIX and multi thread the sign. I also expect to do a Mac port and maybe NT or $\mathrm{OS} / 2$

Copies of NuTank cost $\$ 50$ each.

Contact: Richard Keene; Keene Educational Software

URL: http://www.xmission.com/ rkeene Email: rkeene@parkcity.com or rkeene@xmission.com

NuTank shareware with the Save options disabled is available via anonymous ftp from the Internet, see the file /pub/incoming/nutank.readme on the host cher.media.mit.edu.

\section{Neuralyst}

Name: Neuralyst Version 1.4;

Company: Cheshire Engineering Corporation;

Address: 650 Sierra Madre Villa, Suite 201, Pasedena CA 91107;

Phone: 818-351-0209;

Fax: 818-351-8645;

Basic capabilities: training of backpropogation neural nets. Operating system: Windows or Macintosh running Microsoft Excel Spreadsheet. Neuralyst is an add-in package for Excel. Approx. price: $\$ 195$ for windows or Mac. 


\section{NeuFuz4}

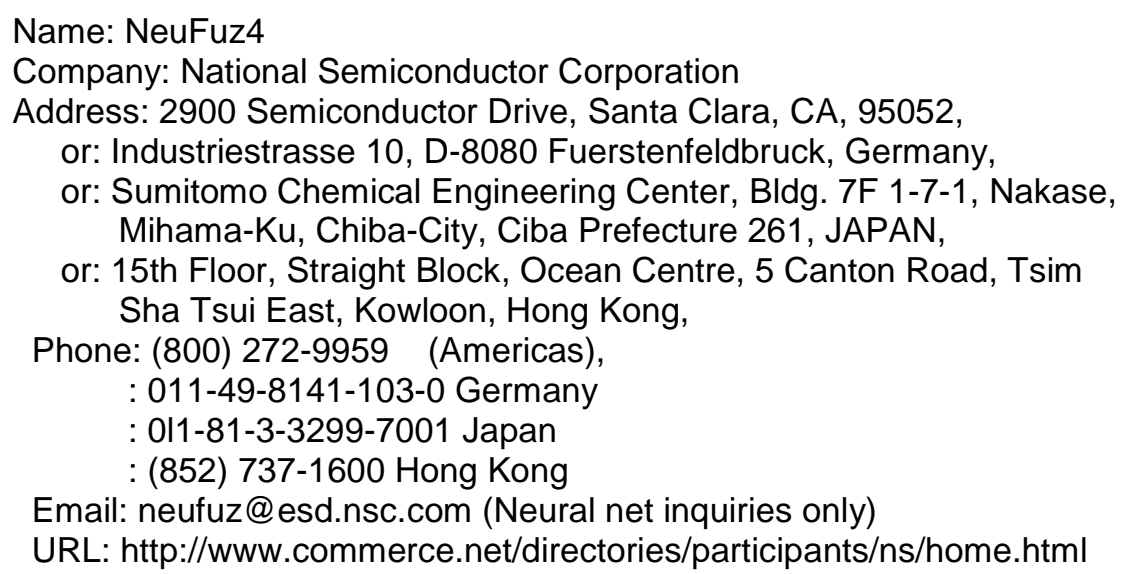

Basic capabilities:

Uses backpropagation techniques to initially select fuzzy rules and membership functions. The result is a fuzzy associative memory (FAM) which implements an approximation of the training data.

Operating Systems: 486DX-25 or higher with math co-processor

DOS 5.0 or higher with Windows 3.1 , mouse,

VGA or better, minimum 4 MB RAM, and parallel port.

Approx. price : depends on version - see below.

\section{Comments}

Not for the serious Neural Network researcher, but good for a person who has little understanding of Neural Nets - and wants to keep it that way. The systems are aimed at low end controls applications in automotive, industrial, and appliance areas. NeuFuz is a neuralfuzzy technology which uses backpropagation techniques to initially select fuzzy rules and membership functions. Initial stages of design using NeuFuz technology are performed using training data and backpropagation. The result is a fuzzy associative memory (FAM) which implements an approximation of the training data. By implementing a FAM, rather than a multi-layer perceptron, the designer has a solution which can be understood and tuned to a particular application using Fuzzy Logic design techniques.

There are several different versions, some with COP8 Code Generator (COP8 is National's family of 8-bit microcontrollers) and COP8 in-circuit emulator (debug module).

\section{Cortex-Pro}

Cortex-Pro information is on WWW at:

http://www.reiss.demon.co.uk/webctx/intro.html.

You can download a working demo from there.

Contact: Michael Reiss (http://www.mth.kcl.ac.uk/ mreiss/mick.html)

email: <m.reiss@kcl.ac.uk>.

\section{Partek}

Partek is a young, growing company dedicated to providing our customers with the best software and services for data analysis and modeling. We do this by providing a combination of statistical analysis and modeling techniques and modern tools such as neural networks, fuzzy logic, genetic algorithms, and data visualization. These powerful analytical tools are delivered with high quality, state of the art software.

Please visit our home on the World Wide Web: http://www.partek.com/

Partek Incorporated

5988 Mid Rivers Mall Dr.

St. Charles, MO 63304

voice: $314-926-2329$ 
fax: 314-441-6881

email: info@partek.com

http://www.partek.com/

\section{NeuroSolutions v3.0}

Name: NeuroSolutions v3.0

Company: NeuroDimension, Inc.

Address: 1800 N. Main St., Suite D4

Gainesville FL, 32609

Phone: (800) 634-3327 or (352) 377-5144

FAX: (352) 377-9009

Email: info@nd.com

URL: http://www.nd.com/

Operating System: Windows 95, Windows NT

Price: \$195 - \$1995 (educational discounts available)

NeuroSolutions is a highly graphical neural network simulator for Windows 95/98 and

Windows NT 4.0/5.0. This leading edge software combines a modular, icon-based network design interface with an implementation of advanced learning procedures, such as recurrent backpropagation and backpropagation through time. The result is a virtually unconstrained environment for designing neural networks for research or to solve real-world problems. Download a free evaluation copy from http://www.nd.com/download/downnsv3.htm.

\section{Topologies}

- Multilayer perceptrons (MLPs)

- Generalized Feedforward networks

- Modular networks

- Jordan-Elman networks

- $\quad$ Self-Organizing Feature Map (SOFM) networks

- Radial Basis Function (RBF) networks

- Time Delay Neural Networks (TDNN)

- Time-Lag Recurrent Networks (TLRN)

- Recurrent Networks (TLRN)

- General Regression Networks (GRNNN)

- Probabilistic Networks (PNN)

- User-defined network topologies

\section{Learning Paradigms}

- Backpropagation

- Recurrent Backpropagation

- Backpropagation through Time

- Unsupervised Learning

- Hebbian

- Oja's

- Sanger's

- Competitive

- Kohonen

\section{Advanced Features}

- ANSI C++ Source Code Generation

- Customized Components through DLLs

- Microsoft Excel Add-in -- NeuroSolutions for Excel

- Visual Data Selection

- Data Preprocessing and Analysis

- Batch Training and Parameter Optimization

- Sensitivity Analysis

- Automated Report Generation 
- DLL Generation Utility -- The Custom Solution Wizard

- Encapsulate any supervised NeuroSolutions NN into a Dynamic Link Library (DLL)

- Use the DLL to embed a NN into your own Visual Basic, Microsoft Excel, Microsoft Access or Visual $\mathrm{C}++_{+}$application

- Support for both Recall and Learning networks available

- Simple protocol for sending the input data and retrieving the network response

- Comprehensive Macro Language

- Fully accessible from any OLE-compliant application, such as:

- Visual Basic

- Microsoft Excel

- Microsoft Access

\section{Qnet For Windows Version 2.0}

Vesta Services, Inc. 1001 Green Bay Rd, Suite 196

Winnetka, IL 60093

Phone: (708) 446-1655

E-Mail: VestaServ@aol.com

Trial Version Available: ftp://oak.oakland.edu/SimTel/win3/neurlnet/qnetv2t.zip Vesta Services announces Qnet for Windows Version 2.0. Qnet is an advanced neural network modeling system that is ideal for developing and implementing neural network solutions under Windows. The use of neural network technology has grown rapidly over the past few years and is being employed by an increasing number of disciplines to automate complex decision making and problem solving tasks. Qnet Version 2 is a powerful, 32-bit, neural network development system for Windows NT, Windows 95 and Windows 3.1/Win32s. In addition its development features, Qnet automates access and use of Qnet neural networks under Windows.

Qnet neural networks have been successfully deployed to provide solutions in finance, investing, marketing, science, engineering, medicine, manufacturing, visual recognition... Qnet's 32-bit architecture and high-speed training engine tackle problems of large scope and size. Qnet also makes accessing this advanced technology easy. Qnet's neural network setup dialogs guide users through the design process. Simple copy/paste procedures can be used to transfer training data from other applications directly to Qnet. Complete, interactive analysis is available during training. Graphs monitor all key training information. Statistical checks measure model quality. Automated testing is available for training optimization. To implement trained neural networks, Qnet offers a variety of choices. Qnet's built-in recall mode can process new cases through trained neural networks. Qnet also includes a utility to automate access and retrieval of solutions from other Windows applications. All popular Windows spreadsheet and database applications can be setup to retrieve Qnet solutions with the click of a button. Application developers are provided with DLL access to Qnet neural networks and for complete portability, ANSI C libraries are included to allow access from virtually any platform.

Qnet for Windows is being offered at an introductory price of $\$ 199$. It is available immediately and may be purchased directly from Vesta Services. Vesta Services may be reached at (voice) (708) 446-1655; (FAX) (708) 446-1674; (e-mail) VestaServ@aol.com; (mail) 1001 Green Bay Rd, \#196, Winnetka, IL 60093

\section{NeuroLab, A Neural Network Library}

Contact: Mikuni Berkeley R \& D Corporation; 4000 Lakeside Dr.; Richmond, CA Tel: 510-222-9880; Fax: 510-222-9884; e-mail: neurolab-info@mikuni.com NeuroLab is a block-diagram-based neural network library for Extend simulation software (developed by Imagine That, Inc.). The library aids the understanding, designing and simulating of neural network systems. The library consists of more than 70 functional blocks for artificial neural network implementation and many example models in several professional fields. The package provides icon-based functional blocks for easy 
implementation of simulation models. Users click, drag and connect blocks to construct a neural network and can specify network parameters--such as back propagation methods, learning rates, initial weights, and biases--in the dialog boxes of the functional blocks. Users can modify blocks with the Extend model-simulation scripting language, ModL, and can include compiled program modules written in other languages using XCMD and XFCN (external command and external function) interfaces and DLL (dynamic linking library) for Windows. The package provides many kinds of output blocks to monitor neural network status in real time using color displays and animation and includes special blocks for control application fields. Educational blocks are also included for people who are just beginning to learn about neural networks and their applications.

The library features various types of neural networks --including Hopfield, competitive, recurrent, Boltzmann machine, single/multilayer feed-forward, perceptron, context, feature map, and counter-propagation-- and has several back-propagation options: momentum and normalized methods, adaptive learning rate, and accumulated learning.

The package runs on Macintosh II or higher (FPU recommended) with system 6.0.7 or later and PC compatibles (486 or higher recommended) with Windows 3.1 or later, and requires 4 Mbytes of RAM. Models are transferable between the two platforms. NeuroLab v1.2 costs US\$495 (US\$999 bundled with Extend v3.1). Educational and volume discounts are available.

A free demo can be downloaded by ftp://ftp.mikuni.com/pub/neurolab or http://www.mikuni.com/. Orders, questions or suggestions can be sent by e-mail to neurolabinfo@mikuni.com.

\title{
17.hav.Software: havBpNet++, havFmNet++, havBpNet:J
}

\author{
Names: havBpNet++ \\ havFmNet++ \\ havBpNet:J \\ Company: hav.Software \\ P.O. Box 354 \\ Richmond, Tx. 77406-0354 - USA \\ Phone: (281) 341-5035 \\ Email: hav@hav.com \\ Web: http://www.hav.com/
}

- havBpNet++ is a C++ class library that implements feedforward, simple recurrent and random-ordered recurrent nets trained by backpropagation. Used for both stand-alone and embedded network training and consultation applications. A simple layer-based API, along with no restrictions on layer-size or number of layers, makes it easy to build standard 3-layer nets or much more complex multiple sub-net topologies.

Supports all standard network parameters (learning-rate, momentum, Cascade- coefficient, weight-decay, batch training, etc.). Includes 5 activation-functions (Linear, Logistic-sigmoid, Hyperbolic-tangent, Sin and Hermite) and 3 error-functions $\left(e^{\wedge} 2, e^{\wedge} 3, e^{\wedge} 4\right)$. Also included is a special scaling utility for data with large dynamic range.

Several data-handling classes are also included. These classes, while not required, may be used to provide convenient containers for training and consultation data. They also provide several normalization/de-normalization methods.

havBpNet++ is delivered as fully documented source $+200 \mathrm{pg}$ User/Developer Manual. Includes a special DLL version. Includes several example trainers and consulters with data sets. Also included is a fully functioning copy of the havBpETT demo (with network-save enabled).

NOTE: a freeware version (Save disabled) of the havBpETT demo may be downloaded from the hav.Software home-page: http://www. neosoft.com/ hav or by anonymous ftp from ftp://ftp.neosoft.com/pub/users/h/hav/havBpETT/demo2.exe.

Platforms: Tested platforms include - PC (DOS, Windows-3.1, NT, Unix), HP (HPux), SUN (Sun/OS), IBM (AIX), SGI (Irix).

Source and Network-save files portable across platforms. 
Licensing: havBpNet++ is licensed by number of developers.

A license may be used to support development on any number and types of cpu's.

No Royalties or other fees (except for OEM/Reseller)

Price: Individual $\$ 50.00$ - one developer

Site $\quad \$ 500.00$ - multiple developers - one location

Corporate $\$ 1000.00$ - multiple developers and locations

OEM/Reseller quoted individually

(by American Express, bank draft and approved company PO)

Media: 3.5 -inch floppy - ascii format (except havBpETT which is in PC-exe format).

- havFmNet++ is a $\mathrm{C}_{++}$class library that implements Self-Organizing Feature Map nets. Map-layers may be from 1 to any dimension.

havFmNet++ may be used for both stand-alone and embedded network training and consultation applications. A simple Layer-based API, along with no restrictions on layer-size or number of layers, makes it easy to build single- layer nets or much more complex multiple-layer topologies. havFmNet++ is fully compatible with havBpNet++ which may be used for pre- and post- processing.

Supports all standard network parameters (learning-rate, momentum, neighborhood, conscience, batch, etc.). Uses On-Center-Off-Surround training controlled by a sombrero form of Kohonen's algorithm. Updates are controllable by three neighborhood related parameters: neighborhood-size, block-size and neighborhood-coefficient cutoff. Also included is a special scaling utility for data with large dynamic range.

Several data-handling classes are also included. These classes, while not required, may be used to provide convenient containers for training and consultation data. They also provide several normalization/de-normalization methods.

havFmNet++ is delivered as fully documented source plus $200 \mathrm{pg}$ User/Developer Manual. Includes several example trainers and consulters with data sets.

Platforms: Tested platforms include - PC (DOS, Windows-3.1, NT, Unix), HP (HPux), SUN (Sun/OS), IBM (AIX), SGI (Irix).

Source and Network-save files portable across platforms.

Licensing: havFmNet++ is licensed by number of developers.

A license may be used

to support development on any number and types of cpu's.

No Royalties or other fees (possible exception for OEM).

Price: Individual $\$ 50.00$ - one developer

Site $\$ 500.00$ - multiple developers - one location

Corporate $\$ 1000.00$ - multiple developers and locations

OEM/Reseller quoted individually

(by American Express, bank draft and approved company PO)

Media: 3.5-inch floppy - ascii format

- havBpNet:J is a Java class library that implements feedforward, simple recurrent (sequential) and random-ordered recurrent nets trained by backpropagation. Used for both stand-alone and embedded network training and consultation applications and applets. A simple layer-based API, along with no restrictions on layer-size or number of layers, makes it easy to build standard 3-layer nets or much more complex multiple sub-net topologies.

Supports all standard network parameters (learning-rate, momentum, Cascade-coefficient, weight-decay, batch training, error threshold, etc.). Includes 5 activation-functions (Linear, Logistic-sigmoid, Hyperbolic-tangent, Sin and Hermite) and 3 error-functions $\left(\mathrm{e}^{\wedge} 2, \mathrm{e}^{\wedge} 3, \mathrm{e}^{\wedge} 4\right)$. Also included is a special scaling utility for data with large dynamic range.

Several data-handling classes are also included. These classes, while not required, may be used to provide convenient containers for training and consultation data. They also provide several normalization/de-normalization methods. 
Platforms: Java Virtual Machines - 1.0 and later

Licensing: No Royalties or other fees (except for OEM/Reseller)

Price: Individual License is $\$ 55.00$

Site, Corporate and OEM/Reseller also available

Media: Electronic distribution only.

\section{IBM Neural Network Utility}

Product Name: IBM Neural Network Utility

Distributor: Contact a local reseller or call 1-800-IBM-CALL, Dept. SA045 to order.

Basic capabilities: The Neural Network Utility Family consists of six products: client/server capable versions for OS/2, Windows, AIX, and standalone versions for OS/2 and Windows. Applications built with NNU are portable to any of the supported platforms regardless of the development platform. NNU provides a powerful, easy to use, point-and-click graphical development environment. Features include: data translation and scaling, applicaton generation, multiple network models, and automated network training. We also support fuzzy rule systems, which can be combined with the neural networks. Once trained, our APIs allow you to embed your network and/or rulebase into your own applications.

Operating Systems: OS/2, Windows, AIX, AS/400

System requirements: basic; request brochure for more details

Price: Prices start at $\$ 250$

For product brochures, detailed pricing information, or any other information, send a note to nninfo@vnet.ibm.com.

\section{NeuroGenetic Optimizer (NGO) Version 2.0}

BioComp's leading product is the NeuroGenetic Optimizer, or NGO. As the name suggests, the NGO is a neural network development tool that uses genetic algorithms to optimize the inputs and structure of a neural network. Without the NGO, building neural networks can be tedious and time consuming even for an expert. For example, in a relatively simple neural network, the number of possible combination of inputs and neural network structures can be easily over 100 billion. The difference between an average network and an optimum network is substantial. The NGO searches for optimal neural network solutions. See our web page at http://www.bio-comp.com./ for a demo that you can download and try out. Our customers who have used other neural network development tools are delighted with both the ease of use of the NGO and the quality to their results.

BioComp Systems, Inc. introduced version 1.0 of the NGO in January of 1995 and now proudly announces version 2.0. With version 2.0 , the NGO is now equipped for predicting time-based information such as product sales, financial markets and instruments, process faults, etc., in addition to its current capabilities in functional modeling, classification, and diagnosis.

While the NGO embodies sophisticated genetic algorithm search and neural network modeling technology, it has a very easy to use GUI interface for Microsoft Windows. You don't have to know or understand the underlying technology to build highly effective financial models. On the other hand, if you like to work with the technology, the NGO is highly configurable to customize the NGO to your liking.

Key new features of the NGO include:

- Highly effective "Continuous Adaptive Time", Time Delay and lagged input Back Propagation neural networks with optional recurrent outputs, automatically competing and selected based on predictive accuracy.

- Walk Forward Train/Test/Validation model evaluation for assuring model robustness,

- Easy input data lagging for Back Propagation neural models,

- Neural transfer functions and techniques that assure proper extrapolation of predicted variables to new highs,

- Confusion matrix viewing of Predicted vs. Desired results, 
- Exportation of models to Excel 5.0 (Win 3.1) or Excel 7.0 (Win'95/NT) through an optional Excel Add-In

- Five accuracies to choose from including; Relative Accuracy, R-Squared, Mean Squared Error (MSE), Root Mean Square (RMS) Error and Average Absolute error.

With version 2.0, the NGO is now available as a full 32 bit application for Windows '95 and Windows NT to take advantage of the 32 bit preemptive multitasking power of those platforms. A 16 bit version for Windows 3.1 is also available. Customized professional server based systems are also available for high volume automated model generation and prediction. Prices start at $\$ 195$.

BioComp Systems, Inc.

Overlake Business Center

2871 152nd Avenue N.E.

Redmond, WA 98052, USA

$1-800-716-6770$ (US/Canada voice) $=20 \quad 1-206-869-6770$ (Local/Int'I voice)

1-206-869-6850 (Fax) http://www.bio-comp.com.

biocomp@biocomp.seanet.com 70673.1554@compuserve.com

\section{WAND}

Weightless Neural Design system for Education and Industry.

Developed by Novel Technical Solutions in association with Imperial College of Science,

Technology and Medicine (London UK).

WAND introduces Weightless Neural Technology as applied to Image Recognition.

It includes an automated image preparation package, a weightless neural simulator and a comprehensive manual with hands-on tutorials.

Full information including a download demo can be obtained from:

http://www.ph.kcl.ac.uk/neuronet/software/nts/neural.html

To contact Novel Technical Solutions email: <neural@nts.sonnet.co.uk>.

\section{The Dendronic Learning Engine}

Dendronic Decisions Limited

3624 - 108 Street, NW

Edmonton, Alberta,

Canada T6J 1B4

Email:arms@dendronic.com

URL: http://www.dendronic.com/

Tel. +14034210800

(Note: The area code 403 changes to 780 after Jan. 25, 1999)

The Dendronic Learning Engine (DLE) Software Development Kit (SDK) allows the user to easily program machine learning technology into high performance applications. Application programming interfaces to $\mathrm{C}$ and $\mathrm{C}_{++}$are provided. Supervised learning is supported, as well as the recently developed reinforcement learning of value functions and Q-functions. Fast evaluation on PC hardware is supported by ALN Decision Trees.

An ALN consists of linear functions with adaptable weights at the leaves of a tree of maximum and minimum operators. The tree grows automatically during training: a linear piece splits if its error is too high. The function computed by an ALN is piecewise linear and continuous, and can approximate any continuous function to any required accuracy.

Statistics are reported on the fit of each linear piece to test data.

The DLE has been very successful in predicting electrical power loads in the Province of Alberta. The 24-hour ahead load for all of Alberta (using seven weather regions) was predicted using a single ALN. Visit http://www.dendronic.com/applications.htm to learn about other successful applications to ATM communication systems, walking prostheses for persons with incomplete spinal cord injury, and many other areas.

Operating Systems: Windows NT 4.0, 95 and higher. 
Price: Prices for the SDK start at $\$ 3495$ US for a single seat, and are negotiable for embedded learning systems. A runtime non-learning system can be distributed royalty-free. The power of the DLE can be tried out using an interactive spreadsheet program,

ALNBench. ALNBench is free for research, education and evaluation purposes. The program can be downloaded from http://www.dendronic.com/beta.htm (Please note the installation key given there!)

For further information please contact:

William W. Armstrong PhD, President

\section{TDL v. 1.1 (Trans-Dimensional Learning)}

Platform: Windows 3 . $^{*}$

Company: Universal Problem Solvers, Inc.

WWW-Site (UPSO): http://pages.prodigy.com/FL/lizard/index.html

or FTP-Site (FREE Demo only): ftp.coast.net, in Directory:

SimTel/win3/neurlnet, File: tdl11-1.zip and tdl11-2.zip

Cost of complete program: US\$20 + (US $\$ 3$ Shipping and Handling).

The purpose of TDL is to provide users of neural networks with a specific platform to conduct pattern recognition tasks. The system allows for the fast creation of automatically

constructed neural networks. There is no need to resort to manually creating neural networks and twiddling with learning parameters. TDL's Wizard can help you optimize pattern recognition accuracy. Besides allowing the application user to automatically construct neural network for a given pattern recognition task, the system supports trans-dimensional learning. Simply put, this allows one to learn various tasks within a single network, which otherwise differ in the number of input stimuli and output responses utilized for describing them. With TDL it is possible to incrementally learn various pattern recognition tasks within a single coherent neural network structure. Furthermore, TDL supports the use of semi-weighted neural networks, which represent a hybrid cross between standard weighted neural networks and weightless multi-level threshold units. Combining both can result in extremely compact network structures (i.e., reduction in connections and hidden units), and improve predictive accuracy on yet unseen patterns. Of course the user has the option to create networks which only use standard weighted neurons.

System Highlights:

1. The user is in control of TDL's memory system (can decide how many examples and neurons are allocated ; no more limitations, except for your computers memory).

2. TDLs Wizard supports hassle-free development of neural networks, the goal of course being optimization of predictive accuracy on unseen patterns.

3. History option allows users to capture their favorite keystrokes and save them. Easy recall for future use.

4. Provides symbolic interface which allows the user to create:Input and output definition files, Pattern files, and Help files for objects (i.e., inputs, input values, and outputs).

5. Supports categorization of inputs. This allows the user to readily access inputs via a popup menu within the main TDL menu. The hierarchical structure of the popup menu is under the full control of the application developer (i. e., user).

6. Symbolic object manipulation tool: Allows the user to interactively design the input/output structure of an application. The user can create, delete, or modify inputs, outputs, input values, and categories.

7. Supports Rule representation: (a) Extends standard Boolean operators (i.e., and, or, not) to contain several quantifiers (i.e., atmost, atleast, exactly, between). (b) Provides mechanisms for rule revision (i.e., refinement) and extraction. (c) Allows partial rule recognition. Supported are first- and best-fit.

8. Allows co-evolution of different subpopulations (based on type of transfer function chosen for each subpopulation).

9. Provides three types of crossover operators: simple random, weighted and blocked. 10.Supports both one-shot as well as multi-shot learning. Multi-shot learning allows for the incremental acquisition of different data sets. A single expert network is constructed, capable 
of recognizing all the data sets supplied during learning. Quick context switching between different domains is possible.

11. Three types of local learning rules are included: perceptron, delta and fastprop.

12. Implements 7 types of unit transfer functions: simple threshold, sigmoid, sigmoid-squash, n-level threshold, new n-level-threshold, gaussian and linear.

13. Over a dozen statistics are collected during various batch training sessions. These can be viewed using the chart option.

14. A $140+$ page hypertext on-line help menu is available.

15.A DEMONSTRATION of TDL can be invoked when initially starting the program.

\section{NeurOn-Line}

Built on Gensym Corp.'s G2(r), Gensym's NeurOn-Line(r) is a graphical, object-oriented software product that enables users to easily build neural networks and integrate them into G2 applications. NeurOn-Line is well suited for advanced control, data and sensor validation, pattern recognition, fault classification, and multivariable quality control applications. Gensym's NeurOn-Line provides neural net training and on-line deployment in a single, consistent environment. NeurOn-Line's visual programming environment provides predefined blocks of neural net paradigms that have been extended with specific features for real-time process control applications. These include: Backprop, Radial Basis Function, Rho, and Autoassociative networks. For more information on Gensym software, visit their home page at http://www.gensym.com/.

\section{NeuFrame, NeuroFuzzy, NeuDesk and NeuRun}

Name: NeuFrame, NeuroFuzzy, NeuDesk and NeuRun

Company: NCS

Address: Unit 3

Lulworth Business Centre

Totton

Southampton

UK

SO40 3WW

Phone: +44 (0)1703 667775

Fax: $\quad+44(0) 1703663730$

Email: robby@ncs-skylake.co.uk

URL: http://www.demon.co.uk/skylake/software.html

\section{NeuFrame}

NeuFrame provides an easy-to-use, visual, object-oriented approach to problem solving using intelligence technologies, including neural networks and neurofuzzy techniques. It provides features to enable businesses to investigate and apply intelligence technologies from initial experimentation through to building embedded implementations using software components.

- Minimum Configuration- Windows 3.1 with win32s, 386DX 33MHz, 8Mb memory, $5 \mathrm{Mb}$ free disk space,VGA graphics, mouse

- Recommended Configuration - Windows 95/NT 486DX 50MHz or above $16 \mathrm{Mb}$ memory, $150 \mathrm{Mb}$ or above hard disc, VGA graphics, Mouse.

- Price Commercial 749 (Pounds Sterling), Educational 435

\section{NeuroFuzzy}

This is an optional module for use within the NeuFrame enviroment. Fuzzy logic differs from neural networks in the sense that neural systems are constructed purely from available data whereas fuzzy systems are expert designed. The relative merits of the two approaches is very much application dependent as it relies on the availability of training data and expert knowledge. Conventional knowledge based systems can also be used to represent expert knowledge within computer systems, but fuzzy logic provides a richer representation.

Benefits include: 
1. Combines the benefits of rule based fuzzy logic and learning from experience of neural networks.

2. Automatically generate optimised neurofuzzy models.

3. Encapsulate expert fuzzy knowledge within the model.

4. Fuzzy models may be modified or created according to the data presented to the network.

5. Includes a pure Fuzzy logic editor.

- Requires NeuFrame

- Price Commercial 249 (Pounds Sterling), Educational 149

\section{NeuDesk}

NeuDesk 2 makes the implementation of a neural network solution very accessible. Running within the Windows 3 environment, NeuDesk 2 is easy for non-specialists to use. Data required for training the neural network can be entered manually, by cut and paste from any other Windows application, or imported from a number of different file formats. Training the network is achieved by a few straightforward point-and-click operations.

- Recommended Configuration - Microsoft Windows 3.0 or higher with a minimum of $2 \mathrm{Mb}$ RAM and 20Mbyte hard disk and mouse. 4Mb RAM, 387 co-processor and a 40Mb hard disk are recommended.

- Price Commercial 349 (Pounds Sterling), Educational 149

\section{NeuRun}

NeuRun provides for the embedding of intelligence technologies developed in NeuFrame or NeuDesk to be embedded into other programs and environments. NeuRun simplifies and speeds up the process of embedding neural networks in your favourite Windows applications to provide on-line intelligence for decisions, predictions, suggestions or classifications. Implementations are easy to duplicate and deploy and can be readily updated if the problem conditions change over time. Typical of the application programs that can be enhanced using NeuRun 3 are: Excel, Microsoft's spreadsheet for creating powerful data manipulations and analysis applications and Visual Basic which can be used to generate user defined screens and functions for custom operator interfaces, data entry forms, control panels etc.

- Price Commercial 50 (Pounds Sterling), Educational 50

\section{OWL Neural Network Library (TM)}

Name: OWL Neural Network Library (TM)

Company: HyperLogic Corporation

Address: PO Box 300010

Escondido, CA 92030

USA

Phone: +1 619-746-2765

Fax: $\quad+1$ 619-746-4089

Email: prodinfo@hyperlogic.com

URL: http://www.hyperlogic.com/hl

The OWL Neural Network Library provides a set of popular networks in the form of a programming library for $\mathrm{C}$ or $\mathrm{C}++$ software development. The library is designed to support engineering applications as well as academic research efforts.

A common programming interface allows consistent access to the various paradigms. The programming environment consists of functions for creating, deleting, training, running, saving, and restoring networks, accessing node states and weights, randomizing weights, reporting the complete network state in a printable ASCII form, and formatting detailed error message strings.

The library includes 20 neural network paradigms, and facilitates the construction of others by concatenation of simpler networks. Networks included are:

- Adaptive Bidirectional Associative Memories (ABAM), including stochastic versions (RABAM). Five paradigms in all.

- Discrete Bidirectional Associative Memory (BAM), with individual bias weights for increased pattern capacity. 
- Multi-layer Backpropagation with many user controls such as batching, momentum, error propagation for network concatenation, and optional computation of squared error. A compatible, non-learning integer fixed-point version is included. Two paradigms in all.

- Nonadaptive Boltzmann Machine and Discrete Hopfield Circuit.

- "Brain-State-in-a-Box" autoassociator.

- Competitive Learning Networks: Classical, Differential, and "Conscience" version. Three paradigms in all.

- Fuzzy Associative Memory (FAM).

- "Hamming Network", a binary nearest-neighbor classifier.

- Generic Inner Product Layer with user-defined signal function.

- "Outstar Layer" learns time-weighted averages. This network, concatenated with Competitive Learning, yields the "Counterpropagation" network.

- "Learning Logic" gradient descent network, due to David Parker.

- Temporal Access Memory, a unidirectional network useful for recalling binary pattern sequences.

- Temporal Pattern Network, for learning time-sequenced binary patterns.

Supported Environments:

The object code version of OWL is provided on MS-DOS format diskettes with object libraries and makefiles for both Borland and Microsoft C. An included Windows DLL supports OWL development under Windows. The package also includes Owgraphics, a mouseless graphical user interface support library for DOS.

Both graphical and "stdio" example programs are included.

The Portable Source Code version of OWL compiles without change on many hosts, including VAX, UINX, and Transputer. The source code package includes the entire objectcode package.

Price:

USA and Canada: (US) \$295 object code, (US) \$995 with source

Outside USA and Canada: (US) \$350 object code, (US) \$1050 with source

Shipping, taxes, duties, etc., are the responsibility of the customer.

\section{Neural Connection}

Name: Neural Connection

Company: SPSS Inc.

Address: 444 N. Michigan Ave., Chicago, IL 60611

Phone: $1-800-543-2185$

$$
\text { 1-312-329-3500 (U.S. and Canada) }
$$

Fax: 1 -312-329-3668 (U.S. and Canada)

Email: sales@spss.com

URL: http://www.spss.com/

SPSS has offices worldwide. For inquiries outside the U.S. and Canada, please contact the U.S. office to locate the office nearest you.

Operating system : Microsoft Windows 3.1 (runs in Windows 95)

System requirements: $386 \mathrm{pc}$ or better, $4 \mathrm{MB}$ memory (8MB recommended), $4 \mathrm{MB}$ free hard disk space, VGA or SVGA monitor, Mouse or other pointing device,

Math coprocessor strongly recommended

Price: \$995, academic discounts available

\section{Description}

Neural Connection is a graphical neural network tool which uses an icon-based workspace for building models for prediction, classification, time series forecasting and data segmentation. It includes extensive data management capabilities so your data preparation is easily done right within Neural Connection. Several output tools give you the ability to explore your models thoroughly so you understand your results.

Modeling and Forecasting tools 
* 3 neural network tools: Multi-Layer Perceptron, Radial Basis Function, Kohonen network

* 3 statistical analysis tools: Multiple linear regression, Closest class means classifier, Principal component analysis

Data Management tools

* Filter tool: transformations, trimming, descriptive statistics, select/deselect variables for analysis, histograms

* Time series window: single- or multi-step prediction, adjustable step size

* Network combiner

* Simulator

* Split dataset: training, validation and test data

* Handles missing values

Output Options

* Text output: writes ASCII and SPSS (.sav) files, actual values, probabilities, classification results table, network output

* Graphical output: 3-D contour plot, rotation capabilties, Whatlf? tool includes interactive sensititivity plot, cross section, color contour plot

* Time series plot

Production Tools

* Scripting language for batch jobs and interactive applications

* Scripting language for building applications

Documentation

* User s guide includes tutorial, operations and algorithms

* Guide to neural network applications

Example Applications

${ }^{*}$ Finance - predict account attrition

* Marketing - customer segmentation

* Medical - predict length of stay in hospital

* Consulting - forecast construction needs of federal court systems

* Utilities - predict number of service requests

* Sales - forecast product demand and sales

* Science - classify climate types

\section{Pattern Recognition Workbench Expo/PRO/PRO+}

Name: Pattern Recognition Workbench Expo/PRO/PRO+

Company: Unica Technologies, Inc.

Address: 55 Old Bedford Rd., Lincoln, MA 01773 USA

Phone, Fax: (617) 259-5900, (617) 259-5901

Email: unica@unica-usa.com

Basic capabilities:

- Supported architectures and training methods include backpropagation, radial basis functions, K nearest neighbors, Gaussian mixture, Nearest cluster, K means clustering, logistic regression, and more.

- Experiment managers interactively control model development by walking you through problem definition and set-up;

- Provides icon-based management of experiments and reports.

- Easily performs automated input feature selection searches and automated algorithm parameter searches (using intelligent search methods including genetic algorithms) 
- Statistical model validation (cross-validation, bootstrap validation, sliding-window validation).

- "Giga-spreadsheets" hold 16,000 columns by 16 million rows of data each (254 billion cells)!

- Intelligent spreadsheet supports data preprocessing and manipulation with over 100 built-in macro functions. Custom user functions can be built to create a library of re-usable macro functions.

- C source code generation, DLLs, and real-time application linking via DDE/OLE links.

- Interactive graphing and data visualization (line, histogram, 2D and 3D scatter graphs). Operating system: Windows 3.1, WFW 3.11, Windows 95, Windows NT (16- and 32-bit versions available)

System requirements: Intel 486+, 8+ MB memory, 5+ MB disk space

Approx. price: software starts at $\$ 995.00$ (call for more info)

Solving Pattern Recognition Problems text book: $\$ 49.95$

Money-back guarantee

Pattern Recognition Workbench (PRW) is a comprehensive environment/tool for solving pattern recognition problems using neural network, machine learning, and traditional statistical technologies. With an intuitive, easy-to-use graphical interface, PRW has the flexibility to address many applications. With features such as automated model generation (via input feature selection and algorithm parameter searches), experiment management, and statistical validation, PRW provides all the necessary tools from formatting and preprocessing your data to setting up, running, and evaluating experiments, to deploying your solution. PRW's automated model generation capability can generate literally hundreds of models, selecting the best ones from a thorough search space, ultimately resulting in better solutions!

\section{PREVia}

PREVia is a simple Neural Network-based forecasting tool. The current commercial version is available in French and English (the downloadable version is in English). A working demo version of PREVia is available for download at: http://www.elseware-fr.com/prod01.htm. This software is being used mainly in France, by banks and some of the largest investment companies, such as: Banque de France (French Central Bank), AXA Asset Management, Credit Lyonnais Asset Management, Caisse des Depots AM, Banque du Luxembourg and others. In order to enhance the research and applications using PREVia, it has been given free of charge to European Engineering and Business Schools, such as Ecole Centrale Paris, London Business School, EURIA, CEFI, Universite du Luxembourg. Interested universities and schools should contact Elseware at the forementioned page.

\section{Introducing Previa}

Based on a detailed analysis of the forecasting decision process, Previa was jointly designed and implemented by experts in economics and finance, and neural network systems specialists including both mathematicians and computer scientists. Previa thus enables the experimentation, testing, and validation of numerous models. In a few hours, the forecasting expert can conduct a systematic experimentation, generate a study report, and produce an operational forecasting model. The power of Previa stems from the model type used, i.e., neural networks. Previa offers a wide range of model types, hence allowing the user to create and test several forecasting systems, and to assess each of them with the same set of criteria. In this way, Previa offers a working environment where the user can rationalise his or her decision process. The hardware requirements of Previa are: an IBM-compatible PC with Windows 3.1 (c) or Windows95. For the best performance, an Intel 486DX processor is recommended. Previa is delivered as a shrink-wrapped application software, as well as a dynamic link library (DLL) for the development of custom software. The DLL contains all the necessary functions and data structures to manipulate time series, neural networks, and associated algorithms. The DLL can also be used to develop applications with Visual BasicTM. A partial list of features: 
* Definition of a forecast equation : *

Definition of the variable to forecast and explanatory variables.

Automatic harmonization of the domains and periodicities involved in the equation.

* Choice of a neuronal model associated with the forecasting equation : * Automatic or manual definition of multi-layered architectures.

Temporal models with loop-backs of intermediate layers.

* Fine-tuning of a neuronal model by training *

Training by gradient back-propagation.

Automatic simplification of architectures.

Definition of training objectives by adaptation of the optimization criterion.

Definition of model form constraints.

Graphing of different error criteria.

* Analysis of a neuronal model: *

View of Hinton graph associated with each network layer.

Connection weight editing.

Calculation of sensitivity and elasticity of the variable to forecast,

in relation to the explanatory variables.

Calculation of the hidden series produced by the neural network.

* Neural Network-Based Forecasting *

Operational use of a neural network.

* Series Analysis *

Visualisation of a series curve. Editing of the series values.

Smoothing (simple, double, Holt \& Winters)

Study of the predictability of a series (fractal dimension)

Comparison of two series. Visualisation of $X-Y$ graphs.

\section{Neural Bench}

Name: Neural Bench.

Company: Neural Bench Development.

Address: 142717, Computer Technology Laboratory, VNIIGAZ, pos. Razvilka,

Address: Leninsky rajon, Moskovskay oblast, Russia.

Phone: 7 (095) 355-9191

Fax: $\quad 7$ (095) 399-1677

Email: develop.nb@vniigaz.com

URL: http://www.vniigaz.com/nb/

Basic capabilities: data processing, train, analysis, statistic, user interface, code generation, Java support.

Operating system: Windows 3.x, Windows 95, Windows NT

Neural Bench package includes:

- Neural Bench neural networks simulator - comprehensive both easy-to-use and sophisticated shell. It includes: Neural Network Builder, Neural Network Wizard, Scale and Randomization, Neurons and Layers Editing, Topology Adjustments, Background Learning, Testing, User Dialog Interface, Source Code Wizard, and much more.

- Data Processor with Data Wizard is a powerful neural network data pre- and postprocessing instrument. Multiple testing and analyses options are available. For the purpose of the complex data visualization the special chart tool provided.

- Dialog Editor with Dialog Wizard is a special utility for the user-defined dialog creation and editing. You can include in your custom dialogs any standard elements as well as bitmap editing elements and different graphics files.

\section{Trajan 2.0 Neural Network Simulator}

Trajan Software Ltd,

Trajan House,

68 Lesbury Close,

Chester-le-Street, 
Co. Durham,

DH2 3SR,

United Kingdom.

WWW: http://www.trajan-software.demon.co.uk/

Email: andrew@trajan-software.demon.co.uk

Tel: +44 191388 5737. (8:00-22:00 GMT).

Features

Trajan 2.1 Professional is a Windows-based Neural Network includes support for a wide range of Neural Network types, training algorithms, and graphical and statistical feedback on Neural Network performance.

Features include:

1. Full 32-bit power. Trajan 2.1 is available in a 32-bit version for use on Windows 95 and Windows NT platforms, supporting virtually-unlimited network sizes (available memory is a constraint). A 16-bit version (network size limited to 8,192 units per layer) is also available for use on Windows 3.1.

2. Network Architectures. Includes Support for Multilayer Perceptrons, Kohonen networks, Radial Basis Functions, Linear models, Probabilistic and Generalised Regression Neural Networks. Training algorithms include the very fast, modern Levenburg-Marquardt and Conjugate Gradient Descent algorithms, in addition to Back Propagation (with timedependent learning rate and momentum, shuffling and additive noise), Quick Propagation and Delta-Bar-Delta for Multilayer Perceptrons; K-Means, K-Nearest Neighbour and PseudoInverse techniques for Radial Basis Function networks, Principal Components Analysis and specialised algorithms for Automatic Network Design and Neuro-Genetic Input Selection. Error plotting, automatic cross verification and a variety of stopping conditions are also included.

3. Custom Architectures. Trajan allows you to select special Activation functions and Error functions; for example, to use Softmax and Cross-entropy for Probability Estimation, or CityBlock Error function for reduced outlier-sensitivity. There are also facilities to "splice" networks together and to delete layers from networks, allowing you to rapidly create pre- and post-processing networks, including Autoassociative Dimensionality Reduction networks. 4. Simple User Interface. Trajan's carefully-designed interface gives you access to large amounts of information using Graphs, Bar Charts and Datasheets. Trajan automatically calculates overall statistics on the performance of networks in both classification and regression. Virtually all information can be transferred via the Clipboard to other Windows applications such as Spreadsheets.

5. Pre- and Post-processing. Trajan 2.1 supports a range of pre- and post-processing options, including Minimax scaling, Winner-takes-all, Unit-Sum and Unit-Length vector. Trajan also assigns classifications based on user-specified Accept and Reject thresholds.

6 . Embedded Use. The Trajan Dynamic Link Library gives full programmatic access to Trajan's facilities, including network creation, editing and training. Trajan 2.1 come complete with sample applications written in ' $C$ ' and Visual Basic.

There is also a demonstration version of the Software available; please download this to check whether Trajan 2.1 fulfils your needs.

\section{DataEngine}

Name: DataEngine, DataEngine ADL, DataEngine V.i

Company: MIT GmbH

Address: Promenade 9

52076 Aachen

Germany

Phone: +49 240894580

Fax: +49 240894582

EMail: mailto:info@mitgmbh.de

URL: http://www.mitgmbh.de/ 
DataEngine is a software tool for data analysis implementing Fuzzy Rule Based Systems, Fuzzy Cluster Methods, Neural Networks, and Neural-Fuzzy Systems in combination with conventional methods of mathematics, statistics, and signal processing.

DataEngine ADL enables you to integrate classifiers or controllers developed with DataEngine into your own software environment. It is offered as a DLL for MS/Windows or as a $\mathrm{C}++$ library for various platforms and compilers.

DataEngine V.i is an add-on tool for LabView (TM) that enables you to integrate Fuzzy Logic and Neural Networks into LabView through virtual instruments to build systems for data analysis as well as for Fuzzy Control tasks.

\title{
32. Machine Consciousness Toolbox
}

Can a machine help you understand the mechanisms of consciousness?

A visual, interactive application for investigating artificial consciousness as inspired by the biological brain.

Free, fully functional, introductory version with user manual and tutorials to download. Based on the MAGNUS neural architecture developed at Imperial College, London, UK. Developed by Novel Technical Solutions.

Full information and download from: http://www.sonnet.co.uk/nts

[Note from FAQ maintainer: While this product explores some of the prerequisites of consciousness in an interesting way, it does not deal with deeper philosophical issues such as qualia.]

\section{Professional Basis of Al Backprop}

Backprop, rprop, quickprop, delta-bar-delta, supersab, recurrent networks for Windows 95 and Unix/Tcl/Tk. Includes $\mathrm{C}++$ source, examples, hypertext documentation and the ability to use trained networks in $\mathrm{C}_{++}$programs. $\$ 30$ for regular people and $\$ 200$ for businesses and government agencies. For details see: http://www.dontveter.com/probp/probp.html or http://www.unidial.com/ drt/probp/probp.html

Questions to: Don Tveter, drt@christianliving.net

\section{STATISTICA: Neural Networks}

\author{
Name: STATISTICA: Neural Networks version 4.0 \\ Company: StatSoft, Inc. \\ Address: 2300 E. 14th St. \\ Tulsa, OK 74104 \\ USA \\ Phone: (918) 749-1119 \\ Fax: (918) 749-2217 \\ Email: info@statsoft.com \\ URL: http://www.statsoft.com/
}

STATISTICA Neural Networks is a comprehensive application capable of designing a wide range of neural network architectures, employing both widely-used and highly-specialized training algorithms. STATISTICA Neural Networks was developed by StatSoft, Inc., the makers of STATISTICA software, and is available and supported through a world-wide network of StatSoft subsidiaries.

The current version STATISTICA Neural Networks 4.0 offers features such as sophisticated training algorithms, an Intelligent Problem Solver that walks the user step-by-step through the analysis, a Neuro-Genetic Input Selection facility, a large selection of supplementary graphs and statistics (e.g., ROC, Response Surfaces, Sensitivity Analysis, Regression and Classification statistics), complete support for API (Application Programming Interface), and the ability to interface with STATISTICA data files and graphs. 
STATISTICA Neural Networks includes traditional learning algorithms, such as back propagation and sophisticated training algorithms such as Conjugate Gradient Descent and Levenberg-Marquardt iterative procedures. Typically, choosing the right architecture of a neural network is a difficult and time-consuming "trial and error" process, but STATISTICA Neural Networks specifically does this for the user. STATISTICA Neural Networks features an Intelligent Problem Solver that utilizes heuristics and sophisticated optimization strategies to determine the best network architecture and walks the user step-by-step through the analysis. The Intelligent Problem Solver compares different network types (including Linear, Radial Basis Function, Multilayer Perceptron, and Bayesian networks), determines the number of hidden units, and chooses the Smoothing factor for Radial Basis Function networks.

The process of obtaining the right input variables in exploratory data analysis -- typically the case when neural networks are used -- also is facilitated by STATISTICA Neural Networks. Neuro-Genetic Input Selection procedures aid in determining the input variables that should be used in training the network. It uses an optimization strategy to compare the possible combinations of input variables to determine which set is most effective. STATISTICA Neural Networks offers complete API support so advanced users (or designers of corporate "knowledge seeking" or "data mining" systems) may be able to integrate the advanced computational engines of the Neural Networks module into their custom applications. STATISTICA Neural Networks can be used as a stand-alone application or can interface directly with STATISTICA. It reads and writes STATISTICA data files and graphs.

\title{
35. Braincel (Excel add-in)
}

Name: Braincel

Company: Promised Land Technologies

Address: 195 Church Street 11th Floor

New Haven, CT 06510

USA

Phone: (800) 243-1806 (Outside USA: (203) 562-7335)

Fax: (203) 624-0655

Email: gideon@miracle.net

URL: http://www.promland.com/

also see http://www.jurikres.com/catalog/ms bcel.htm

Braincel is an add-in to Excel using a training method called backpercolation.

\section{DESIRE/NEUNET}

\author{
Name: DESIRE/NEUNET \\ Company: G.A. and T.M. Korn Industrial Consultants \\ Address: 7750 South Lakeshore Road, \# 15 \\ Chelan, WA 98816 \\ USA \\ Phone: (509) 687-3390 \\ Email: gatmkorn@aol.com \\ URL: http://members.aol.com/gatmkorn \\ Price: $\$ 775$ (PC) \\ $\$ 2700$ (SPARCstation) \\ $\$ 1800$ (SPARCstation/educational) \\ Free educational version
}

DESIRE (Direct Executing SImulation in REal time) is a completely interactive system for dynamic-system simulation (up to 6,000 differential equations plus up to 20,000 difference equations in scalar or matrix form; 13 integration rules) for control, aerospace, and chemical engineering, physiological modeling, and ecology. Easy programming of multirun studies (statistics, optimization). Complex frequency-response plots, fast Fourier transforms, screen editor, connection to database program. 
DESIRE/NEUNET adds interactive neural-network simulation (to 20,000 interconnections) and fuzzy logic. Simulates complete dynamic systems controlled by neural networks and/or fuzzy logic. Users can develop their own neural networks using an easily readable matrix notation, as in:

VECTOR layer2 $=\tanh (\mathrm{W}$ * layer $1+$ bias $)$

Over 200 examples include:

- backpropagation, creeping random search

- Hopfield networks, bidirectional associative memories

- perceptrons, transversal filters and predictors

- competitive learning, counterpropagation

- very fast emulation of adaptive resonance

- simulates fuzzy-logic control and radial-basis functions

SCREEN-EDITED PROGRAMS RUN IMMEDIATELY AT HIGH SPEED

Package includes 2 textbooks by G.A. Korn: "Neural Networks and Fuzzy-logic Control on Personal Computers and Workstations" (MIT Press, 1995), and "Interactive Dynamic-system Simulatiuon under Windows 95 and NT" (Gordon and Breach, 1998). Please see our Web site for complete tables of contents of books, screen shots, list of users:

http://members.aol.com/gatmkorn

Complete educational versions of DESIRE/NEUNET for Windows 95 and NT can now be downloaded FREE as a .zip file which you un-zip to get an automatic INSTALLSHIELD installation program. The educational version is identical to our full industrial version except for smaller data areas ( 6 instead of 6000 differential equations, smaller neural networks). It will run most examples from both textbooks.

\section{BioNet Simulator}

Name: BioNet Simulator

Company: NCSB - Development Ltd.

Address: 46 Moriah St., Haifa 34572, ISRAEL

Phone: +972-4-8377449

Fax: $\quad+972-4-8361687$

Email: support@ncsb-bionet.com

URL: http://www.ncsb-bionet.com

BioNet Simulator in a Neural Networks Generator implementing innovative biological networks. The product provides a concept of brain-like Neural networks, incorporating many of the significant features of the brain. BioNet Simulator provides possibilities for designing large and complex nets: tens of thousands of cells and hundreds of thousands of connections. It offers a user friendly graphic interface, easy to use wizards and object oriented programming. Facilitates easy designing of large-scale networks, and requires no proficiency in advanced mathematics or programming. Ideal for brain-models simulations. Platforms: Windows 95, Windows NT.

\section{Viscovery SOMine}

Name: Viscovery SOMine

Company: eudaptics software gmbh

Address: Helferstorferstr. $5 / 8$

A-1010 Vienna

AUSTRIA

Phone: (+43 1) 5320570

Fax: (+43 1) $5320570-21$

e-mail: office@eudaptics.co.at

URL: http://www.eudaptics.co.at/

Operating System: Windows 95, Windows NT 4.0

Prices: $\$ 1495$ (commercial), $\$ 695$ (non-commercial, i.e. universities) 
Viscovery SOMine is a powerful and easy-to-use tool for exploratory data analysis and data mining. Employing an enhanced version of Self Organizing Maps it puts complex data into order based on its similarity. The resulting map can be used to identify and evaluate the features hidden in the data. The result is presented in a graphical way which allows the user to analyze non-linear relationships without requiring profound statistical knowledge. The system further supports full pre- and postprocessing, cluster search, association/recall, prediction, statistics, filtering, and animated system state monitoring. Through the implementation of techniques such as SOM scaling, the speed in creating maps is increased compared to the original SOM algorithm.

Download a free evaluation copy from http://www.eudaptics.co.at/demo.htm

\section{NeuNet Pro}

Name: NeuNet Pro

Company: CorMac Technologies Inc.

Address: 34 North Cumberland Street

Thunder Bay, ON P7A 4L4

Canada

Phone: (807) 345-7114

Fax: (807) 345-7114

Email: sales@cormactech.com

URL: http://www.cormactech.com/

NeuNet Pro is a complete neural network development system:

- Requires Windows 95, Windows 98, or Windows NT4(sp3).

- Powerful, easy to use, point and click, graphical development environment.

- Choose either SFAM or Back Propagation.

- Access data directly from MDB database file.

- Data may contain up to 255 fields.

- Split data into training set and testing set, up to 32,000 rows each.

- Comprehensive graphical reporting of prediction accuracy.

- Table browse, confusion matrix, scatter graph, and time series graph.

- Context sensitive help file with 70 page manual.

- Includes eight sample projects and assortment of sample data.

- Additional sample data available from URL above.

- Entire program may be downloaded from URL above.

\section{Neuronics}

Name: NNetView

Company: Neuronics Inc.

Address: Technoparkstr. 1

$\mathrm{CH}-8005$ Zurich Switzerland

Phone: +4114451640

Fax: $\quad+4114451644$

URL: http://www.neuronics.com/

Operating systems: Windows 95/98/NT and on MacOS.

Prices: 120 EUR for Simulator

310 EUR for Full version incl. camera- and serial interface

1260 EUR for Class licence

NNetView is a simulator for neural networks that allows you to connect the network directly to the video camera input as well as the input/output of the serial port of your PC. In addition, the network can include a free architecture of 2-dimensional layers with connections in all directions. The most interesting feature is that you can combine different standard network types (such as Backpropagation, Hebb, Reinforcement Learning, Kohonen or Hopfield 
networks). NNetView allows to learn images (such as faces or colored objects) online and to make robots and other machines adaptive. 